\title{
Growth, defect structure, and THz application of stoichiometric lithium niobate
}

\author{
K. Lengyel, ${ }^{1}$ Á. Péter, ${ }^{1}$ L. Kovács, ${ }^{1}$ G. Corradi, ${ }^{1}$ L. Pálfalvi, ${ }^{2}$ J. Hebling, ${ }^{2,3}$ M. Unferdorben, ${ }^{2}$ \\ G. Dravecz, ${ }^{1}$ I. Hajdara, ${ }^{1}$ Zs. Szaller, ${ }^{1}$ and K. Polgár ${ }^{1}$ \\ ${ }^{1}$ Wigner Research Centre for Physics, Hungarian Academy of Sciences, 1121 Budapest, \\ Konkoly-Thege M. út 29-33, Hungary \\ ${ }^{2}$ Institute of Physics, University of Pécs, 7624 Pécs, Ifjúság útja 6, Hungary \\ ${ }^{3}$ MTA-PTE High Field Terahertz Research Group, 7624 Pécs, Hungary
}

(Received 15 April 2015; accepted 17 June 2015; published online 20 October 2015)

\begin{abstract}
Owing to the extraordinary richness of its physical properties, congruent lithium niobate has attracted multidecade-long interest both for fundamental science and applications. The combination of ferro-, pyro-, and piezoelectric properties with large electro-optic, acousto-optic, and photoelastic coefficients as well as the strong photorefractive and photovoltaic effects offers a great potential for applications in modern optics. To provide powerful optical components in high energy laser applications, tailoring of key material parameters, especially stoichiometry, is required. This paper reviews the state of the art of growing large stoichiometric $\mathrm{LiNbO}_{3}(\mathrm{sLN})$ crystals, in particular, the defect engineering of pure and doped $\mathrm{sLN}$ with emphasis on optical damage resistant (ODR) dopants (e.g., Mg, Zn, In, Sc, Hf, Zr, Sn). The discussion is focused on crystals grown by the high temperature top seeded solution growth (HTTSSG) technique using alkali oxide fluxing agents. Based on high-temperature phase equilibria studies of the $\mathrm{Li}_{2} \mathrm{O}-\mathrm{Nb}_{2} \mathrm{O}_{5}-\mathrm{X}_{2} \mathrm{O}$ ternary systems $(\mathrm{X}=\mathrm{Na}, \mathrm{K}, \mathrm{Rb}, \mathrm{Cs})$, the impact of alkali homologue additives on the stoichiometry of the lithium niobate phase will be analyzed, together with a summary of the ultraviolet, infrared, and far-infrared absorption spectroscopic methods developed to characterize the composition of the crystals. It will be shown that using HTTSSG from $\mathrm{K}_{2} \mathrm{O}$ containing flux, crystals closest to the stoichiometric composition can be grown characterized by a UV-edge position of at about $302 \mathrm{~nm}$ and a single narrow hydroxyl band in the IR with a linewidth of less than $3 \mathrm{~cm}^{-1}$ at $300 \mathrm{~K}$. The threshold concentrations for ODR dopants depend on crystal stoichiometry and the valence of the dopants; Raman spectra, hydroxyl vibration spectra, and Z-scan measurements prove to be useful to distinguish crystals below and above the photorefractive threshold. Crystals just above the threshold are preferred for most nonlinear optical applications apart holography and have the additional advantage to minimize the absorption even in the far-infrared (THz) range. The review also provides a discussion on the progress made in the characterization of non-stoichiometry related intrinsic and extrinsic defect structures in doped LN crystals, with emphasis on ODR-ion-doped and/or closely stoichiometric systems, based on both spectroscopic measurements and theoretical modelling, including the results of first principles quantum mechanical calculations on hydroxyl defects. It will also be shown that new perspective applications, e.g., the generation of high energy THz pulses with energies on the tens-of-mJ scale, are feasible with ODR-doped sLN crystals if optimal conditions, including the contact grating technique, are applied. (C) 2015 AIP Publishing LLC.
\end{abstract}

[http://dx.doi.org/10.1063/1.4929917]

\section{TABLE OF CONTENTS}

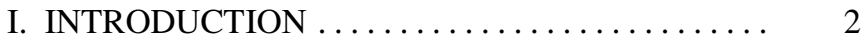

II. GROWTH OF STOICHIOMETRIC $\mathrm{LiNbO}_{3} \ldots \ldots \quad 2$

A. Early works ................... 2

B. Phase equilibria of $\mathrm{Li}_{2} \mathrm{O}-\mathrm{Nb}_{2} \mathrm{O}_{5}-\mathrm{X}_{2} \mathrm{O}$ $(\mathrm{X}=\mathrm{Na}, \mathrm{K}, \mathrm{Rb}$ and $\mathrm{Cs}$ ) ternary systems... 3

C. HTTSS growth of sLN crystals from $\mathrm{K}_{2} \mathrm{O}-$ fluxed melts .................... 6

D. Growth of ODR-ion doped sLN crystals.... 7
III. COMPOSITION AND PROPERTIES OF PURE AND ODR-ION DOPED $\mathrm{LiNbO}_{3}$ CRYSTALS ..

A. Spectroscopic characterization of undoped LN ............................ 8

1. Ultraviolet absorption edge .......... 8

2. $\mathrm{OH}^{-}$absorption ................. 9

B. Properties of Mg-doped sLN crystals...... 10

1. $\mathrm{OH}^{-}$vibration, $\mathrm{UV}$ absorption edge and Raman spectroscopy ............... 11

2. Z-scan measurements ............. 15 
3. Absorption, refractive index in the far-

IR $(\mathrm{THz})$ range..................

C. Other divalent, trivalent, and tetravalent ODR dopants . .................... 18

D. Transition metal and rare earth dopants .... IV. THEORETICAL MODELS FOR INTRINSIC

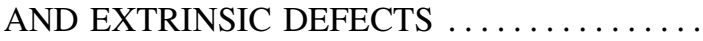

A. Intrinsic defects ...................

B. Dopant ions $\ldots \ldots \ldots \ldots \ldots \ldots \ldots \ldots \ldots \ldots$

C. $\mathrm{OH}^{-}$ions $\ldots \ldots \ldots \ldots \ldots \ldots \ldots \ldots \ldots \ldots$.

V. THz GENERATION-A PROMISING

APPLICATION

VI. SUMMARY AND OUTLOOK

\section{INTRODUCTION}

Lithium niobate $\left(\mathrm{LiNbO}_{3}, \mathrm{LN}\right)$ has been recognized as one of the most versatile materials for applications in modern optics in a broad range extending from the near UV to the far IR. The combination of ferro-, pyro-, and piezoelectric properties with large electro-optic, acousto-optic, and photoelastic coefficients as well as strong photorefractive and photovoltaic effects made $\mathrm{LN}$ to one of the most extensively studied materials over the last 50 years. Extended device applications required the growth of high-quality single crystals with properties depending on a detailed control of their intrinsic and extrinsic defect structures.

In the late 1960's and early 70's, detailed investigations of the binary phase diagram showed that $\mathrm{LiNbO}_{3}$ was a congruently melting material with a congruent composition noticeably differing from the stoichiometric one represented by the chemical formula: ${ }^{1-5}$ in fact, nonstoichiometry implies several percents of defect sites in the lattice making the crystal sensitive to high energy laser radiation.

By the end of the 1980's, by using the Czochralski growth method, the preparation of high quality congruent single crystals had been solved and huge amounts of data on physical properties were collected, ${ }^{6-9}$ opening the way for technical applications. At the same time, both characterization methods for controlling the real state of LN and theoretical models for understanding the formation and role of native defect structures were rapidly progressing.

Starting from the early 90's, interest in the use of LN for higher energy laser applications was intensified. As congruent $\mathrm{LiNbO}_{3}$ (cLN) was easily damaged, to provide more resistant optical components for laser applications, tailoring of key material parameters via stoichiometry control and/or doping by additives promoting optical damage resistant (ODR) behaviour in the visible-near infrared region, e.g., $\mathrm{Mg}, \mathrm{Zn}$, In, Sc, etc., ${ }^{10}$ has been introduced. For producing stoichiometric samples, new techniques, including the preparation of stoichiometric wafers or fibers from cLN crystals by the vapor transport equilibration (VTE) method ${ }^{11,12}$ as well as various solution growth techniques, have been applied. As the demand for pure and doped bulk stoichiometric $\mathrm{LiNbO}_{3}$ (sLN) crystals kept increasing, efforts became concentrated on the development of crystal growth techniques, such as the continuous filling double crucible growth ${ }^{13}$ and the high temperature top seeded solution growth (HTTSSG). ${ }^{14}$

Technological advances in the growth of large stoichiometric crystals led to a breakthrough in defect engineering of pure and ODR-ion doped SLN crystals promoting, e.g., the development of quasi-phase-matched frequency conversion applications using periodically poled LN (PPLN) crystals ${ }^{15}$ and also the advent of new devices for the generation of high energy THz pulses. ${ }^{16}$

The present review starts with a history of solution grown LN crystals describing recent progress in the understanding and control of their chemical and structural inhomogeneities. We focus on developments achieved in our laboratories in the preparation, characterization, modelling, and application of undoped and doped sLN crystals with emphasis on ODR dopants. A detailed description will be given on the high temperature phase equilibria of the $\mathrm{Li}_{2} \mathrm{O}-\mathrm{Nb}_{2} \mathrm{O}_{5}-\mathrm{K}_{2} \mathrm{O}$ ternary system and on the optimization of the flux composition for the growth of sLN. Methods worked out for the determination of the crystal composition of congruent to stoichiometric LN (based on the UV absorption edge or the $\mathrm{OH}^{-}$absorption and Raman band shapes) will be discussed. Spectroscopic achievements are also supported by recent results on theoretical modelling based on quasi-potentials for intrinsic and extrinsic defects and on first principles quantum mechanical calculations for hydroxyl ions in sLN. Finally, a new promising application for the generation of high energy THz pulses using ODRion doped sLN crystals will be presented.

\section{GROWTH OF STOICHIOMETRIC $\mathrm{LiNbO}_{3}$}

\section{A. Early works}

Investigation of the homogeneity of Czochralski grown crystals in the early 1970's led to the identification of non-stoichiometric, congruently melting oxides with $\mathrm{LiNbO}_{3}$ among the first examples. Peterson ${ }^{1}$ and Carruthers et al. ${ }^{2}$ found that stoichiometric crystals could be pulled only from strongly off-stoichiometric melts with $\sim 58.0 \mathrm{~mol} . \% \mathrm{Li}_{2} \mathrm{O}$ content and even those crystals were small and/or of inferior quality.

Based on detailed investigations of the phase diagram of the $\mathrm{Li}_{2} \mathrm{O}-\mathrm{Nb}_{2} \mathrm{O}_{5}$ binary system, Byer et al. ${ }^{3}$ grew high quality LN crystals, thereby locating the congruently melting composition of $\mathrm{LiNbO}_{3}$ at $48.6 \mathrm{~mol}$. \% $\mathrm{Li}_{2} \mathrm{O}$ content. Lerner et al.'s investigation ${ }^{4}$ of the phase equilibrium showed that $\mathrm{LN}$ has an asymmetric solid solution range, which narrows towards the stoichiometric composition with decreasing temperature (extending at $1000{ }^{\circ} \mathrm{C}$ from 46.0 to $50.0 \mathrm{~mol} \% \%$ $\mathrm{Li}_{2} \mathrm{O}$ and at room temperature only from 48.0 to $50.0 \mathrm{~mol}$. \% $\mathrm{Li}_{2} \mathrm{O}$ ). As reported by Svaasand et al., ${ }^{5}$ the binary solidus path is limited by the temperature of the binary eutectic reaction of $\mathrm{LiNbO}_{3}-\mathrm{Li}_{3} \mathrm{NbO}_{4}$ at $1160^{\circ} \mathrm{C}$. The upper temperature limit of the solidus at stoichiometric composition is at about $1170^{\circ} \mathrm{C}$, above this temperature, the solid phase composition shifts towards the Li deficient side. This means that in order to shift the thermodynamic equilibrium towards the stoichiometric composition, the crystallization temperature has to be kept close to or below $1170^{\circ} \mathrm{C}$. 
From the late 1970's, several attempts have been made to obtain sLN crystals by using flux methods for lowering the crystallization temperature. To a large extent, the success of the flux growth depends on the choice of the flux composition and the appropriate growth conditions. Voronkova et al. ${ }^{17}$ tested $\mathrm{V}_{2} \mathrm{O}_{5}, \mathrm{WO}_{3}$, and $\mathrm{B}_{2} \mathrm{O}_{3}$ containing fluxes. Kondo, ${ }^{18}$ Hemmerling and Hergt, ${ }^{19}$ and Hibiya ${ }^{20}$ reported the $\mathrm{Li}_{2} \mathrm{O}-\mathrm{V}_{2} \mathrm{O}_{5}$ mixture to be a suitable solvent both for liquid phase epitaxy and bulk flux growth of sLN crystals. Recently, Huang et al. ${ }^{21}$ identified the crystallization region of $\mathrm{LN}$ in the $\mathrm{B}_{2} \mathrm{O}_{3}-\mathrm{Li}_{2} \mathrm{O}-\mathrm{Nb}_{2} \mathrm{O}_{5}$ ternary system. Despite the lower critical crystallization temperatures below $1170{ }^{\circ} \mathrm{C}$ for all these growth experiments, the results of the composition measurements were not fully satisfactory as the solvent components $(\mathrm{V}, \mathrm{B}, \mathrm{W}$ ions) were also incorporated into the crystals (Voronkova reported built-in concentrations of $3-5$ at. \%).

The preparation of bulk stoichiometric crystals derives from the report of Vartanyan ${ }^{22}$ on the unusual properties of "congruent" crystals doped with 6 wt. $\% \mathrm{~K}_{2} \mathrm{O}$. As was shown by Malovichko et al., ${ }^{23,24}$ these crystals are nearly potassium free and their composition is close to stoichiometric. To obtain pure stoichiometric crystals, Kitamura et al..$^{13}$ also used an alkali additive, i.e., Li by applying the continuous filling double crucible method, thereby again preparing bulk crystals in the $\mathrm{Li}_{2} \mathrm{O}-\mathrm{Nb}_{2} \mathrm{O}_{5}$ binary system from extremely Li-rich melt $\left(58 \% \mathrm{Li}_{2} \mathrm{O}\right)$ similarly to the early attempts of Peterson ${ }^{1}$ and Carruthers et al. ${ }^{2}$ Later, by using starting melts with $\mathrm{K}_{2} \mathrm{O}$ added in concentrations from 10 to $16 \mathrm{~mol} . \%$, Polgár et al. ${ }^{14}$ showed that the high temperature top-seeded solution growth technique was an effective method for growing stoichiometric $\mathrm{LiNbO}_{3}$ single crystals.

Following the early results, considerable development has been achieved in the growth of large stoichiometric crystals. In this section, the current state of sLN crystal growth will be reviewed, and based on the results of Cochez et al., ${ }^{25}$ Péter et $a l .,{ }^{26}$ and Dravecz et al. ${ }^{27}$ on high-temperature phase equilibria of $\mathrm{Li}_{2} \mathrm{O}-\mathrm{Nb}_{2} \mathrm{O}_{5}-\mathrm{X}_{2} \mathrm{O}(\mathrm{X}=\mathrm{Na}, \mathrm{K}, \mathrm{Rb}, \mathrm{Cs})$ ternary systems, the impact of alkali homologue additives $(\mathrm{Li} / \mathrm{Na} / \mathrm{K} /$ $\mathrm{Rb} / \mathrm{Cs}$ ) on the stoichiometry of the lithium niobate phase will be discussed. In addition, the effect of ODR dopants on the growth of sLN crystals will be summarized.

\section{B. Phase equilibria of $\mathrm{Li}_{2} \mathrm{O}-\mathrm{Nb}_{2} \mathrm{O}_{5}-\mathrm{X}_{2} \mathrm{O}(\mathrm{X}=\mathrm{Na}, \mathrm{K}, \mathrm{Rb}$ and $\mathrm{Cs}$ ) ternary systems}

The interest to establish more precisely the hightemperature phase equilibria of the $\mathrm{Li}_{2} \mathrm{O}-\mathrm{Nb}_{2} \mathrm{O}_{5}-\mathrm{K}_{2} \mathrm{O}$ ternary system has arisen due to the increasing demand of the preparation of sLN crystals. The first experiments on growing sLN with $\mathrm{K}_{2} \mathrm{O}$ additive used congruent $\mathrm{Li} / \mathrm{Nb}$ ratios in the starting melt. ${ }^{23}$ Later, by testing various flux compositions, Polgár et al. ${ }^{28}$ found that the crystals grown from fluxes with starting composition of $\mathrm{Li} / \mathrm{Nb}=1$ and $\mathrm{K}_{2} \mathrm{O}$ in the range of $0.16-0.195\left[\mathrm{~K}_{2} \mathrm{O}\right] /\left[\mathrm{LiNbO}_{3}\right]$ ratio resulted in improved stoichiometry. It was also shown that the key parameter determining the composition of the growing crystal was the crystallization temperature.
The optimization of the flux composition and the growth conditions requires an extended knowledge of the crystallization range of $\left\langle\mathrm{LiNbO}_{3}\right\rangle$ in the $\mathrm{Li}_{2} \mathrm{O}-\mathrm{Nb}_{2} \mathrm{O}_{5}-\mathrm{K}_{2} \mathrm{O}$ ternary system. Previously, the phase relations of the $\mathrm{Li}_{2} \mathrm{O}-\mathrm{Nb}_{2} \mathrm{O}_{5}-\mathrm{K}_{2} \mathrm{O}$ system were examined by Scott $e t$ al. ${ }^{29}$ and Ikeda and Kiyohashi ${ }^{30}$ in the solid-solution field of tungsten bronze-type $\mathrm{K}_{3} \mathrm{Li}_{2} \mathrm{Nb}_{5} \mathrm{O}_{15}(\mathrm{KLN})$ and $\mathrm{K}_{3} \mathrm{LiNb}_{6} \mathrm{O}_{17}$ compounds. The primary crystallization field and the phase relations of $\left\langle\mathrm{LiNbO}_{3}\right\rangle$ have first been investigated by Cochez et $a l^{25}$ using differential scanning calorimetry (DSC) experiments and X-ray powder diffraction. The temperatures corresponding to the lithium niobate liquidus surface and the solid phases involved in the ternary invariant reactions were established along the vertical sections cut along the 10,20, and $25 \mathrm{~mol} . \% \mathrm{~K}_{2} \mathrm{O}$ isopleths within the ranges from 25-55, $30-60$, and $40-60$ mol. \% $\mathrm{Nb}_{2} \mathrm{O}_{5}$, respectively. Vertical sections of the $\mathrm{LN}$ phase field along $g_{1}=\left(\mathrm{LiNbO}_{3}-\mathrm{K}_{2} \mathrm{O}\right)$, $g_{2}=\left(\mathrm{LiNbO}_{3}-E_{1}\right)$, and $g_{3}=\left(\mathrm{LiNbO}_{3}-\mathrm{KNbO}_{3}(K N)\right)$ lines (see Fig. 1(a)) were detailed later by Polgár et al. ${ }^{31}$ The liquidus surface beyond the $\mathrm{LiNbO}_{3}-\mathrm{KNbO}_{3}$ join for $\mathrm{Nb}_{2} \mathrm{O}_{5}$ content between 50 and $55 \mathrm{~mol} \%$ was only estimated.

The phase boundaries were established by DSC analyses discussed in Ref. 25. The liquidus surface of $\langle\mathrm{LN}\rangle$ is limited by four monovariant lines with endpoints shown on Fig. 1(a): (i) Liq. $+\left\langle\mathrm{Li}_{3} \mathrm{NbO}_{4}\right\rangle+\left\langle\mathrm{LiNbO}_{3}\right\rangle$ ranging from $\mathrm{e}_{1}$ to $\mathrm{E}_{1}$, (ii) Liq. $+\left\langle\mathrm{KNbO}_{3}\right\rangle+\left\langle\mathrm{LiNbO}_{3}\right\rangle$ from $\mathrm{P}$ to $\mathrm{E}_{1}$, (iii) Liq. $+\langle\mathrm{KLN}\rangle+\left\langle\mathrm{LiNbO}_{3}\right\rangle$ from $\mathrm{X}$ to $\mathrm{P}$, and (iv) Liq. $+\left\langle\mathrm{LiNb}_{3} \mathrm{O}_{8}\right\rangle+\left\langle\mathrm{LiNbO}_{3}\right\rangle$ from $\mathrm{e}_{2}$ to X. At $997^{\circ} \mathrm{C}$, a ternary eutectic reaction occurs between liquid, $\left\langle\mathrm{LiNbO}_{3}\right\rangle$, $\left\langle\mathrm{Li}_{3} \mathrm{NbO}_{4}\right\rangle$, and $\left\langle\mathrm{KNbO}_{3}\right\rangle$. The composition of the eutectic liquid $\left(E_{1}\right)$ was located at about $45.0 \mathrm{~mol} \% \quad \mathrm{Nb}_{2} \mathrm{O}_{5}$, 26.0 mol. $\% \mathrm{~K}_{2} \mathrm{O}$, and $29.0 \mathrm{~mol}$ \% $\mathrm{Li}_{2} \mathrm{O}$. A quasi-peritectic reaction has also been identified at a temperature of about $1050-1055^{\circ} \mathrm{C}$. The quasi-peritectic liquid $(P)$ has a composition roughly equal to $49 \mathrm{~mol} . \% \mathrm{Nb}_{2} \mathrm{O}_{5}, 25.5 \mathrm{~mol} . \% \mathrm{~K}_{2} \mathrm{O}$, and $25.5 \mathrm{~mol} . \% \mathrm{Li}_{2} \mathrm{O}$.

During crystallization of the $\langle\mathrm{LN}\rangle$ phase, the point representing the liquid in equilibrium with the solid moves on the liquidus surface towards one of the monovariant lines, limiting the liquidus surface. Upon further decrease in the temperature, the liquid composition reaches a point on one of the monovariant lines, and the liquid composition proceeds along this line while the two solids separate. Solidification is completed when the liquid composition reaches the ternary eutectic point $E_{1}$.

The assessment of the phase diagram by crystal growth experiments was reported by Péter $e t a l^{26}$ The evolution of the solid composition was determined by the HTTSSG method, covering the whole single-phase area with pulling out of the maximum amount of single crystal. Since $\mathrm{K}_{2} \mathrm{O}$ is insoluble in lithium niobate $\left(\mathrm{K}^{+}\right.$practically not entering the lattice), the crystallization path may be traced with ease; crystallization of $\langle\mathrm{LN}\rangle$ starts when the temperature reaches that corresponding to the liquidus and the liquid composition evolves along the straight line joining the starting composition with that of $\mathrm{LiNbO}_{3}$ and ends at a point on an intersecting monovariant line (as shown by the " $g$ " lines in Fig. 1(a)).

In Fig. 2, crystals grown from compositions located on the $\mathrm{LiNbO}_{3}-\mathrm{K}_{2} \mathrm{O}\left(g_{1}\right)$ and the $\mathrm{LiNbO}_{3}-\mathrm{KNbO}_{3}\left(g_{3}\right)$ lines are 

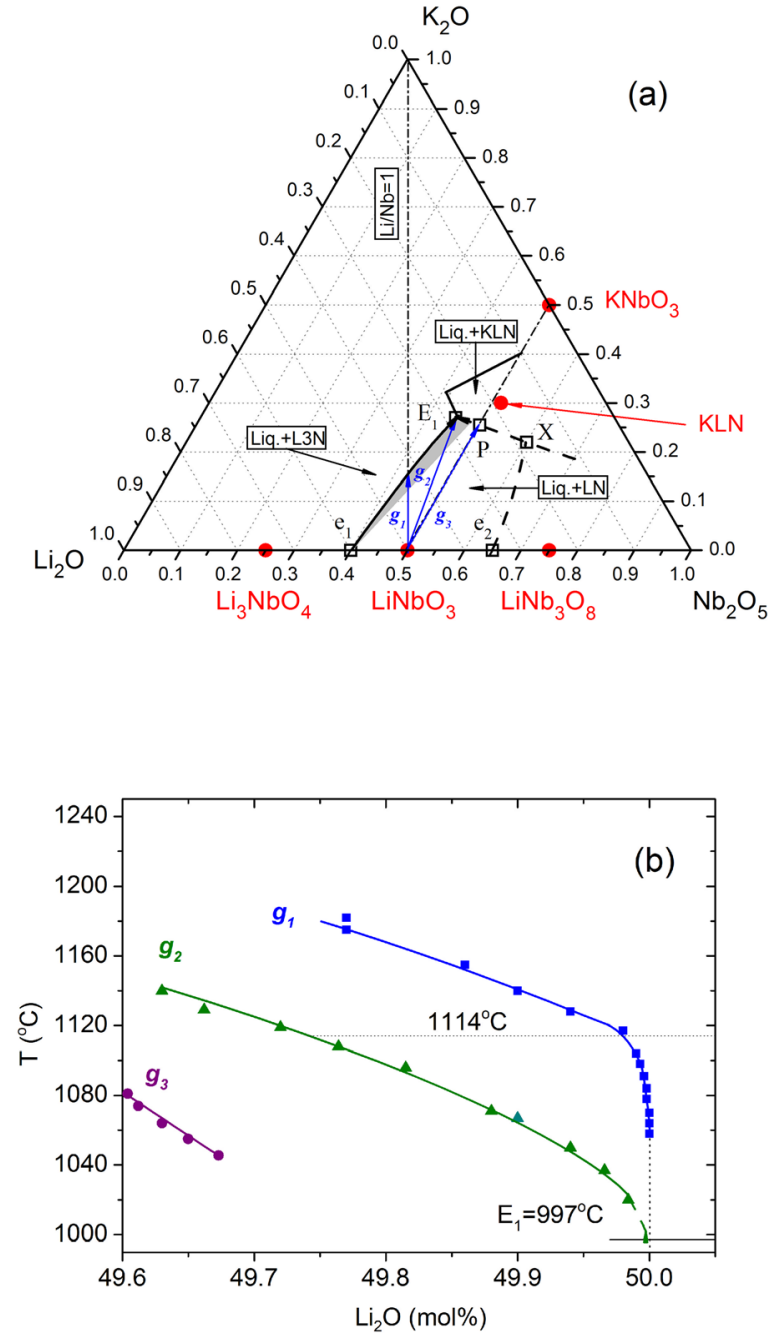

FIG. 1. Phase relations in the growth of stoichiometric lithium niobate. (a) The projection of the primary crystallization field of $\langle\mathrm{LN}\rangle$ phase in the $\mathrm{Li}_{2} \mathrm{O}-\mathrm{Nb}_{2} \mathrm{O}_{5}-\mathrm{K}_{2} \mathrm{O}$ ternary system. $\mathrm{E}_{1}: \mathrm{LiNbO}_{3}-\mathrm{Li}_{3} \mathrm{NbO}_{4}-\mathrm{KNbO}_{3}$ ternary eutectic point, $\mathrm{e}_{1}, \mathrm{e}_{2}$ binary eutectic points, $\mathrm{P}$ : peritectic point, $\mathrm{g}_{1}, \mathrm{~g}_{2}, \mathrm{~g}_{3}$ : traces of investigated vertical sections of the phase diagram. $\mathrm{LN}: \mathrm{LiNbO}_{3}$, $\mathrm{L} 3 \mathrm{~N}: \mathrm{Li}_{3} \mathrm{NbO}_{4}, \mathrm{KLN}$ : tungsten bronze-type solid solution, gray area: crystallization region of $\langle\mathrm{sLN}\rangle$. Reproduced with permission from K. Polgár et al., Phys. Status Solidi A 201, 284-288 (2004). Copyright 2004 Wiley. (b) Evolution of the solidus in the $\mathrm{Li}_{2} \mathrm{O}-\mathrm{Nb}_{2} \mathrm{O}_{5}$ binary system in the region close to the near-stoichiometric LN composition for the $\mathrm{g}_{1}, \mathrm{~g}_{2}, \mathrm{~g}_{3}$ growth experiments. Reproduced with permission from Á. Péter et al., J. Alloys Compd. 386, 246-252 (2005). Copyright 2005 Elsevier.

shown. These crystals were prepared by continuing the growth process after having pulled out the maximum amount of the single crystalline phase. On the bottom part of the boule, polycrystalline phase separation can be seen. The constituent phases determined by $\mathrm{X}$-ray phase analysis were $\left\langle\mathrm{LiNbO}_{3}\right\rangle+\left\langle\mathrm{Li}_{3} \mathrm{NbO}_{4}\right\rangle$ and $\left\langle\mathrm{LiNbO}_{3}\right\rangle+\langle\mathrm{KLN}$ solid solution $\rangle$ for $g_{1}$ and $g_{3}$ growth, respectively, in accordance with the evolution of the composition of the remaining liquid along the corresponding monovariant line $\left(e_{1}-E_{1}\right.$, and $\left.P-E_{1}\right)$, respectively. Using the results of various growth experiments covering the whole single-phase area, the yield of the $\langle\mathrm{LN}\rangle$ phase can be determined. Assuming stoichiometric composition and no $\mathrm{K}_{2} \mathrm{O}$ contamination for the solid phase, the coordinates of the limits of the $\mathrm{LiNbO}_{3}$ liquidus surface can be


(b)

FIG. 2. Crystals grown by continuing the process beyond the single phase stage along a monovariant line limiting the liquidus surface, the starting compositions located (a) on the $\mathrm{LiNbO}_{3}-\mathrm{K}_{2} \mathrm{O} \mathrm{g}_{1}$ line at $10 \mathrm{~mol} \% \mathrm{~K}_{2} \mathrm{O}$ content; Reproduced with permission from G. Dravecz et al., J. Cryst. Growth 286, 334-337 (2006). Copyright 2006 Elsevier and (b) on the $\mathrm{LiNbO}_{3}-\mathrm{KNbO}_{3} \mathrm{~g}_{3}$ line at $20 \mathrm{~mol} \% \quad \mathrm{~K}_{2} \mathrm{O}$ content. The co-crystallized phases on the bottom (see white polycrystalline and yellow parts) were identified as $\left\langle\mathrm{LiNbO}_{3}\right\rangle+\left\langle\mathrm{Li}_{3} \mathrm{NbO}_{4}\right\rangle$ and $\left\langle\mathrm{LiNbO}_{3}\right\rangle+\langle\mathrm{KLN}$ solid solution $\rangle$ for $\mathrm{g}_{1}$ and $\mathrm{g}_{3}$ growth, respectively.

calculated. These estimates for the limits, compared with those given by the phase diagram, are in good agreement. ${ }^{26}$

The establishment of isothermal tie lines, representing solid-liquid concentration relationships across the solidsolution range, relies on the same principle: as the actual crystallization temperature is determined by the melt composition, the tie lines can be located by assessing the evolution path of the solid composition and the corresponding $\mathrm{K}_{2} \mathrm{O}$ content of the melt as functions of the crystallization fraction. The determination of the $\mathrm{Li} / \mathrm{Nb}$ ratio of the crystals requires the use of a well established physical method of sufficient precision, better than available by chemical analytical techniques. The measurement of the position of the fundamental absorption edge in the near UV region, as reported by Földvári et al. ${ }^{32}$ and Kovács et al., ${ }^{33}$ and described in more detail in Section III A 1, has proved to be a convenient and fast method to determine the solid composition. For establishing the solid-liquid concentration relationships, the solid composition along the growth axes can be determined on crystal slices cut perpendicular to the growth axes, providing also the actual liquid composition if the mass balance of the pulled amount is taken into account. Hence, the corresponding crystallization temperature can be deduced from the vertical cut of the phase diagram.

Using $\mathrm{K}_{2} \mathrm{O}$ containing melts, the solidus paths can be extended down to $\sim 1000^{\circ} \mathrm{C}$ (Fig. 1(b)). For crystals grown on the $\mathrm{LiNbO}_{3}-\mathrm{K}_{2} \mathrm{O}$ line $\left(g_{1}\right)$, for $\mathrm{K}_{2} \mathrm{O}>13.8$ mol. $\%$, below $1114{ }^{\circ} \mathrm{C}$, the solidus composition path clearly has a constant segment with a composition very close to $\mathrm{Li} / \mathrm{Nb}=1$. Working with a $\mathrm{Li} / \mathrm{Nb}<1$ ratio in the flux (see, e.g., the growth along the $g_{2}$ and $g_{3}$ lines), the stoichiometric composition can also be approached; however, at the same crystallization temperature, less and less stoichiometric crystals with decreased $\mathrm{Li} / \mathrm{Nb}$ ratio are obtained. On the $g_{2}$ line, solid compositions in 
the range from $\mathrm{Li} / \mathrm{Nb}=0.979$ to 0.992 can be achieved; along the $g_{3}$ line, the composition limit to be reached is at about $\mathrm{Li} /$ $\mathrm{Nb}=0.984$. For $\mathrm{Li} / \mathrm{Nb}>1$ ratios and similar $\mathrm{K}_{2} \mathrm{O}$ content in the flux, the yield is rather low, the stoichiometric composition can be obtained only at the end of the crystallization range, when the liquidus practically reaches the monovariant line near $1100^{\circ} \mathrm{C} .{ }^{31}$ The above results on solid-liquid concentration relationships obtained from the assessment of the phase diagram by crystal growth experiments ${ }^{26}$ compare well with earlier data published in the literature, i.e., are consistent with the solid compositions deduced from UV cut-off wavelengths (measured at $\alpha=20 \mathrm{~cm}^{-1}$ absorption; see the results of Serrano et al., ${ }^{34}$ Niwa et al., ${ }^{35}$ and Polgár et al. ${ }^{28}$ ).

Solvents, based on other alkali metal oxides $\left(\mathrm{Na}_{2} \mathrm{O}\right.$, $\mathrm{Rb}_{2} \mathrm{O}$, and $\mathrm{Cs}_{2} \mathrm{O}$ ), have also proved to be useful fluxes for the growth of sLN crystals by lowering the crystallization temperature. ${ }^{27}$ While $\mathrm{Na}$ ions entered the crystal lattice with a segregation coefficient of $\mathrm{k}_{\mathrm{sol} / \text { liq }}\left(\mathrm{Na}_{2} \mathrm{O}\right) \sim 0.2$, the others $\left(\mathrm{Rb}_{2} \mathrm{O}\right.$ and $\left.\mathrm{Cs}_{2} \mathrm{O}\right)$ were found practically insoluble in $\mathrm{LiNbO}_{3}$, similarly to $\mathrm{K}_{2} \mathrm{O}$. The phase boundary limit of the $\mathrm{LiNbO}_{3}$ liquid surface in the $\mathrm{Li}_{2} \mathrm{O}-\mathrm{Nb}_{2} \mathrm{O}_{5}-\mathrm{X}_{2} \mathrm{O}(\mathrm{X}=\mathrm{Na}, \mathrm{K}$, $\mathrm{Rb}, \mathrm{Cs})$ ternary systems monotonously shifted with the increase in the ion radius of alkali ion added: For the vertical cut along the $\mathrm{Li} / \mathrm{Nb}=1$ ratio, the liquid phase boundaries for $\mathrm{K}_{2} \mathrm{O}-, \mathrm{Rb}_{2} \mathrm{O}$ - and $\mathrm{Cs}_{2} \mathrm{O}$-containing fluxes were found to be at alkali oxide contents of $17.2,16.5$, and $15.8 \mathrm{~mol} \%$, respectively. In the case of the $\mathrm{Na}_{2} \mathrm{O}$-based flux, from the yield of the pulled-out $\langle\mathrm{LN}\rangle$ phase and the amount of incorporated $\mathrm{Na}$ content, this limit was estimated to be $\sim 14.1 \mathrm{~mol} . \%$ of $\mathrm{Na}_{2} \mathrm{O}$. The establishment of isothermal solid-liquid concentration relationships for $\mathrm{K}_{2} \mathrm{O}, \mathrm{Rb}_{2} \mathrm{O}$, and $\mathrm{Cs}_{2} \mathrm{O}$ based fluxes on the $\mathrm{Li} / \mathrm{Nb}=1$ vertical cut of the ternary phase diagram is shown in Fig. 3. At the same alkali content, the crystallization temperature was found to be lowest for $\mathrm{K}_{2} \mathrm{O}$ containing flux, and slightly increased (by $25-50{ }^{\circ} \mathrm{C}$ ) for $\mathrm{Cs}_{2} \mathrm{O}, \mathrm{Rb}_{2} \mathrm{O}$, and $\mathrm{Na}_{2} \mathrm{O}$ additives (Fig. 3(a)). These differences in the crystallization temperatures are manifested in the results of the UV measurements and also in the evolution of the solidus composition paths as shown in Figs. 3(b) and 3(c). While for crystals grown from $\mathrm{K}_{2} \mathrm{O}-, \mathrm{Rb}_{2} \mathrm{O}-$, or $\mathrm{Cs}_{2} \mathrm{O}$-based fluxes, the measured UV-edge position (i.e., the $\mathrm{Li} / \mathrm{Nb}$ ratio) depends on the crystallization temperature alone, for the crystal grown from $\mathrm{Na}_{2} \mathrm{O}$ containing flux, it is also affected by the incorporated $\mathrm{Na}$ ions. Thus from the point of view of the HTTSS growth of stoichiometric $\mathrm{LiNbO}_{3}$ crystals, the choice of starting compositions along the $\mathrm{Li} / \mathrm{Nb}=1$ line (above 13 mol. $\% \mathrm{~K}_{2} \mathrm{O}$ content) is advisable. For doped crystals, to ensure both sufficient incorporation and near stoichiometry of the crystals, starting compositions with $\mathrm{Li} / \mathrm{Nb}<1$ have to be considered as well.

For LN crystals grown from Li-rich melts by the double crucible growth method, $\mathrm{Li} / \mathrm{Nb}$ ratios in the range 0.988-0.993 were reported by Furukawa et al. ${ }^{36}$ In this case, the seeding temperature had to be chosen close to the upper temperature limit of the binary solidus $\left(1165-1175^{\circ} \mathrm{C}\right.$ for stoichiometric composition) as the crystallization temperature was limited from below by the temperature of the binary eutectic at $1160^{\circ} \mathrm{C}$. With the use of other alkali fluxed melts $\left(\mathrm{K}_{2} \mathrm{O}\right.$ or even $\mathrm{Rb}_{2} \mathrm{O}$ or $\left.\mathrm{Cs}_{2} \mathrm{O}\right)$, the stoichiometry of the grown
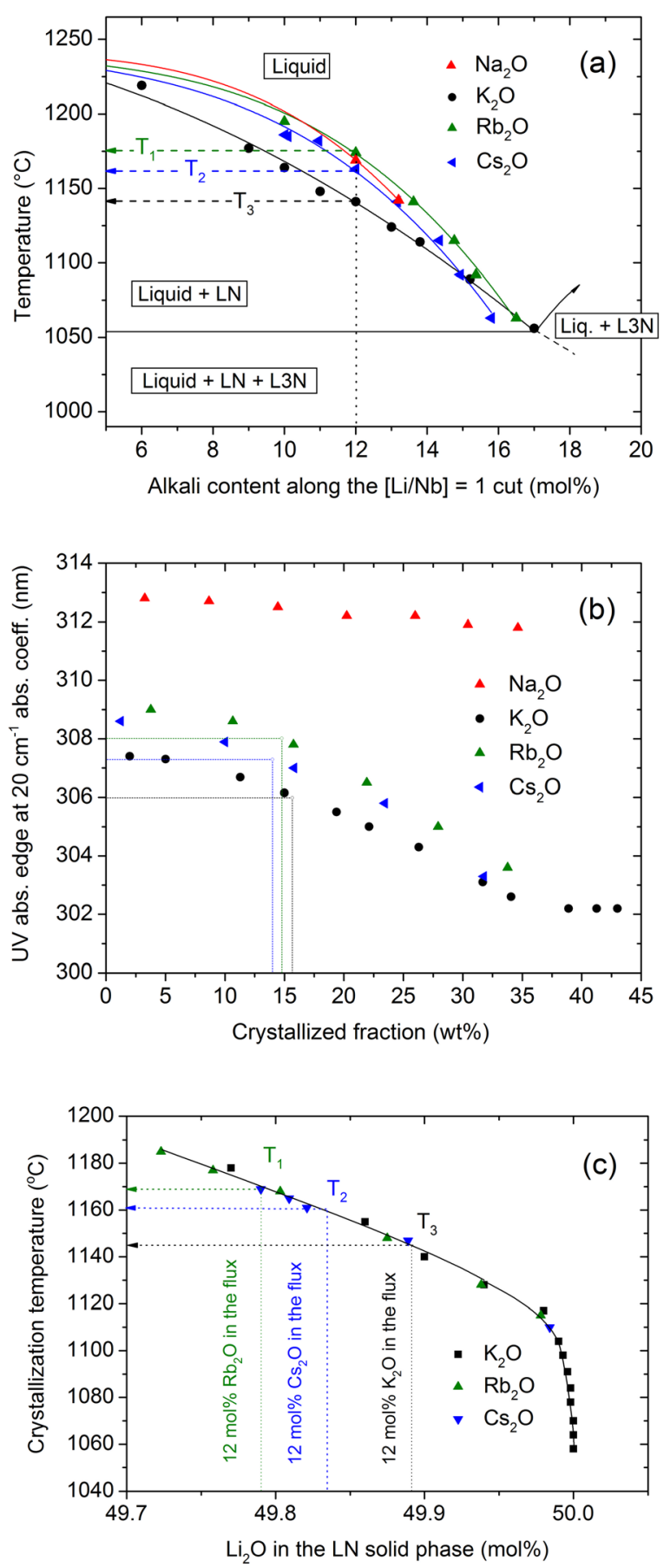

FIG. 3. Establishment of solid-liquid concentration relationships for the $\mathrm{Li}_{2} \mathrm{O}-\mathrm{Nb}_{2} \mathrm{O}_{5}-\mathrm{X}_{2} \mathrm{O}(\mathrm{X}=\mathrm{Na}, \mathrm{K}, \mathrm{Rb}$ and $\mathrm{Cs})$ ternary system. (a) Vertical sections of the $\mathrm{LiNbO}_{3}$ phase field in the $\mathrm{Li}_{2} \mathrm{O}-\mathrm{Nb}_{2} \mathrm{O}_{5}-\mathrm{X}_{2} \mathrm{O}$ ternary system along the $\mathrm{LiNbO}_{3}-\mathrm{X}_{2} \mathrm{O}$ line $\left(\mathrm{LN}\right.$ : $\left.\mathrm{LiNbO}_{3}, \mathrm{~L} 3 \mathrm{~N}: \mathrm{Li}_{3} \mathrm{NbO}_{4}\right)$. (b) UV absorption edge positions of consecutive slices cut perpendicular to the growth axes of crystals grown with starting compositions $\mathrm{Li} / \mathrm{Nb}=1$ and $10 \mathrm{~mol}$. \% $\mathrm{X}_{2} \mathrm{O}$ alkali additives. Reproduced with permission from G. Dravecz et al., J. Cryst. Growth 286, 334-337 (2006). Copyright 2006 Elsevier. (c) Evolution of the solidus composition paths in the $\mathrm{Li}_{2} \mathrm{O}-\mathrm{Nb}_{2} \mathrm{O}_{5}$ binary system for liquidus paths along the $\mathrm{LiNbO}_{3}-\mathrm{X}_{2} \mathrm{O}$ line of the $\mathrm{X}_{2} \mathrm{O}-\mathrm{Nb}_{2} \mathrm{O}_{5}-\mathrm{Li}_{2} \mathrm{O}$ ternary system.

crystals can be further improved, since for flux compositions located on the $\mathrm{LiNbO}_{3}-\mathrm{X}_{2} \mathrm{O}$ join, the crystallization temperature can be lowered down to $\sim 1000^{\circ} \mathrm{C}$. The seeding temperatures at $1165^{\circ} \mathrm{C}$ can already be ensured with only $\sim 10.6 \mathrm{~mol} . \%$ of $\mathrm{K}_{2} \mathrm{O}$ or between 12 and $13 \mathrm{~mol}$. \% content of $\mathrm{Rb}_{2} \mathrm{O}$ or $\mathrm{Cs}_{2} \mathrm{O}$. 
Alkali additives have been reported to be beneficial in the growth of other ferroelectric compounds of the $\mathrm{Li}_{2} \mathrm{O}-\mathrm{Nb}_{2} \mathrm{O}_{5}-\mathrm{K}_{2} \mathrm{O}$ ternary system as well. In the growth of $\mathrm{KN}$ and the tungsten bronze-type KLN crystals by the HTTSSG method, Beh et al. ${ }^{37}$ used $\mathrm{Rb}_{2} \mathrm{O}$, Péter et al. ${ }^{38}$ used $\mathrm{Cs}_{2} \mathrm{O}$ additive in the melt to improve the stoichiometry of the KN and KLN crystals, respectively. Again, the fluxing agents practically did not enter either the KN or the KLN lattices, similarly to the role of $\mathrm{K}^{+}$ions in the growth of $\mathrm{LN}$ crystals; they have affected the crystal properties only via decreasing the crystallization temperature; thus, as $\mathrm{K}_{2} \mathrm{O}$ in the case of $\mathrm{LN}$, these additives could also be considered as appropriate fluxing agents in the respective systems. The impact of alkali homologue ions $\left(\mathrm{Na}^{+}, \mathrm{K}^{+}, \mathrm{Rb}^{+}\right.$and $\left.\mathrm{Cs}^{+}\right)$on the compositional variation of ferroelectric single crystals seems to be correlated with their ionic radii: The incorporation of the smaller alkali ions into the crystal is promoted via the mixed alkali effect (i.e., enforced, preferential occupancy of low energy sites by the smaller cations, e.g., $\mathrm{K}^{+} \rightarrow \mathrm{Li}: \mathrm{LN}$, $\mathrm{Rb}^{+} \rightarrow \mathrm{K}: \mathrm{LN}$, and $\left.\mathrm{Cs}^{+} \rightarrow \mathrm{K}: \mathrm{KLN}\right)$.

\section{HTTSS growth of sLN crystals from $\mathrm{K}_{2} \mathrm{O}$-fluxed melts}

The information obtained from the investigation of the high-temperature phase equilibria of the $\mathrm{Li}_{2} \mathrm{O}-\mathrm{Nb}_{2} \mathrm{O}_{5}-\mathrm{K}_{2} \mathrm{O}$ ternary system has greatly advanced the technology of growing sLN crystals with desired perfection and homogeneity. According to the phase diagram, the stoichiometric composition of the crystals can be ensured by using starting compositions situated along the $\mathrm{LiNbO}_{3}-\mathrm{K}_{2} \mathrm{O}$ line of the ternary system, with the potassium content of the fluxes above $13.8 \mathrm{~mol} \%$. In these cases, the liquidus-solidus tie lines evolve along the quasi-binary join and the $\mathrm{Li} / \mathrm{Nb} \sim 1$ ratio stays constant both in the liquid and the growing crystal.

The use of $\mathrm{K}_{2} \mathrm{O}$-fluxed melts necessitated an adaptation of the technology to the requirements of solution growth (i.e., increased viscosity of the fluxed melt, decreased growth rates, and finer temperature control). For the bulk growth of good quality crystals, the top-seeded arrangement with steep thermal gradients above the melt has proved quite adequate. ${ }^{14}$ The proper choice of the operating parameters of the HTTSSG method is related to the design of apparatus. Crystals can be prepared using either RF or resistance heating furnaces. Vertical temperature gradients just above the melt surface were reported within the range of $0.5-7^{\circ} \mathrm{C} / \mathrm{mm}$, the pulling rates adjusted to $0.1-0.2 \mathrm{~mm} / \mathrm{h}$, and seed rotation rates between 4 and 45 rotations per minute $(\mathrm{rpm}) .{ }^{14,35}$ The increased viscosity of the solution limits mixing and mass transport, and makes it difficult to obtain uniform supersaturation and effective convection to the growth interfaces. Szaller et al. ${ }^{39}$ have investigated the optimal conditions for facet-free growth of crystals pulled along the $\mathrm{Z}$ axis. To eliminate the flow instabilities and to achieve an interface shape conform to the very low convexity requirement a gradually adjusted rotation rate program was used realising thermal conditions characterized by the relation $\mathrm{Gr} / \mathrm{Re}^{2}>1$ for the mixed convection interaction parameter (where $\mathrm{Gr}$ is the dimensionless Grashof number and $\mathrm{Re}$ the rotational Reynolds number, characteristic for the buoyancy and the forced convection, respectively).

The crystallization temperature of stoichiometric crystals pulled from $\mathrm{K}_{2} \mathrm{O}$-fluxed melts is below the Curie temperature all along the growth process, thus the resulting domain structure of the crystals is no more related to the ferroelectric phase transition but only to the self-generated poling effects during growth or cooling down. The temperature gradients, and in some cases the impurity/dopant concentration gradient via the induced non-uniform electric field can supply potential differences sufficient for poling. By all means, the poling field required for domain reversal is much less in stoichiometric crystals than in the congruent ones, as shown by Grisard et al. ${ }^{40}$ and Gopalan et al. ${ }^{41}$

The HTTSS grown sLN crystals show pronounced tendency towards faceting. The presence of the facets can be delineated by the associated strain pattern, chemical etching, or by the observation of incorporated micro-inclusions at edges of the facets. Facets cause regions of strain in crystals which are usually accommodated elastically, but sometimes, the stress developed may exceed the yield point of mechanical twinning (Fig. 4(a)). Close connection has been observed between faceted growth and the appearance of domain reversal as well. The low coercive force typical for sLN promotes ferroelectric domain reversal in the faceted region (Figs. 4(b) and 4(c) central regions) and also the formation of micro domains manifested as small light scattering centres in Fig. 4(c).

Faceting, related to both the shape of the growth interface and the pulling direction, generally occurs in those areas of the crystal-melt interface, where the growth front is parallel to the morphologically important (heaviest packed) crystal planes. In these cases, both the impurity segregation at facets and the developing stress may promote the reversal of domain patterns of the crystal. Polgár et al. ${ }^{28}$ carried out comparative studies with growth axes parallel to the $\mathrm{Z}=\langle 0001\rangle, \mathrm{Y}=\langle 01 \overline{1} 0\rangle, \mathrm{X}=\langle 2 \overline{1} \overline{1} 0\rangle$ axes as well as in the $\langle 01 \overline{1} 1\rangle$ and $\langle 0 \overline{2} 22\rangle$ directions and showed that development


FIG. 4. (00.1) slices of faceted asgrown sLN crystals pulled along $\mathrm{Z}=\langle 0001\rangle$ direction. (a) Mechanical twins observed through crossed polarizers. (b) Pyramidal facets on the bottom and (c) domain patterns of an adjacent bottom slice observed through crossed polarizers. 
of facets occurred primarily along the $\{01 \overline{1} 2\}$ pyramidal planes. For LN crystals, the pyramidal facets may form when the angle between the growth direction and the direction normal to the $\{01.2\}$ planes is obtuse. Thus to reduce or eliminate the facets for pulling along the $\mathrm{Z}, \mathrm{X}$, and $\mathrm{Y}$ directions near planar for the $\langle 01 \overline{1} 1\rangle$ or $\langle 0 \overline{2} 21\rangle$ growth directions, slightly convex growth interface shapes are required. Pulling along the $\mathrm{Z}$ axis, the steep axial thermal gradient by itself was sufficient for the growth of single domain crystals without additional poling. The crystals grown with nearly planar interface were always single domain, virtually all along the boule; for the other growth directions, the resulting domain structure depended on the ratio of the axial and radial temperature gradients at the growth interface. For crystals grown along the directions perpendicular to the spontaneous polarization vector (e.g., along the $\mathrm{X}$ or $\mathrm{Y}$ direction), the boule usually consisted of two domain regions, with a vertical boundary parallel to the growth axis.

The degree of structural perfection is highly affected by the necking process. Growth ridges on the shoulder surface and facets on the growth front are the major source of structural defects. After seeding, the crystal grows with conically increasing diameter on a strongly convex growth front until the desired diameter is reached. The rate of the increase in the crystal diameter is influenced by the cone angle. Ridge formation also depends on the cone angle (i.e., direction of growth at the conical part): On crystals grown along the Z-axis with acute cone angle, at the shoulder part, both $(10 . \overline{2})$ and $(01 . \overline{2})$ type pyramidal planes assist in ridge formation, while at the cylindrical part where the growth conditions are stable, only type (10. $\overline{2}$ ) is acting. Stress associated with large ridges promotes both cracking and mechanical twinning during the cooling down process. Therefore, to avoid faceting is a must for the growth of good quality crystals, together with a near planar growth interface during the preparation of the cylindrical part.

\section{Growth of ODR-ion doped sLN crystals}

For the photonic application of nonlinear optical materials at high light intensities, the optical damage is a major scientific and technological issue. Light induced refractive index change due to the combined action of photoconductivity and electro-optic activity may result in chaotic beam distortion, ruling out any control of the propagating light wave front. The unwanted appearance of the photorefractive effect is a serious obstacle for the application of nominally undoped $\mathrm{LiNbO}_{3}$ as well. Understanding this problem requires detailed knowledge of the defect structure and the charge transport properties of the material.

Controlling optical damage in LN crystals essentially involves the removal of rechargeable defects, both extrinsic and intrinsic, playing central roles in photorefraction (PR). The main defects in question are the impurities $\mathrm{Fe}, \mathrm{Cu}, \mathrm{Mn}$, and $\mathrm{Rh}$ (contaminants from raw materials and crucible), and antisite $\mathrm{Nb}$. Elimination of the latter can be achieved, beside improving the stoichiometry, by doping with optical damage resistant elements above a given threshold concentration.
The family of ODR ions includes divalent $(\mathrm{Mg}, \mathrm{Zn})$, trivalent (In, Sc), and tetravalent (Hf, $\mathrm{Zr}, \mathrm{Sn}$ ) ions as well.

The defect chemistry of LN crystals based on the preferred Li vacancy model $^{42}$ will be detailed in Section III, where the impact of ODR ions in suppressing the antisite $\mathrm{Nb}_{\mathrm{Li}}$ defects will also be discussed. As follows from the analysis, the critical threshold concentrations of the ODR dopants depend both on the actual $\mathrm{Li} / \mathrm{Nb}$ ratio and the valence of the built-in dopant. A stoichiometric $\mathrm{LiNbO}_{3}$ crystal having fewer intrinsic defects requires lower dopant concentrations for tailoring its properties. While for cLN, the threshold concentration for di-, tri-, and tetravalent ODR ions is roughly 5,4 , and $2 \mathrm{~mol} \%$, respectively, it is below 1 mol. \% for sLN crystals. Understanding of the respective models and advances in the technology of growing stoichiometric crystals strongly promoted the preparation of large optical-damage-resistant single crystals with desired perfection and homogeneity (Fig. 5). Most widely used in applications from the visible to the $\mathrm{THz}$ range are $\mathrm{MgO}$ doped $\mathrm{LN}$ crystals. Periodically poled sLN:Mg (PPLN), in particular, received special attention in quasi-phase-matched frequency conversion devices. ${ }^{15}$

Investigations on the critical threshold concentration of ODR ions in HTTSS grown near stoichiometric crystals have been reported for $\mathrm{Mg}, \mathrm{Zn}$, In, and $\mathrm{Zr}$ ions using alkali fluxed systems, ${ }^{43-46}$ and for Sc using a Li-rich solution; ${ }^{47}$ further references and discussion on this topic will be given in Section III C.

Thermal analyses have shown that in the $\mathrm{Li}_{2} \mathrm{O}-\mathrm{Nb}_{2} \mathrm{O}_{5}-$ $\mathrm{K}_{2} \mathrm{O}$ ternary system, the $\mathrm{MgO}$ additive of concentrations below 2 mol. $\%$ has minimal influence on the solidusliquidus phase relations of the fluxed system. Similar results may be expected for the other ODR additives as well. Therefore, it seems reasonable to explain the crystallization of ODR-ion doped crystals on the basis of the knowledge gained on the phase equilibria of undoped $\mathrm{Li}_{2} \mathrm{O}-\mathrm{Nb}_{2} \mathrm{O}_{5}-\mathrm{K}_{2} \mathrm{O}$ ternary and $\mathrm{Li}_{2} \mathrm{O}-\mathrm{Nb}_{2} \mathrm{O}_{5}$ binary systems, including their partitioning behaviour between $\mathrm{Li}$ and $\mathrm{Nb}$ sites during the growth. The $\mathrm{Li} / \mathrm{Nb}$ ratio of the solidus can be ensured to be nearly constant and close to the stoichiometric composition by the appropriate choice of the flux composition both in the framework of HTTSS growth and the double-crucible automated powder supply technique. As was shown for the $\mathrm{Li}_{2} \mathrm{O}-\mathrm{Nb}_{2} \mathrm{O}_{5}-\mathrm{K}_{2} \mathrm{O}$ ternary system, growth along the $g_{1}$ line



FIG. 5. High quality stoichiometric $\mathrm{LiNbO}_{3}$ crystal grown by the HTTSSG method. 
results in a constant composition segment of the solidus (detailed in Fig. 1(b)). In the $\mathrm{Li}_{2} \mathrm{O}-\mathrm{Nb}_{2} \mathrm{O}_{5}$ binary system, the use of an automated powder supply technique maintaining fixed molar $\left[\mathrm{Li}_{2} \mathrm{O}\right] /\left[\mathrm{Nb}_{2} \mathrm{O}_{5}\right] \sim 58 / 42$ ratio $^{36}$ allows to keep constant both the liquid and solid compositions. To interpret the incorporation of ODR ions into flux grown LN crystals, both the segregation between solvent and solute and the distribution of dopants between $\mathrm{Li}$ and $\mathrm{Nb}$ sites have to be considered at the same time.

As examined for $\mathrm{MgO}$ doping in the $\mathrm{Li}_{2} \mathrm{O}-\mathrm{Nb}_{2} \mathrm{O}_{5}-\mathrm{K}_{2} \mathrm{O}$ ternary system, ${ }^{43}$ the decrease in the growth yield (i.e., the maximal amount of available $\mathrm{LiNbO}_{3}$ phase) is already considerable at $0.1 \mathrm{~mol} . \%$ doping and decreases further at higher dopant concentrations. Chemical analysis of the builtin concentration of $\mathrm{Mg}$ indicates a slightly higher value for the segregation coefficient in the case of below-threshold crystals compared to above-threshold ones (for both cases $\mathrm{k}_{\mathrm{eff}} \geq 1$, independently of the $\mathrm{Li} / \mathrm{Nb}$ ratio). The optimal concentration of $\mathrm{MgO}$ required for the growth of damage resistant (above threshold) crystals was found to depend on the crystallization temperature; thus by choosing an optimal combination of the crystallization temperature (i.e., $\mathrm{Li} / \mathrm{Nb}$ ratio) and the amount of dopant, the crystal properties can be tailored. It is interesting to note that conditions may slightly change along the boule, i.e., in crystals doped with $\mathrm{MgO}$ near to the critical threshold concentration, an extended transition region may be produced separating the clearly below- and above-threshold parts, with the transition region manifesting defect characteristics of both type (e.g., OH absorption bands at both 3465 and $3534 \mathrm{~cm}^{-1}$ ) indicating that $\mathrm{Mg}$ ions may simultaneously be incorporated at both $\mathrm{Li}$ and $\mathrm{Nb}$ sites (see Fig. 9 in Section III).

In the $\mathrm{Li}_{2} \mathrm{O}-\mathrm{Nb}_{2} \mathrm{O}_{5}-\mathrm{K}_{2} \mathrm{O}$ ternary system, the lowest in-melt concentration of the $\mathrm{MgO}$ dopant resulting in abovethreshold crystals is $0.2 \mathrm{~mol} \%$. For $\mathrm{Zn}$-doped near sLN grown from $\mathrm{K}_{2} \mathrm{O}$ fluxed melt, the reported threshold concentration was between 2 and 3 mol. $\%,{ }^{44}$ for In doping at about $1.1 \mathrm{~mol} . \%{ }^{45}$ and for $\mathrm{Zr}$ doping at about $0.1 \mathrm{~mol} . \%{ }^{46}$

In the $\mathrm{Li}_{2} \mathrm{O}-\mathrm{Nb}_{2} \mathrm{O}_{5}$ binary system using $\mathrm{Li}_{2} \mathrm{O}$ rich solution, to suppress the photorefractive damage with $\mathrm{Mg}$ doping, a minimum of 1 mol. $\%,{ }^{48}$ with Sc 0.4 mol. \% (Ref. 47 ) was required. The scatter of these values is related both to the unknown real $\mathrm{Li} / \mathrm{Nb}$ ratio in the allegedly "near stoichiometric" $\mathrm{LiNbO}_{3}$ crystals and to the differing valences of the dopants as it will be discussed in detail in Section III C. It should be noted that in crystals prepared for device applications, ODR dopant concentrations slightly above the critical threshold are preferred in order to suppress the formation of unwanted microdomains (see Fig. 4(c)).

\section{COMPOSITION AND PROPERTIES OF PURE AND ODR-ION DOPED LINbO ${ }_{3}$ CRYSTALS}

The stoichiometric composition of $\mathrm{LiNbO}_{3}$, compared to congruent, not only requires different growth conditions but also results in markedly different, mostly advantageous physical properties due to the far more perfect lattice, as, e.g., increased resistance to optical damage. The change of physical properties, on the other hand, can be used for the determination of the crystal composition. Several straightforward methods, such as measurements of lattice constants, density, ferroelectric Curie-temperature, etc., have originally been used to characterize crystals with compositions from congruent to stoichiometric. Later, a number of optical properties, including refractive indices, birefringence, optical frequency doubling (phase matching tuned by temperature or angle), holographic scattering, etc., have been used to develop calibrations for the determination of the crystal composition. All these methods, including also various spectroscopic techniques were summarized by Wöhlecke et al. ${ }^{49}$ The spectroscopic techniques, in particular, two easily applicable methods most sensitive for near-stoichiometric and ODR-ion doped $\mathrm{LiNbO}_{3}$, will be discussed in detail in Section III A.

ODR dopants making $\mathrm{LiNbO}_{3}$ optical damage resistant (see also Section IID) also change the properties of the crystal in a manner often similar to improved stoichiometry. Best results for application can in fact be achieved by combining both crystal tailoring strategies, thereby avoiding structural instabilities of highly stoichiometric crystal growth and reducing the required threshold concentrations of ODR dopants. The effect of ODR dopants on the properties of $\mathrm{LiNbO}_{3}$ will be discussed in Sections III B and III C. An overview about the incorporation of transition metal and rare earth ions in $\mathrm{LN}$ with various compositions and/or ODR co-dopings will be given in Section III D. Special attention will be paid to $\mathrm{Mg}$ and its effects on nonlinear optical properties in the far-IR spectral range playing an essential role in recent THz applications (see Section V).

\section{A. Spectroscopic characterization of undoped LN}

Out of the numerous spectroscopic methods considered for the characterization of the composition and properties of $\mathrm{LN}^{49}$ here only two techniques, those involving the measurement of the fundamental UV absorption edge and the IR absorption of the hydroxyl ion $\left(\mathrm{OH}^{-}\right)$stretch mode, respectively, will be summarized. Both methods are simple, fast, and accurate for the determination of the crystal composition especially near to the stoichiometric composition.

\section{Ultraviolet absorption edge}

Though the difference in the position of the optical absorption edge for a congruent and a more stoichiometric $\mathrm{LiNbO}_{3}$ crystal has already been measured by Redfield and Burke, ${ }^{50}$ the concept of using the spectral position of the fundamental UV absorption edge as an indicator for the composition of $\mathrm{LiNbO}_{3}$ crystals was introduced by Földvári et al. ${ }^{32}$ in 1984. At that time, however, no samples with well defined near stoichiometric compositions were available. Later, based on the results of successful HTTSS growth and vapour transport equilibration treatments, $\mathrm{LiNbO}_{3}$ crystals with a wide range of crystal compositions from $\mathrm{Li} / \mathrm{Nb} \approx 0.9$ to $\mathrm{Li} / \mathrm{Nb} \approx 1$ could be investigated. ${ }^{33}$ The real crystal composition of the samples was determined using accurate birefringence and second harmonic generation (SHG) measurements based on careful comparisons with Curie temperature calibrations. ${ }^{51}$ The next step was to produce a calibration curve 
connecting crystal compositions to results of simple absorption measurements in the near UV spectral range. The position of the band edge was defined as the wavelength where the absorption coefficient $\alpha$ equalled $20 \mathrm{~cm}^{-1}$, but the parameters of the calibration curve have also been determined for $\alpha=15 \mathrm{~cm}^{-1}$. This relatively weak absorption in the band tail is related less to the perfect lattice but essentially to intrinsic defects like antisite niobiums $\mathrm{Nb}_{\mathrm{Li}}$ (Ref. 32) and possibly lithium vacancies $\mathrm{V}_{\mathrm{Li}}{ }^{52}$ Both types of defects are present in nonstoichiometric crystals charge compensating each other and disappear simultaneously at the stoichiometric composition.

Taking into account a correction for reflection losses as well, for increasing $\mathrm{Li}_{2} \mathrm{O}$ content, a monotonously decreasing wavelength was obtained (Fig. 6). A square root fit for the energy shift of the absorption edge versus the deviation from stoichiometric composition was found to be accurate in the whole composition range (see the inset of Fig. 6)

$$
\mathrm{E}=\mathrm{k}\left(50-\mathrm{c}_{\mathrm{Li}}\right)^{1 / 2}+\mathrm{E}_{0},
$$

where $\mathrm{E}$ is the photon energy corresponding to the absorption edge at the chosen value of $\alpha, c_{\mathrm{Li}}$ is the $\mathrm{Li}_{2} \mathrm{O}$ concentration in the sample in mol. $\%, \mathrm{k}$ and $\mathrm{E}_{0}$ are the parameters of the fit. For $\mathrm{T}=22^{\circ} \mathrm{C}$ and ordinary polarization, $\mathrm{k}$ representing the slope of the straight line is equal to $-0.189 \pm 0.003 \mathrm{eV} /$ $\sqrt{\mathrm{mol} . \%}$ and $\mathrm{E}_{0}=4.112 \pm 0.002 \mathrm{eV}$ (for $\alpha=20 \mathrm{~cm}^{-1}$ ) corresponding to the absorption edge of the stoichiometric crystal with $\mathrm{c}_{\mathrm{Li}}=50 \mathrm{~mol} . \%$. The absolute accuracy thus provided is better than $0.1 \mathrm{~mol} . \%$, while for near stoichiometric compositions, the relative accuracy reached an exceptional value of about $0.01 \mathrm{~mol}$. \%. As proved later by IR absorption measurements of hydroxyl stretching vibrations described in Section III A 2, the latter value can also be considered as the absolute accuracy in the near stoichiometric limit.

This simple and efficient technique was used for characterizing the composition of LN crystals during the investigations of phase equilibria and HTTSS growth from various alkali oxide solvents as reviewed in Section II. Though the

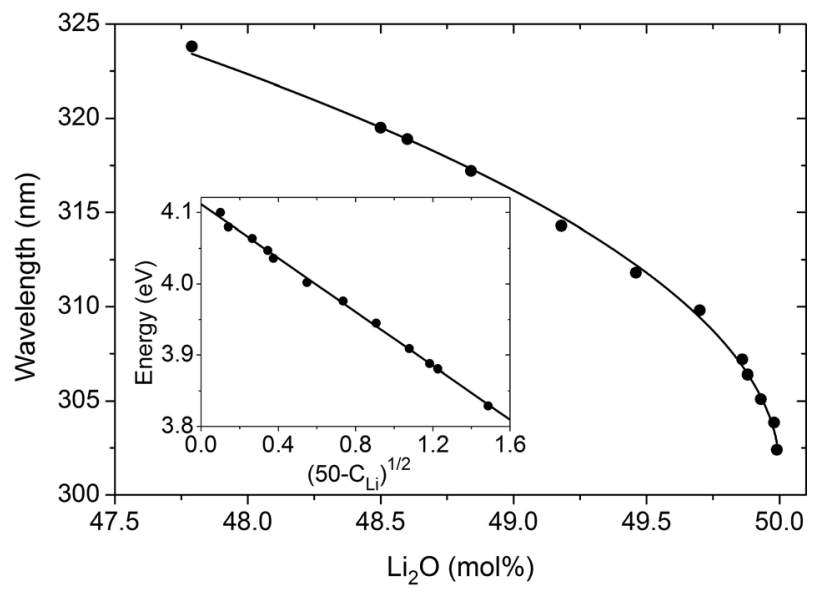

FIG. 6. The fundamental absorption edge of $\mathrm{LiNbO}_{3}$ at $\alpha=20 \mathrm{~cm}^{-1}$ for ordinary polarization as a function of crystal composition. The lines are calculated using Eq. (3.1) with the parameter values given in the text. Reproduced with permission from L. Kovács et al., Appl. Phys. Lett. 70, 2801-2803 (1997). Copyright 1997 American Institute of Physics. calibration curve shown in Fig. 6 is valid only for undoped LN crystals, the method could be extended and successfully used also for Mg doped crystals since the effect of Mg prevails through changing the number of antisite niobiums and their compensating lithium vacancies (see Section III B). The technique was widely applied by research groups working on stoichiometric $\mathrm{LiNbO}_{3}$ crystals for determining the crystal composition of their samples, see, e.g., Refs. 34 and 53-57, etc.

\section{2. $\mathrm{OH}^{-}$absorption}

$\mathrm{LiNbO}_{3}$ crystals grown in air always contain hydroxyl ions $\left(\mathrm{OH}^{-}\right)$incorporated during the growth process. The $\mathrm{OH}^{-}$ions occupy regular oxygen sites in the lattice with possible charge compensators in their surroundings. The stretching vibration of the $\mathrm{OH}^{-}$ion in cLN can be detected in the IR spectral range at about $3484 \mathrm{~cm}^{-1}(2.87 \mu \mathrm{m})$. It was found that the shape of the absorption band depends on the composition of LN crystals. ${ }^{58}$ In cLN crystals, the band is broad with a full width at half maximum (FWHM) of at about $30 \mathrm{~cm}^{-1}$ containing at least three overlapping components. The closer the composition to stoichiometric the narrower the band components, and the amplitudes of the high frequency components are approaching zero (see Fig. 7). This tendency culminates in the $\mathrm{OH}^{-}$band of the stoichiometric crystal characterized by a single narrow line at about $3465 \mathrm{~cm}^{-1}$ with an FWHM equal to at about $3 \mathrm{~cm}^{-1}$ at $300 \mathrm{~K}^{14}$

The complex absorption band of cLN crystals is related to the presence of defects in the vicinity of the hydroxyl ions. The various surroundings of the $\mathrm{OH}^{-}$ions result in different stretching frequencies. In sLN crystals with practically no intrinsic defects, only a single line appears. Consequently, the $\mathrm{OH}^{-}$spectra can be used as a probe of the defect structure of lithium niobate. In Section IV, we discuss various defect models and their relation to the $\mathrm{O}-\mathrm{H}$ vibrational frequencies.

The possibility of considering the $\mathrm{OH}^{-}$band shape as a characteristic of the crystal composition has arisen in the early works of Kovács et al. ${ }^{58,59}$ At that time, however, no

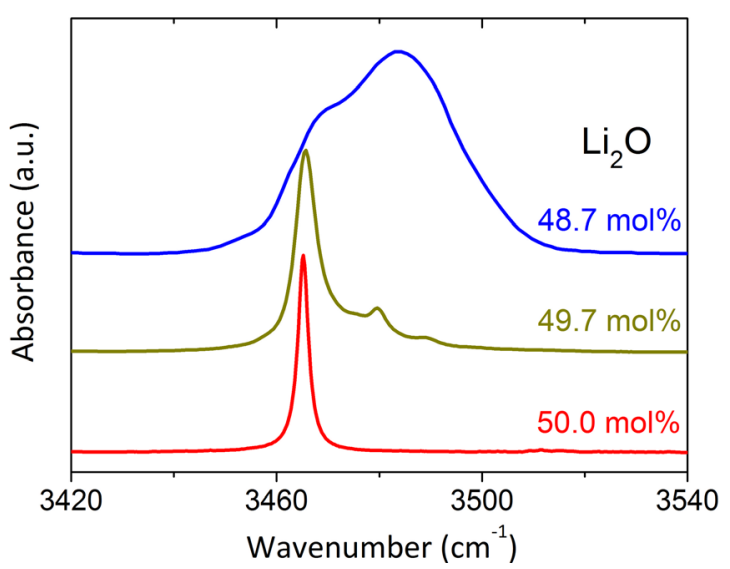

FIG. 7. The change of the $\mathrm{OH}^{-}$vibration band as a function of crystal composition. Reproduced with permission from K. Polgár et al., J. Cryst. Growth 177, 211-216 (1997). Copyright 1997 Elsevier. 
stoichiometric LN crystals were available, and the decomposition of the $\mathrm{OH}^{-}$band shape of congruent and nearcongruent crystals was ambiguous. Another difficulty impeding this ambition was the change of the band shape with time. $^{60}$ Finally, both problems were solved, and a simple technique for the determination of the crystal composition based on the intensity ratio $(\mathrm{R})$ of two components at 3465 and $3480 \mathrm{~cm}^{-1}$ was introduced and successfully used close to the stoichiometric composition. ${ }^{61,62}$

A series of LN crystals were grown by the HTTSSG method from fluxes containing additional alkali metal oxide $\left(\mathrm{K}_{2} \mathrm{O}, \mathrm{Rb}_{2} \mathrm{O}\right.$, or $\left.\mathrm{Cs}_{2} \mathrm{O}\right)$ as described in Section II. The $\mathrm{Li}_{2} \mathrm{O}$ contents of the samples between 49.7 and $50.0 \mathrm{~mol}$. \% were determined by UV absorption edge measurements with a relative accuracy of $0.01 \mathrm{~mol} \%$. The $\mathrm{OH}^{-}$absorption spectra measured by a Bruker IFS 66v/S FTIR spectrometer showed the presence of three bands at 3465,3480 , and $3490 \mathrm{~cm}^{-1}$, the latest being very weak (see Fig. 8). Thus, the intensity ratio $\mathrm{R}=\mathrm{I}_{3480} / \mathrm{I}_{3465}$ can be easily determined. The spectra in Fig. 8 were normalized to the $3480 \mathrm{~cm}^{-1}$ band. The higher the $\mathrm{Li}_{2} \mathrm{O}$ content of the crystal, the higher the intensity of the $3465 \mathrm{~cm}^{-1}$ line, i.e., the intensity ratio $\mathrm{R}$ decreases almost linearly with increasing $\mathrm{Li}_{2} \mathrm{O}$ content


FIG. 8. Absorption spectra of LN crystals with 49.72 (black), 49.80 (red), and 49.94 mol. \% (blue) $\mathrm{Li}_{2} \mathrm{O}$ content, normalized to the peak at $3480 \mathrm{~cm}^{-1}$ (a). The intensity ratio $\left(\mathrm{R}=\mathrm{I}_{3480} / \mathrm{I}_{3465}\right)$ of the $\mathrm{OH}^{-}$band components as a function of crystal composition was measured at $0(\boldsymbol{\square}), 7.5(\mathbf{\Delta}), 16(\boldsymbol{\nabla})$, and 18 (O) months after crystal growth (b). Reproduced with permission from G. Dravecz and L. Kovács, Appl. Phys. B 88, 305-307 (2007). Copyright 2007 Springer Science+Business Media.

$$
\mathrm{R}(\mathrm{t})=\mathrm{S}(\mathrm{t})\left(\mathrm{C}-\left[\mathrm{Li}_{2} \mathrm{O}\right]\right)
$$

where $\left[\mathrm{Li}_{2} \mathrm{O}\right]$ is the lithium oxide content of the crystal in mol. \% and $\mathrm{S}(\mathrm{t})$ is the slope of the straight lines changing with sample storage time. Using least square fits, the parameter $\mathrm{C}$ was always found to be equal to 50 with a very high accuracy $(<0.005 \mathrm{~mol} . \%)$. This result is highly expected, since at the stoichiometric composition (at $\left[\mathrm{Li}_{2} \mathrm{O}\right]=50 \mathrm{~mol} . \%$ ), the $\mathrm{OH}^{-}$defects appearing at $3480 \mathrm{~cm}^{-1}$ due to non-stoichiometry should disappear providing $\mathrm{R}=0$ (see the lowest (red) curve in Fig. 7). The fact that $\mathrm{R}$ reaches 0 exactly at $50 \mathrm{~mol} \%$ in all cases proves that the absolute accuracy is also in the range of $0.01 \mathrm{~mol} \%$. A posteriori this also demonstrates that the UV absorption edge method on its turn, used for the composition determination of the samples, has an absolute accuracy of at least $0.01 \mathrm{~mol} . \%$ in this region. Earlier, this was assumed to be only at about $0.1 \mathrm{~mol} . \%$ and the composition calibration, in the absence of a "zero-parameter" like R, was only based on less precise Curie-temperature measurements. ${ }^{51}$

Fig. 8(b) shows, however, that the slope of the curves changes with time passed after crystal growth. This indicates that the thermal equilibrium of the protons moving from one oxygen site to another is reached after a long time. The obtained slope values for given storage times fit well to a first order exponential curve

$$
\mathrm{S}(\mathrm{t})=\mathrm{S}_{\infty}-\mathrm{A} \exp (-\mathrm{t} / \tau)
$$

where $\mathrm{S}_{\infty}$ represents the slope of the calibration line at $\mathrm{t}=\infty$ (i.e., in thermal equilibrium at RT) and $\tau$ is the time constant of the thermally induced change of the $\mathrm{OH}^{-}$bands $\left(\mathrm{S}_{\infty}=2.01 \pm 0.021 / \mathrm{mol} . \%, \quad \mathrm{~A}=1.27 \pm 0.02 \quad 1 / \mathrm{mol} . \%\right.$, $\tau=5.9 \pm 0.3$ months). This value of $\tau$ is in good agreement with the lifetime of holographic gratings in photorefractive LN crystals, proving the role of hydroxyl ions in the hologram erasure/fixation process. ${ }^{63,64}$ Equations (3.2) and (3.3) allow one to determine the $\mathrm{Li}_{2} \mathrm{O}$ content of the crystal kept at RT for any time after the growth. Thus, beside UV absorption edge measurements, another simple independent non-destructive method is available for the determination of the composition of LN crystals near to the stoichiometric composition.

Although only undoped crystals were used to prepare the calibration described above, our experience showed that dopants and impurities below at about $0.1 \mathrm{~mol} \%$ do not affect the $\mathrm{OH}^{-}$spectra. The ODR dopants like $\mathrm{Mg}, \mathrm{Zn}, \mathrm{In}$, Sc, etc., influence the $\mathrm{OH}^{-}$bands only if added at the level of at least $0.1-0.2 \mathrm{~mol} \%$ even in near-stoichiometric $\mathrm{LiNbO}_{3}$, where a new $\mathrm{OH}^{-}$band appears as described in detail in Sections III B and C.

\section{B. Properties of Mg-doped sLN crystals}

By doping with $\mathrm{MgO}$ above the threshold concentration, the optical damage resistance of a congruent $\mathrm{LiNbO}_{3}$ crystal can be improved by several orders of magnitude. ${ }^{65}$ Moreover, quite a number of physical properties like Curie temperature, ${ }^{66}$ Raman spectrum, ${ }^{67}$ UV-edge, ${ }^{68}$ etc., depend on $\mathrm{MgO}$ addition, showing, in particular, an abrupt change at the threshold. The latter was found at about $5 \mathrm{~mol} \% \mathrm{MgO}$ 
for congruent $\mathrm{LiNbO}_{3},{ }^{65,69}$ strongly depending on the stoichiometry of the crystal. $^{60}$ In this section, the IR, UV, Raman, and Z-scan spectroscopic data measured in $\mathrm{Mg}$ doped LN crystals of a wide range of $\mathrm{Mg}$ concentrations and $\mathrm{Li} / \mathrm{Nb}$ ratios are summarized.

To analyse the spectroscopic results, some assumptions about the $\mathrm{Mg}$ incorporation mechanism have to be made. Models describing the incorporation of $\mathrm{Mg}$ ions ${ }^{42,70-72}$ usually assume that $\mathrm{Mg}$ ions compete for $\mathrm{Li}$ sites with antisite $\mathrm{Nb}_{\mathrm{Li}}$ ions up to the threshold concentration where all antisites are eliminated, while above the threshold, $\mathrm{Mg}$ ions replace both $\mathrm{Li}$ and $\mathrm{Nb}$ ions in the lattice. The main differences in the models are the specific reaction formulas describing the incorporation mechanism in the successive stages.

The composition of an undoped $\mathrm{LiNbO}_{3}$ crystals can be characterized using a parameter $x$ defined by the $\left(\mathrm{Li}_{2} \mathrm{O}\right)_{50-x}$ $\left(\mathrm{Nb}_{2} \mathrm{O}_{5}\right)_{50+\mathrm{x}}$ formula. Owing to the lack of a direct method to characterize the $\mathrm{Li} / \mathrm{Nb}$ ratio in the $\mathrm{Mg}$-doped samples, the definition of the $\mathrm{X}$-value was extended to the $\mathrm{Mg}$-doped crystals by assigning the same $\mathrm{x}$-value to all crystals grown from melts with the same $\mathrm{Li} / \mathrm{Nb}$ ratio and the same growth conditions. ${ }^{73}$ This definition is independent of the $\mathrm{Mg}$ incorporation model, which is required for calculating the $\mathrm{Li} / \mathrm{Nb}$ ratio and the antisite niobium concentration on the basis of $\mathrm{x}$ and the $\mathrm{Mg}$ concentration $\mathrm{c}_{\mathrm{Mg}}$ in the bulk. Following the model of Liu et al., ${ }^{42}$ the threshold, where the $\mathrm{Nb}_{\mathrm{Li}}$ antisites vanish, can be determined as

$$
c_{M g}^{t h}=\frac{1000 x}{3(100+2 x)},
$$

where $c_{M g}^{t h}$ is the threshold concentration of $\mathrm{Mg}$ in units of mol. $\%$.

\section{1. $\mathrm{OH}^{-}$vibration, UV absorption edge and Raman spectroscopy}

Infrared absorption measurements. In below-threshold $\mathrm{Mg}$ doped sLN crystals, the complex $\mathrm{OH}^{-}$band appears near $3465 \mathrm{~cm}^{-1}$, similarly to undoped samples. In this case, $\mathrm{Mg}$ doping only affects the linewidth of the $\mathrm{OH}^{-}$band decreasing with growing $\mathrm{Mg}$ content. ${ }^{68}$ Upon increasing the $\mathrm{MgO}$ concentration above the threshold, this band is replaced by another $\mathrm{OH}^{-}$band at a higher frequency of at about $3534 \mathrm{~cm}^{-1}$. ${ }^{65}$ This behaviour was observed at different $\mathrm{Mg}$ concentrations in $\mathrm{LiNbO}_{3}$ crystals with various $\mathrm{Li} / \mathrm{Nb}$ ratios. ${ }^{60}$ As discussed in Section II, the concentration of $\mathrm{Mg}$, $\mathrm{Li}$, and $\mathrm{Nb}$ in the solution or melt usually undergoes changes during the growth process. Accordingly, for suitable nearthreshold starting mixtures, a transition along the boule from below- to above-threshold states can be achieved. The $\mathrm{OH}^{-}$ infrared absorption spectra of sLN:Mg samples resulting from such a growth can be seen in Fig. 9.

In Fig. 10, symbols corresponding to a series of $\mathrm{Mg}$ doped $\mathrm{LiNbO}_{3}$ samples are shown in the $\mathrm{c}_{\mathrm{Mg}}-\mathrm{X}$ plane. Triangle, square, and circle symbols represent the congruent $(\mathrm{x} \approx 1.4)$, intermediate $(\mathrm{x} \approx 0.75)$, and stoichiometric $(\mathrm{x}<0.2)$ compositions, respectively. A symbol is full (empty) if, according to the IR spectra, the Mg concentration of the sample is above (below) the threshold. The theoretical

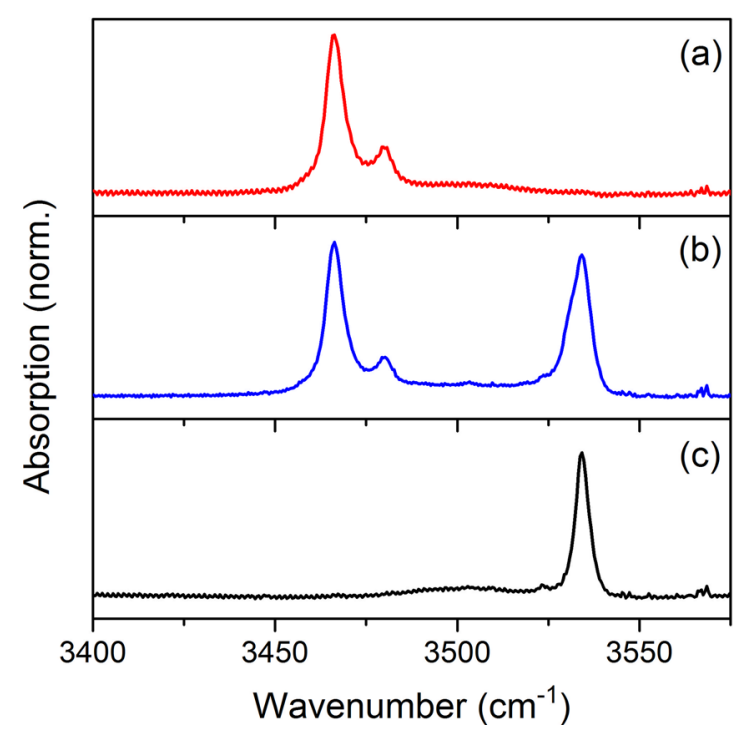

FIG. 9. IR spectra of samples from various parts of a threshold doped nearly stoichiometric, LN:Mg crystal boule: below threshold at the top (a) and above threshold at the bottom part (c), with a transition region in between where $\mathrm{OH}^{-}$absorption bands at both frequencies can be seen (b). Reproduced with permission from Á. Péter et al., J. Cryst. Growth 284, 149-155 (2005). Copyright 2005 Elsevier.

solid line corresponding to Eq. (3.4) displays the threshold concentrations in agreement with experiment by separating the below- and above-threshold samples.

Additional information can be derived for $\mathrm{Mg}$ concentrations exceeding the threshold concentration: the $\mathrm{OH}^{-}$ stretching vibrational band positions monotonically shift to higher wavenumbers with increasing $\mathrm{Mg}$ content above the threshold $^{74}$ (see Fig. 11). The band frequency does not depend on the composition of the samples but only on the $\mathrm{Mg}$ concentration. Samples with different compositions (plotted with various symbols) but with the same Mg content have equal frequencies of the $\mathrm{OH}^{-}$absorption band. An approximate square root relationship

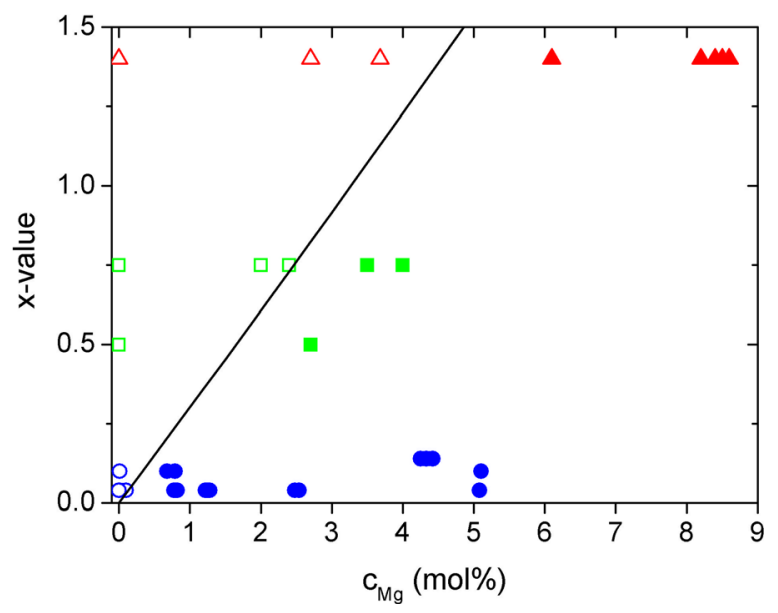

FIG. 10. Undoped and $\mathrm{Mg}$-doped $\mathrm{LiNbO}_{3}$ samples represented in the $\mathrm{c}_{\mathrm{Mg}}-\mathrm{X}$ plane (open and full symbols denote below- and above-threshold samples, respectively; for the definition of $\mathrm{x}$ characterizing the crystal composition, see text). The theoretical solid line corresponds to Eq. (3.4). Reproduced with permission from K. Lengyel et al., Phys. Status Solidi C 2, 171-174 (2005). Copyright 2005 John Wiley and Sons. 


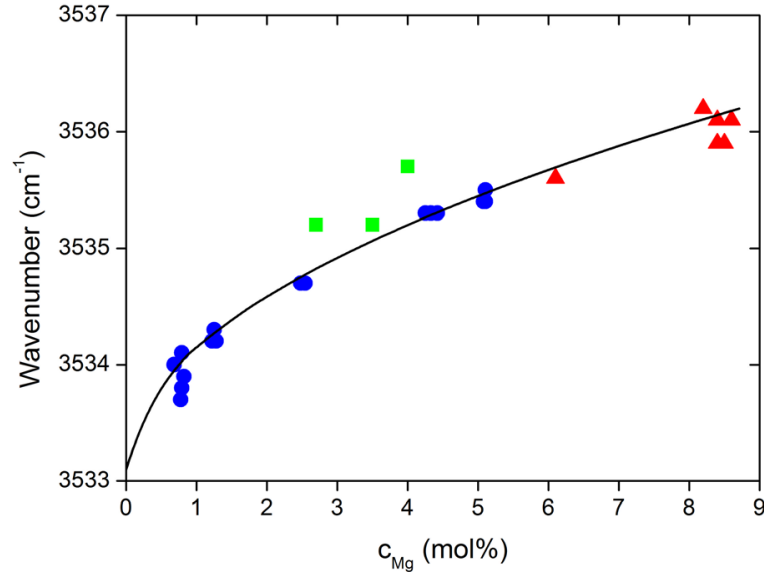

FIG. 11. Wavenumber of the $\mathrm{OH}^{-}$vibrational band vs. the $\mathrm{Mg}$ concentration in over-threshold $\mathrm{LiNbO}_{3}$ crystals. Reproduced with permission from K. Lengyel et al., Phys. Status Solidi C 2, 171-174 (2005). Copyright 2005 John Wiley and Sons.

$$
\nu=a \sqrt{c_{M g}}+b
$$

was determined from the data points, the calculated fitting parameters are $\mathrm{a}=1.05 \pm 0.05 \mathrm{~cm}^{-1} / \sqrt{(\mathrm{mol} \%)}$ and $\mathrm{b}=3533.1 \pm 0.2 \mathrm{~cm}^{-1}$, the latter corresponding to the frequency of the $\mathrm{OH}^{-}$absorption band of an ideal stoichiometric $\mathrm{LiNbO}_{3}: \mathrm{Mg}$ crystal just above the threshold.

These results suggest a simple method for determining the $\mathrm{Mg}$ content of over-threshold samples using IR absorption measurements. As shown in Ref. 70, the lattice constants of $\mathrm{LiNbO}_{3}: \mathrm{Mg}$ crystals increase with growing $\mathrm{Mg}$ concentration, resulting in an increase in the $\mathrm{O}-\mathrm{O}$ distances. This in turn leads to increased $\mathrm{OH}^{-}$vibration frequencies as the adjacent $\mathrm{O}^{2-}$ ion moves away. ${ }^{75}$ Thus, the correlated increase in $\mathrm{OH}^{-}$frequency and $\mathrm{Mg}$ concentration above the threshold can be interpreted via the increasing lattice constant.

In addition to data on band position and shape, both characterizing the immediate neighbourhood of the proton, basic information concerning its migration in the lattice can also be derived from IR spectroscopy. To investigate the stability of $\mathrm{OH}^{-}$defects, the IR spectra of over-threshold LN:Mg crystals with different $\mathrm{Li} / \mathrm{Nb}$ ratios and $\mathrm{Mg}$ contents were measured in the $20-500{ }^{\circ} \mathrm{C}$ temperature range. ${ }^{76}$ Upon heating, the $3465 \mathrm{~cm}^{-1}$ band, well-known from crystals slightly below the threshold, appeared and kept growing at the expense of the over-threshold band. The process, shown in Fig. 12(a) for a cLN:Mg crystal, was reversible for all samples. For crystals with fixed $\mathrm{Li} / \mathrm{Nb}$ ratio, the temperature of the appearance of the $3465 \mathrm{~cm}^{-1}$ band shifted with growing excess $\mathrm{Mg}$ concentration above the threshold towards higher temperatures, as indicated for sLN:Mg crystals in Fig. 12(b).

The Arrhenius plots of the ratios of below- and abovethreshold band areas (see Fig. 13) gave the same energy parameter $\Delta \mathrm{E}=0.25 \pm 0.02 \mathrm{eV}$ for all samples, independent of the $\mathrm{Li} / \mathrm{Nb}$ ratios and $\mathrm{c}_{\mathrm{Mg}}$ values. Assuming that the moving species are protons migrating from oxygen to oxygen, this activation energy can be interpreted as the difference of the bonding energies of protons in below- and abovethreshold environments. This is supported by the identical
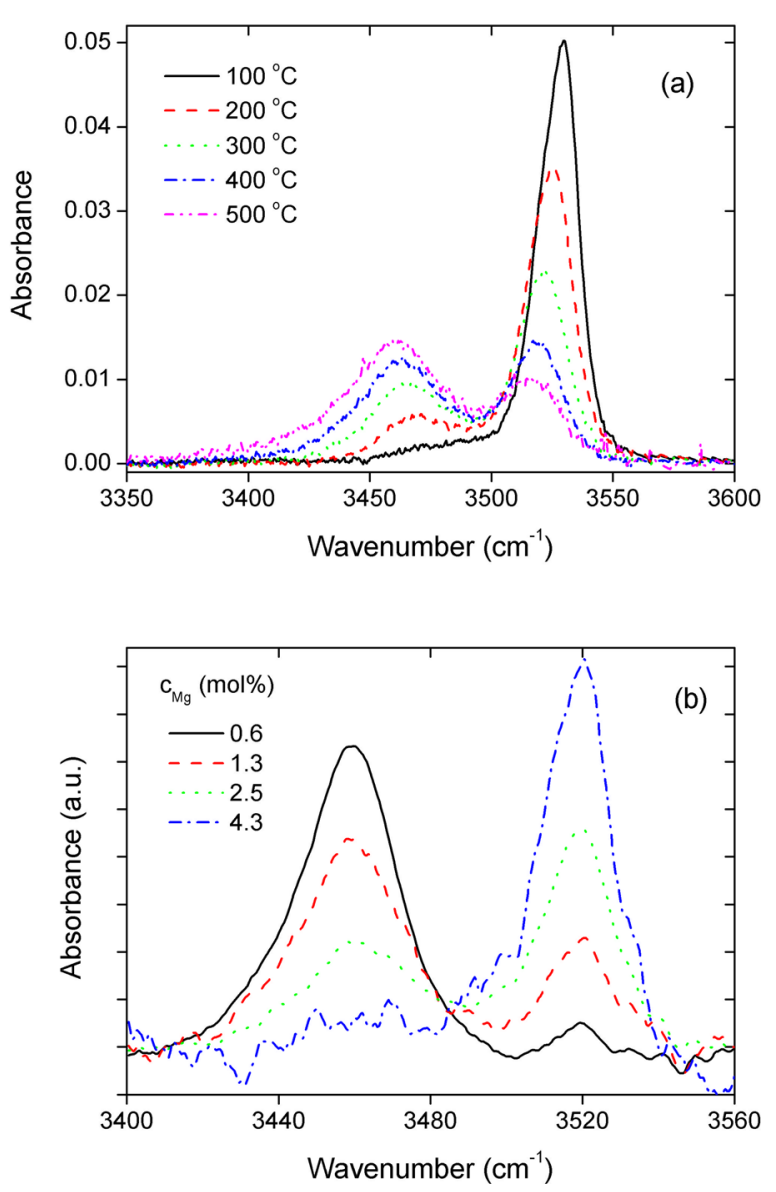

FIG. 12. IR absorption spectra measured at $100-500^{\circ} \mathrm{C}$ in a cLN crystal containing $6.1 \mathrm{~mol} . \% \mathrm{Mg}$ (a) and at $400^{\circ} \mathrm{C}$ in sLN crystals containing 0.6, $1.3,2.5$, and $4.3 \mathrm{~mol} . \% \mathrm{Mg}$ (b). Reproduced with permission from $\mathrm{K}$. Lengyel et al., Appl. Phys. Lett. 96, 191907 (2010). Copyright 2010 American Institute of Physics.

result of Arizmendi et al. ${ }^{77}$ obtained for thermal treatments and holographic fixing in $\mathrm{Mg}$ and $\mathrm{Mg}+\mathrm{Fe}$ doped cLN.

UV absorption edge measurements. The position of the UV absorption edge of undoped $\mathrm{LiNbO}_{3}$ crystals, as



FIG. 13. Determination of the bonding energy difference of $\mathrm{OH}^{-}$ions in belowand above-threshold environments in $\mathrm{LN}: \mathrm{Mg}$ samples with different $\mathrm{Li} / \mathrm{Nb}$ ratios and $\mathrm{Mg}$ contents. Reproduced with permission from K. Lengyel et al., Appl. Phys. Lett. 96, 191907 (2010). Copyright 2010 American Institute of Physics. 
discussed in Section III A, is determined by intrinsic defects, antisite $\mathrm{Nb}_{\mathrm{Li}}$ ions in the first place. As found earlier for congruent crystals, upon $\mathrm{Mg}$ doping with increasing concentration up to the threshold, the UV-edge gradually shifts to shorter wavelength, while this tendency is reversed for further increase above the threshold. ${ }^{68}$ The behaviour of below-threshold samples was again attributed, though qualitatively, to the decreasing $\mathrm{Nb}_{\mathrm{Li}}$ concentration.

More recently, for understanding the role of the $\mathrm{Mg}$ dopant in the whole composition region, detailed UV absorption studies have been performed. The same series of crystals with various $\mathrm{Mg}$ concentrations and $\mathrm{Li} / \mathrm{Nb}$ ratios as used previously for IR studies has systematically been investigated in the near UV region. ${ }^{73}$ The UV-edge positions are plotted in Fig. 14(a) as a function of $\mathrm{MgO}$ concentration using the symbol types introduced in Fig. 10. For over-threshold samples, a linear dependence of the UV-edge position on the $\mathrm{Mg}$ concentration was found independent of the $\mathrm{x}$ value of the $\mathrm{LiNbO}_{3}: \mathrm{Mg}$ samples. A linear calibration function

$$
\lambda\left(\text { at } \alpha=20 \mathrm{~cm}^{-1}\right)=\mathrm{a} \cdot \mathrm{c}_{\mathrm{Mg}}+\mathrm{b}
$$
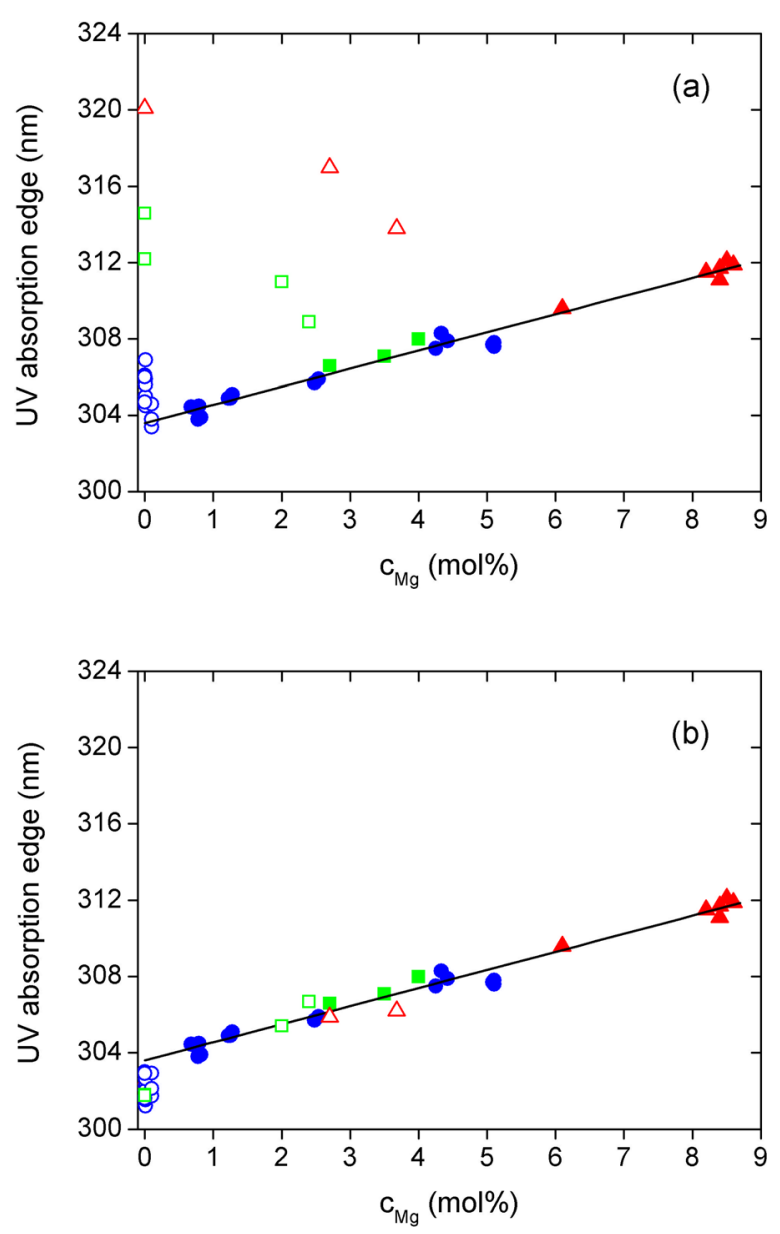

FIG. 14. UV-edge of the LN:Mg samples as a function of $\mathrm{Mg}$ concentration (a), the same after subtracting the contribution of $\mathrm{Nb}_{\mathrm{Li}}$ ions (b). Open/full symbols represent samples below/above the threshold, triangles, squares, and circles indicating congruent $(\mathrm{x} \approx 1.4)$, intermediate $(\mathrm{x} \approx 0.75)$, and stoichiometric $(\mathrm{x}<0.2)$ composition, respectively. Reproduced with permission from K. Lengyel et al., Phys. Status Solidi C 2, 171-174 (2005). Copyright 2005 John Wiley and Sons. was fitted to these data points with parameters $\mathrm{a}=0.95 \pm 0.03 \mathrm{~nm} / \mathrm{mol} . \%$ and $\mathrm{b}=303.6 \pm 0.1 \mathrm{~nm}$, the value of $b$ approximating the UV-edge position of an ideally stoichiometric $\mathrm{LiNbO}_{3}: \mathrm{Mg}$ crystal just above the threshold. Since above the threshold, no $\mathrm{Nb}_{\mathrm{Li}}$ antisites are present, the shift of the UV-edge to longer wavelengths had to be attributed to an increasing number of $\mathrm{Mg}$-associated defects.

The UV-edge position of below-threshold samples within all three composition groups (congruent, intermediate and stoichiometric) was found to shift to shorter wavelengths with increasing $\mathrm{Mg}$ concentration (see open symbols in Fig. $14(\mathrm{a})$ ) in agreement with previous experimental results. ${ }^{68,78,79}$ The conclusion was that the edge position of below-threshold $\mathrm{LiNbO}_{3}: \mathrm{Mg}$ crystals is determined by both $\mathrm{Nb}_{\mathrm{Li}}$ and $\mathrm{Mg}-$ associated defects. The contribution of $\mathrm{Nb}_{\mathrm{Li}}$ to the UV-edge shift of undoped crystals can be derived using charge compensation models and Eq. (3.1).

Hence, assuming simple additivity of the contributions, the effect of $\mathrm{Mg}$ defects could be separately estimated below the threshold. For this calculation, the antisite niobium concentration $\left(c_{N b_{L i}}\right)$ was determined as a function of $\mathrm{x}$ and $\mathrm{c}_{\mathrm{Mg}}$ using the model of Liu et al. ${ }^{42}$ The UV-edge shift due to this $c_{N b_{L i}}$ was calculated using Eq. (3.1) and subtracted from the experimental UV-edge position. The results plotted in Fig. 14(b) fit excellently to the over-threshold data re-plotted in the figure. This coincidence suggests that $\mathrm{Mg}$ ions have a uniform effect on the UV-edge in the whole concentration region, ${ }^{73}$ apparently independent of their incorporation site. This experimental result also indirectly supports Liu's model for the description of $\mathrm{Mg}$ incorporation into the $\mathrm{LiNbO}_{3}$ crystal lattice below and above the threshold.

Raman spectroscopic measurements. As described in the review of Fontana and Bourson (see this issue of APR), ${ }^{80}$ the Raman spectrum of $\mathrm{LiNbO}_{3}$ crystals sensitively depends on the composition changes and the amounts of doping materials, so it can also be used to investigate the incorporation of $\mathrm{Mg}$ into the crystal lattice. Although the Raman spectra of undoped as-grown $\mathrm{LiNbO}_{3}$ crystals were investigated soon after the first successful Czochralski growth, ${ }^{81}$ the exact assignment of all bands to vibrational modes was established only three decades later. ${ }^{82}$ In previous Raman experiments, the $\mathrm{Mg}$ incorporation was investigated only in congruent crystals. ${ }^{67,83}$ However, our series of undoped and Mg-doped $\mathrm{LiNbO}_{3}$ crystals with different $\mathrm{Li} / \mathrm{Nb}$ ratios successfully used in other experiments for clarifying the incorporation mechanism of $\mathrm{Mg}$ ions led us to extend the investigations also to Raman spectroscopy. ${ }^{74,84}$

The $\mathrm{E}\left(\mathrm{TO}_{3}\right)-\mathrm{E}\left(\mathrm{TO}_{9}\right)$ and $\mathrm{A}_{1}\left(\mathrm{TO}_{1}\right)-\mathrm{A}_{1}\left(\mathrm{TO}_{4}\right)$ phonon modes were investigated in $\mathrm{y}(\mathrm{zx}) \mathrm{y}$ and $\mathrm{y}(\mathrm{zz}) \mathrm{y}$ geometries, respectively. The normalized $\mathrm{E}(\mathrm{TO})$ spectra of undoped and heavily Mg-doped (7.8 mol. \%) cLN samples and the A(TO) modes of a similar pair ( 0 and $4.9 \mathrm{~mol} . \% \mathrm{Mg}$ ) of sLN crystals can be seen in Figs. 15(a) and 15(b), respectively.

For a detailed analysis of the spectra, a careful fitting process to derive the band parameters was performed. The $\mathrm{E}(\mathrm{TO})$ band positions, except for the $\mathrm{E}\left(\mathrm{TO}_{7}\right)$ mode, ${ }^{74,84}$ are practically independent of the $\mathrm{Mg}$ doping and $\mathrm{Li} / \mathrm{Nb}$ ratio as well (the frequency data are scattered in a range of about 

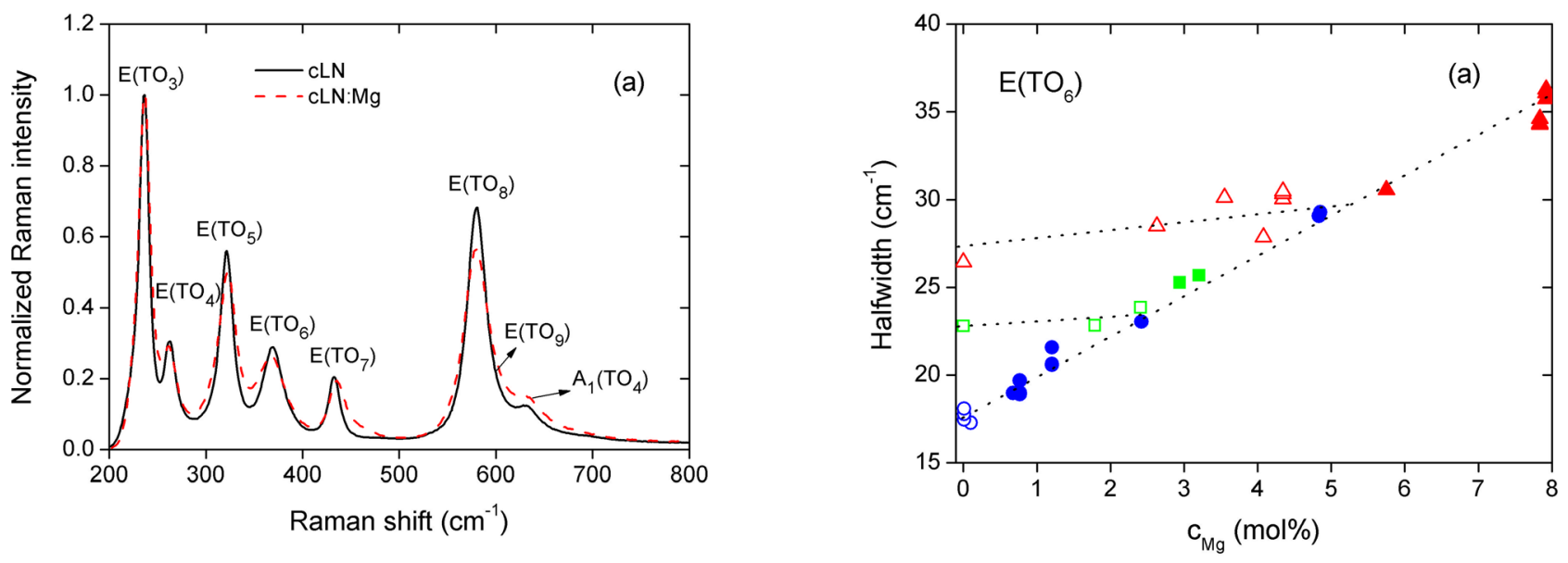

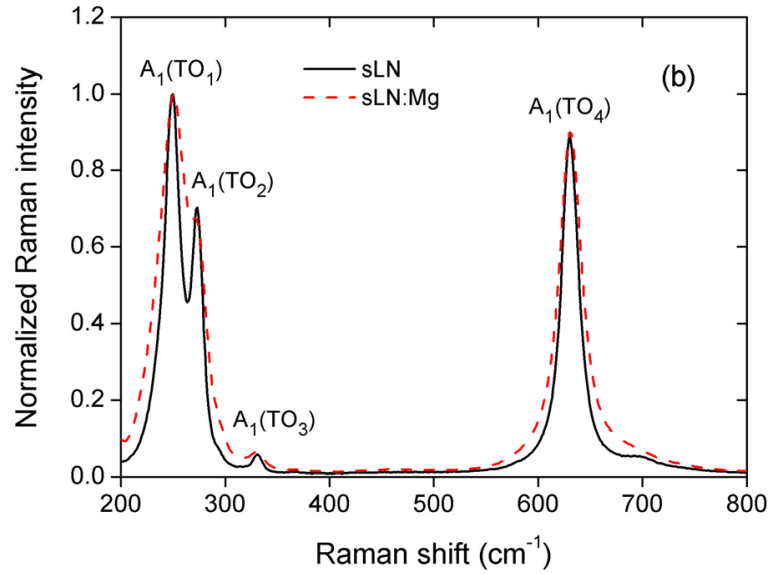

FIG. 15. Raman spectra of undoped and heavily Mg-doped (7.8 mol. \%) cLN crystals in y(zx)y (a) and undoped and strongly Mg-doped (4.9 mol. \%) sLN crystals in y(zz)y (b) backscattering geometries. Reproduced with permission from K. Lengyel et al., Appl. Phys. B: Lasers Opt. 87, 317-322 (2007). Copyright 2007 Springer Science+Business Media.

$1.5 \mathrm{~cm}^{-1}$ ). However, the halfwidth of the $\mathrm{E}(\mathrm{TO})$ bands of undoped samples changes with composition, while for a given $\mathrm{X}$-value, the halfwidths of the below-threshold samples only slightly increase with $\mathrm{Mg}$ content (see, e.g., $\mathrm{E}\left(\mathrm{TO}_{6}\right)$ in Fig. 16(a)). In contrary, for over-threshold samples, the damping varies linearly with the $\mathrm{Mg}$ concentration independent of the $\mathrm{Li} / \mathrm{Nb}$ ratio.

The $\mathrm{A}_{1}(\mathrm{TO})$ modes can be divided into two groups. In the first group, the positions of the $\mathrm{A}_{1}\left(\mathrm{TO}_{1}\right)$ and $\mathrm{A}_{1}\left(\mathrm{TO}_{4}\right)$ bands essentially do not change, while in the second group, the frequencies of the $\mathrm{A}_{1}\left(\mathrm{TO}_{2}\right)$ and $\mathrm{A}_{1}\left(\mathrm{TO}_{3}\right)$ bands slightly decrease with increasing $\mathrm{Mg}$ content for all $\mathrm{Li} / \mathrm{Nb}$ ratios. ${ }^{83}$ The halfwidths of all $\mathrm{A}_{1}(\mathrm{TO})$ modes (see, e.g., $\mathrm{A}_{1}\left(\mathrm{TO}_{4}\right)$ in Fig. 16(b)) show the same composition-dependent threshold effect as the E(TO) bands. It is important to notice that the threshold concentrations inferred from Raman halfwidths coincide with those derived from IR and UV spectroscopy. The $\mathrm{Mg}$ concentration of the above-threshold $\mathrm{LiNbO}_{3}$ crystals can be determined by measuring the halfwidth of, e.g., the $\mathrm{E}\left(\mathrm{TO}_{6}\right)$ or $\mathrm{A}_{1}\left(\mathrm{TO}_{4}\right)$ Raman bands (see Figs. 16(a) and 16(b))

$$
\begin{gathered}
c_{\mathrm{Mg}}=0.453 \Gamma_{\mathrm{E}\left(\mathrm{TO}_{6}\right)}-8.1, \\
\mathrm{c}_{\mathrm{Mg}}=0.644 \Gamma_{\mathrm{A}_{1}\left(\mathrm{TO}_{4}\right)}-12.3,
\end{gathered}
$$

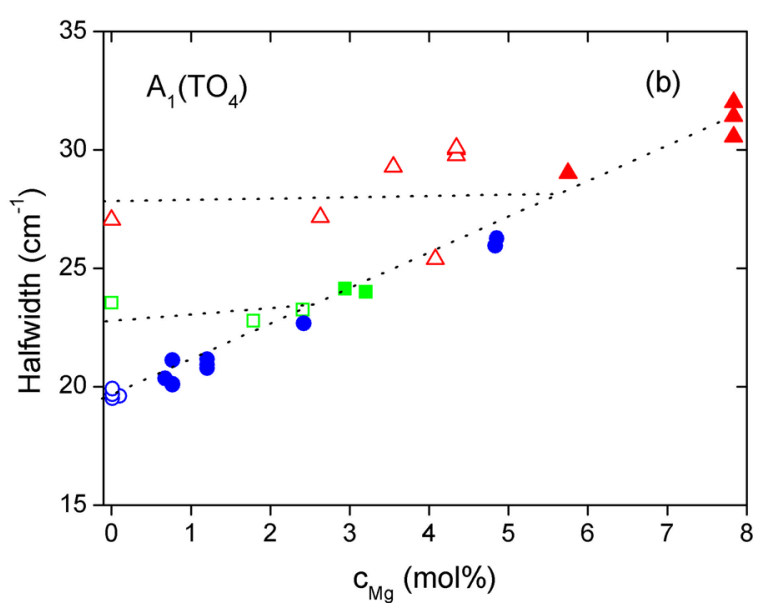

FIG. 16. The $\mathrm{Mg}$ dependence of the half-width of $\mathrm{E}\left(\mathrm{TO}_{6}\right)$ (a) and $\mathrm{A}_{1}\left(\mathrm{TO}_{4}\right)$ (b) modes. The triangle, square, and circle symbols represent the congruent $(\mathrm{x} \approx 1.4)$, intermediate $(\mathrm{x} \approx 0.75)$, and stoichiometric $(\mathrm{x}<0.2)$ compositions, respectively. Empty/full symbols indicate samples with $\mathrm{Mg}$ content below/ above the photorefractive threshold. Reproduced with permission from K. Lengyel et al., Appl. Phys. B: Lasers Opt. 87, 317-322 (2007). Copyright 2007 Springer Science+Business Media.

where the units to be used are mol. $\%$ and $\mathrm{cm}^{-1}$, and the error of the calculated $\mathrm{Mg}$ content is estimated to be about \pm 0.2 mol. $\%$.

The $\mathrm{A}_{1}(\mathrm{LO})$ bands together with the $\mathrm{E}(\mathrm{TO})$ modes can be measured in $\mathrm{z}(\mathrm{xx}) \mathrm{z}$ backscattering geometry (see Fig. 17(a)). The $\mathrm{A}_{1}\left(\mathrm{LO}_{4}\right)$ phonon mode at $873 \mathrm{~cm}^{-1}$, a band well separated from all other bands, could be decomposed into a main band with a satellite. The halfwidth of the main $\mathrm{A}_{1}\left(\mathrm{LO}_{4}\right)$ band as a function of $\mathrm{c}_{\mathrm{Mg}}$ can be seen in Fig. 17(b). The damping of the above- and below-threshold samples with a given $\mathrm{X}$-value increases linearly with growing $\mathrm{Mg}$ concentration. Almost parallel lines were obtained for the stoichiometric, intermediate, and congruent series. For the above-threshold samples, this behaviour differs from that obtained for the E(TO) and A(TO) Raman bands. This property can be used to determine both the composition and the $\mathrm{Mg}$ content of $\mathrm{LiNbO}_{3}$ crystals above the photorefractive threshold by measuring, e.g., the halfwidth of the $\mathrm{A}_{1}\left(\mathrm{TO}_{4}\right)$ band to calculate $\mathrm{c}_{\mathrm{Mg}}$ and that of the $\mathrm{A}_{1}\left(\mathrm{LO}_{4}\right)$ band to estimate the x-value of the sample using Figs. 16(b) and 17(b), respectively. The different behaviour of the transverse and 

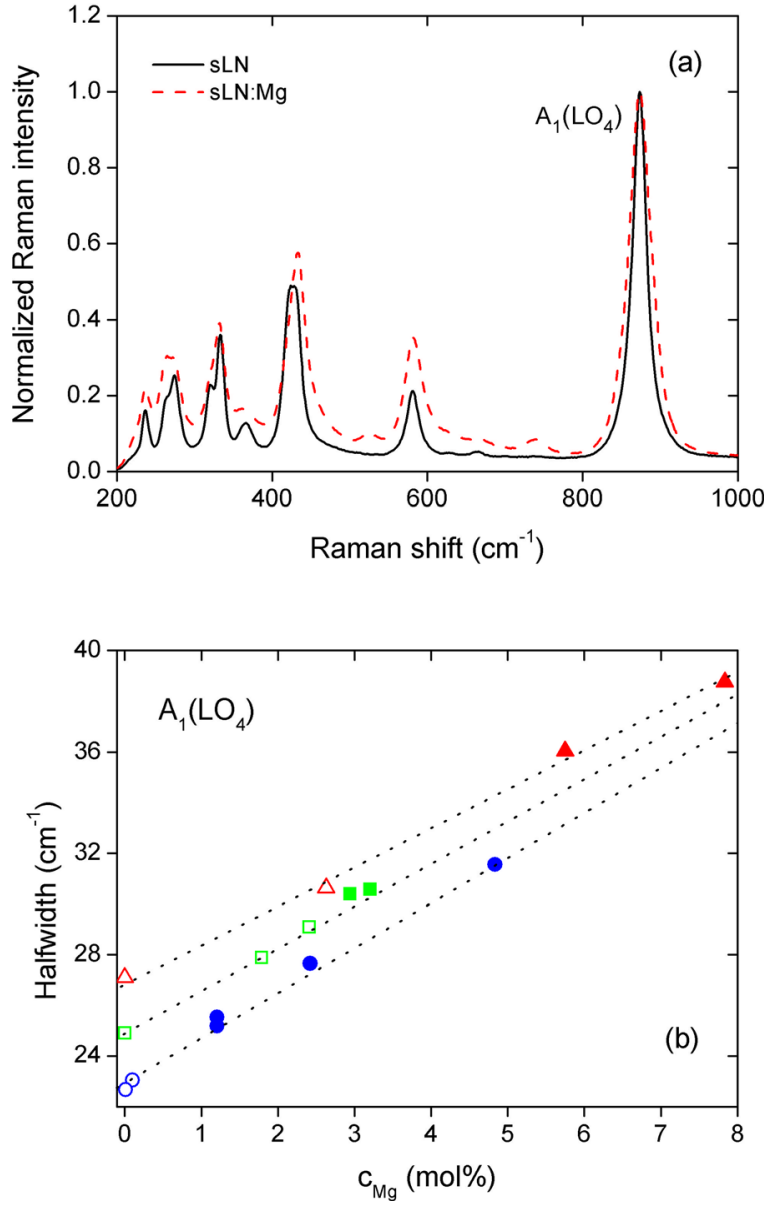

FIG. 17. Raman spectra of undoped and $4.9 \mathrm{~mol}$. \% Mg-doped stoichiometric $(\mathrm{x}<0.2) \mathrm{LN}$ : Mg crystals in $\mathrm{z}(\mathrm{xx}) \mathrm{z}$ backscattering geometry (a) and the $\mathrm{Mg}$ concentration dependence of the halfwidth of the $\mathrm{A}_{1}\left(\mathrm{LO}_{4}\right)$ band (b). For symbol types, see Fig. 16. Reproduced with permission from K. Lengyel et al., Appl. Phys. B: Lasers Opt. 87, 317 (2007). Copyright 2007 Springer Science+Business Media.

longitudinal modes may be related to the large anisotropy of the crystal.

\section{Z-scan measurements}

$Z$-scan is the most popular and powerful technique for the study of nonlinear absorption and refraction because of its simplicity, accuracy, and sensitivity. ${ }^{85}$ The method was elaborated for the determination of the parameters usually required for nonlinear optical applications, the nonlinear index of refraction $n_{2}$, and the nonlinear absorption coefficient $\beta$. In the measurement, the nonlinear sample is scanned along the propagation direction $z$ of a focused Gaussian beam in the vicinity of its focal plane, and the transmittance is monitored in the far field as shown in Fig. 18.

If one is interested in $n_{2}$, the aperture size has to be chosen significantly smaller than the far field beam radius (closed-aperture Z-scan), thus the transmitted power is proportional to the on-axis intensity. In order to determine $\beta$, the aperture has to be opened to let the whole beam enter the detector (open-aperture $Z$-scan). In each case, the transmittance curves should be normalized by the transmittance value measured for the sample position far from the focus. Typical

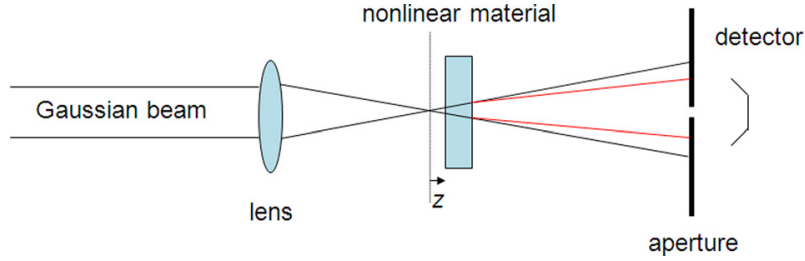

FIG. 18. The Z-scan measurement setup.

Z-scan curves are shown in Fig. 19. The nonlinear parameters can be obtained by fitting the $Z$-scan curves by appropriate theoretical formulae. ${ }^{85,86}$ Evaluation of the measured curves with these theories is valid if the variation of the refractive index and the absorbance can be given as $\Delta n=n_{2} I$ and $d I=-\beta I d z$, respectively.

If $\mathrm{Mg}$ doped sLN samples are exposed to cw light with intensity levels in the $\mathrm{kW} / \mathrm{cm}^{2}-\mathrm{MW} / \mathrm{cm}^{2}$ region, basically two effects are responsible for the laser induced change of the refractive index: $\mathrm{PR}$ and the thermo-optical effect. ${ }^{87}$ (The Kerr-effect due to cubic nonlinearity is negligible in this intensity range.) The characteristic features of PR are (i) negative nonlinearity (prefocal peak, postfocal valley in the $Z$-scan curve) which cannot be given in the simple form of $\Delta n=n_{2} I$, (ii) elliptically shaped beam distortion, (iii) characteristic build-up time on the second scale that depends on the stoichiometry and the concentration of the incorporated Mg. ${ }^{87-89}$ Due to these facts only an estimated value of $n_{2}$ can be given to characterize PR. In contrary, the thermo-optical effect shows (i) positive nonlinear refraction ( $Z$-scan structure with prefocal valley and postfocal peak) which can be given in the form of $\Delta n=n_{2} I$, (ii) beam distortion with cylindrical symmetry, (iii) practically composition independent build-up time in the sub-ms scale. These characteristics are verified also theoretically. ${ }^{87,89,90}$

In order to clarify the contribution of the PR and the thermo-optical effect to the light induced change of refraction in sLN:Mg, Z-scan measurements were performed on various samples differing in $\mathrm{Mg}$ content. ${ }^{88,89}$ Measurements complementary to the $Z$-scan were also performed, such as



FIG. 19. Z-scan traces of sLN: 0.7 mol. $\% \mathrm{Mg}$ measured at different incident light powers $(\mathrm{P}=0.6,1,1.85 \mathrm{~W})$. The continuous lines are theoretical fitting curves. The inset shows the linear power dependence of $n_{2}$. Reproduced with permission from L. Pálfalvi et al., J. Appl. Phys. 95, 902-908 (2004). Copyright 2004 American Institute of Physics. 
the detailed diagnostics of the beam transmitted through the sample during scanning and the measurement of the build-up time of the nonlinear effect at fixed sample positions. For the measurements, the focused beam of an all-line visible $\mathrm{cw}$ Ar-ion laser was used with $\mathrm{MW} / \mathrm{cm}^{2}$ maximal intensity level at the focus. The thickness of the crystals was $2 \mathrm{~mm}$.

From the results of these measurements, it was recognized that the effect of PR can be reduced by increasing the $\mathrm{Mg}$ content. For sLN samples with $\mathrm{Mg}$ concentrations exceeding the threshold value, none of the features (i, ii, iii) characteristic for PR were observed. The positive sign of $n_{2}$ determined from the Z-scan fittings, the isotropic distortions, and the sub-ms value of the build-up time, all unambiguously verified the exclusively thermo-optical origin of the observed nonlinear effect.

In order to clarify the origin of the thermo-optical effect, $Z$-scan measurements at different beam powers were performed on a sLN: $0.7 \mathrm{~mol} \% \mathrm{Mg}$ sample. The results are shown in Fig. 19. The $n_{2}$ values determined from the fitting of the curves show a linear dependence on the beam power $P$. This behaviour verifies the dominant role of the nonlinear absorption in the thermo-optical effect, since in this case, the nonlinear refraction can be expressed as ${ }^{89}$

$$
n_{2}=0.06 P \beta(d n / d T) / \pi \kappa,
$$

where $\kappa$ is the thermal conductivity and $d n / d T$ the derivative of the linear refraction with respect to the temperature. For lack of knowledge of $\kappa$ and $d n / d T$ values for the investigated composition, the corresponding values of undoped congruent LN were used in Eq. (3.9), resulting in values of the order of magnitude $10^{3} \mathrm{~cm} / \mathrm{GW}$ for $\beta$. Z-scans with polarized beams at fixed $(2 \mathrm{~W})$ power were also performed on sLN: $0.7 \mathrm{~mol} . \% \mathrm{Mg}$ samples; ${ }^{89}$ for ordinary polarization of the beam, the $n_{2}$ value was found to be approximately three times larger than for extraordinary polarization (see Fig. 20(a) and Table I).

The ratio of the $\beta$ values obtained from the closed aperture fittings (Fig. 20(a)) corresponding to different polarizations was found to be identical with the ratio of $n_{2}$ values. In order to obtain independent information on the non-linear absorption, open-aperture measurements with both polarizations were also performed. As shown in Fig. 20 and Table I, the maximally absorbed power is about three times larger in the case of ordinary compared to extraordinary polarization. These measurements strongly proved the interdependence of nonlinear absorption and nonlinear refraction, as well as their anisotropy for sLN: Mg.

\section{Absorption, refractive index in the far-IR (THz) range}

The nonlinear optical properties of sLN advantageous also in the $\mathrm{THz}$ frequency range can be utilized in experiments, such as high-energy $\mathrm{THz}$ pulse generation, nonlinear $\mathrm{THz}$ spectroscopy, and $\mathrm{THz}$ nonlinear optics. For designing experiments and for preliminary model calculations, the knowledge of the absorption coefficient and the refractive index of the material in the $\mathrm{THz}$ range are of key importance. $\mathrm{Mg}$ doping has an effect on various spectroscopic features of sLN, such as the UV absorption edge, ${ }^{68,79}$ the IR absorption
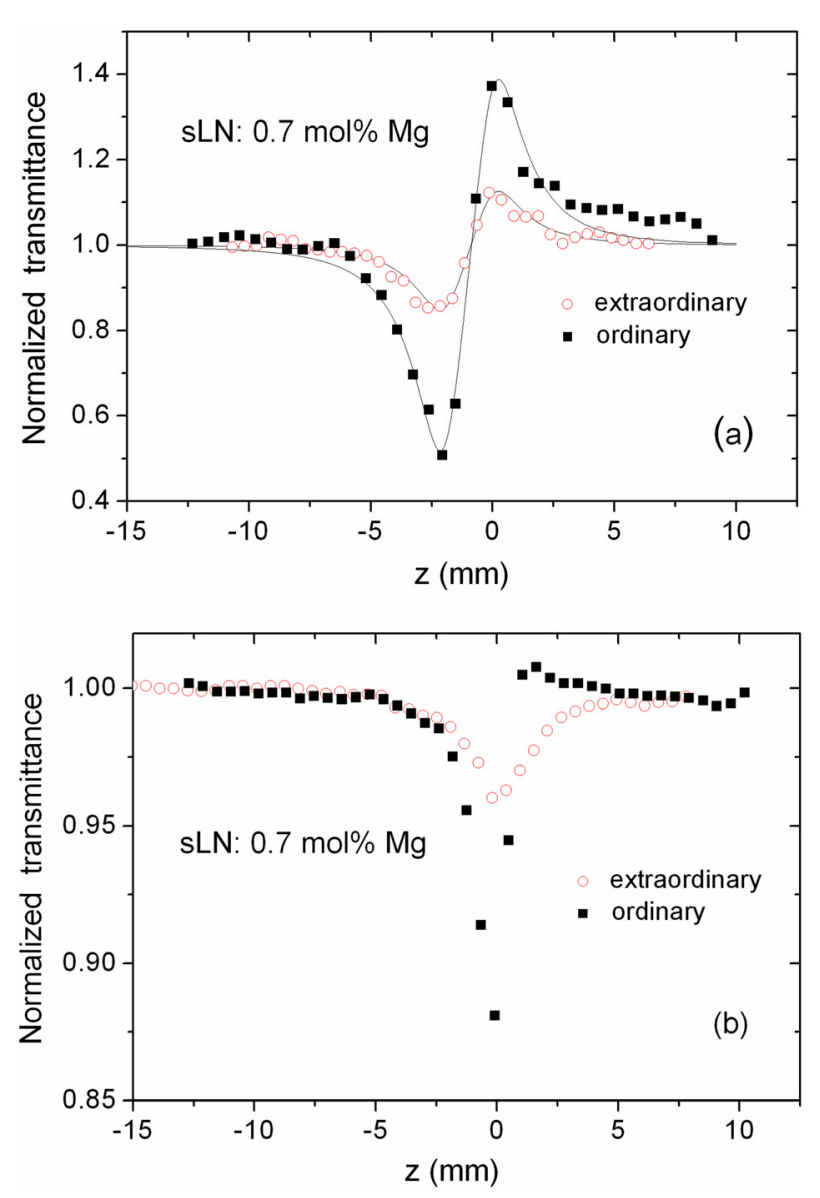

FIG. 20. Closed- (a) and open-aperture (b) Z-scan traces of sLN: 0.7 mol. \% $\mathrm{Mg}$. In both figures, open circles and squares denote extraordinary and ordinary polarization, respectively. The continuous lines are theoretical fitting curves. Reproduced with permission from L. Pálfalvi et al., J. Appl. Phys. 95, 902-908 (2004). Copyright 2004 American Institute of Physics.

band, ${ }^{68,91}$ and the PR effect (the latter is disadvantageous in the case of nonlinear applications). ${ }^{48}$ In order to obtain information about the effect of $\mathrm{Mg}$ doping on $\mathrm{THz}$ absorption and refraction, the following measurements were performed.

The extraordinary index of refraction and absorption coefficient of a series of $\mathrm{Mg}$-doped (0.7, 1.5, $4.2 \mathrm{~mol} \%$ incorporated $\mathrm{Mg}$ content) and undoped sLN crystals were determined in a wide spectral range $(0.9-4.6 \mathrm{THz})$ with farinfrared Fourier transform (FIR FT) spectroscopy. The transmission of the samples was recorded by a Bruker 113 V FIR FT spectrometer. The measurements were performed at temperatures of $300,200,100$, and $10 \mathrm{~K}$. The sample thicknesses were 0.2 and $0.5 \mathrm{~mm} .^{92}$

Based on an analysis of the interferometrically resolved transmitted spectra, the group indices were directly

TABLE I. Nonlinear characteristics for the sLN:0.7 mol. \% Mg sample for ordinary $(\mathrm{O})$ and extraordinary $(\mathrm{E})$ polarization. ${ }^{89}$

\begin{tabular}{lccc}
\hline \hline Polarization & $n_{2}\left[10^{-11} \mathrm{~cm}^{2} / \mathrm{W}\right]$ & $\beta\left[10^{3} \mathrm{~cm} / \mathrm{GW}\right]$ & Maximal absorption \\
\hline $\mathrm{O}$ & 13.4 & 1.7 & $39.7 \%$ \\
$\mathrm{E}$ & 4.3 & 0.55 & $11.9 \%$ \\
Ratio (O/E) & 3.11 & 3.09 & 3.3 \\
\hline \hline
\end{tabular}


determined and used for the calculation of the phase index of refraction. The absorption coefficient as a function of frequency was determined from the smoothed transmission curve, taking into account Fresnel-losses.

For all samples, the extraordinary refractive index shows a monotonous increase with frequency in the $0.9-4.6 \mathrm{THz}$ frequency range with a typical value of $n \approx 5$ and an increase in at about $20 \%$ in this frequency range.

The effect of the unwanted curvature of crystal surfaces $^{92}$ caused difficulties in the evaluation of the measurements. The correction was done in the absorption coefficient values using an additive constant, which was chosen to result in zero absorption at the lowest temperature $(10 \mathrm{~K})$ and frequency $(0.9 \mathrm{THz})$. For other frequencies and temperatures, the same additive constant was used for a given sample.

Figure 21 shows the absorption coefficients of the stoichiometric crystals at $10 \mathrm{~K}$. The absorption coefficient function increases with frequency approaching towards the TO phonon resonance frequency, however, it has a fine structure with local maxima, which can be explained by the defect structure of the crystal. In the $0.9-3.3 \mathrm{THz}$ frequency range, the absorption coefficient is lowest when the $\mathrm{Mg}$ content is closest to the photorefractive threshold value, which is near 0.7 mol. \%. ${ }^{92}$ In fact for this near threshold composition, practically all antisite $\mathrm{Nb}$ ions are replaced by $\mathrm{Mg}$ which results in an optimal defect structure decreasing absorption. Above the photorefractive threshold (1.5 and $4.2 \mathrm{~mol} . \%$ ), absorption monotonously increases with $\mathrm{Mg}$ content, since in this region, $\mathrm{Mg}$ replaces $\mathrm{Nb}$ ions at $\mathrm{Nb}$ sites.

Control measurements were performed in order to clarify the previously mentioned uncertainty in the absorption coefficient values due to the curved crystal surfaces. Undoped and $\mathrm{Mg}$-doped $(0.7,1.5,4.2 \mathrm{~mol}$ \% incorporated $\mathrm{Mg}$ content) sLN samples originating from the same crystals used for FIR FT spectroscopy with precisely polished planparallel surfaces were investigated with a TERA K8 timedomain $\mathrm{THz}$ spectrometer (Menlo Systems) in the 0.25-2.5 $\mathrm{THz}$ frequency range at $300 \mathrm{~K}$ temperature. The sample thicknesses were 0.5 and $0.6 \mathrm{~mm}$.

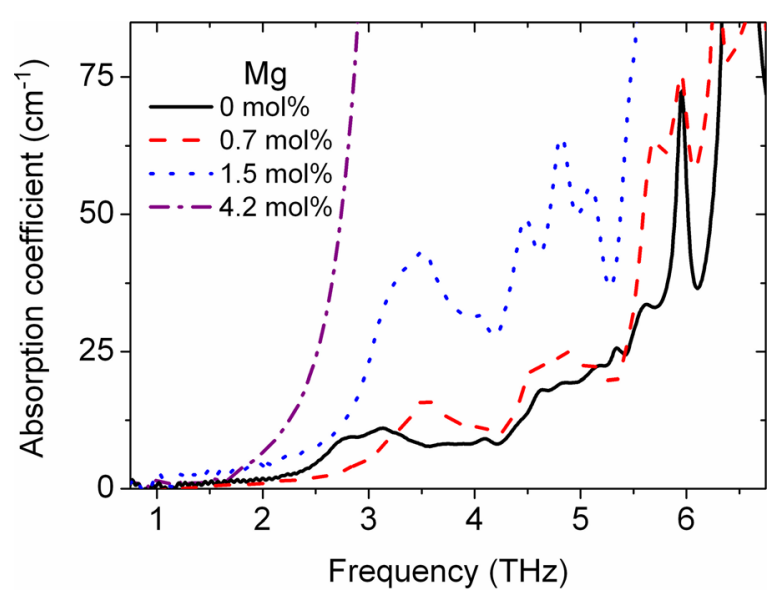

FIG. 21. Frequency dependence of the absorption coefficient of undoped and $\mathrm{Mg}$-doped sLN crystals at $10 \mathrm{~K}$ temperature. Reproduced with permission from L. Pálfalvi et al., J. Appl. Phys. 97, 123505 (2005). Copyright 2005 American Institute of Physics.
In time domain $\mathrm{THz}$ spectroscopy (TDTS) measurements, the electric field of a $\mathrm{THz}$ beam with and without sample is monitored as a function of time. From the temporal shape, the spectral amplitude and spectral phase can be determined by Fourier transformation. From the spectral amplitude, the absorption coefficient, while from the spectral phase, the refractive index was obtained.

Fig. 22 shows the frequency dependence of absorption coefficient of $\mathrm{Mg}$-doped sLN crystal with $\mathrm{Mg}$ dopant level closest to the photorefractive threshold $(0.7 \mathrm{~mol} . \% \mathrm{Mg}$ content) determined from FIR FT spectroscopy (black solid line) and TDTS (red solid line) measurements. The absorption coefficient curves differ from each other in an additive constant. The deficiency of the results shown by the black solid curve is the previously mentioned uncertainty of the absorption coefficient explained by the nonparallel crystal surfaces of the samples used for FIR FT spectroscopy measurements. The deficiency of the results shown by the red solid curve is the reduced confidential interval (about 0.3-2.5 THz). Absorption data which are considered most reliable for a wide frequency range are represented by the black dashed line, which was constructed by shifting the black curve by a constant value to fit the red one at low frequencies.

Figs. 23(a) and 23(b) show the frequency dependence of ordinary and extraordinary refractive indices, respectively, for undoped and Mg-doped sLN crystals measured by TDTS. Both the extraordinary and the ordinary refractive indices increase with frequency in the confidential interval for all samples.

Beside the well known strong birefringence of sLN in the $\mathrm{THz}$ range, it can be observed that for all compositions, the dispersion is larger for the ordinary than for the extraordinary refractive index. Furthermore, it can be seen that for ordinary polarization, there is no significant difference between the refractive index values belonging to different compositions. For extraordinary polarization, the small difference between the curves belonging to three samples (undoped, 0.7 and $1.5 \mathrm{~mol} \% \mathrm{Mg}$ doped) is comparable to the measurement error, but the curve of the sample with



FIG. 22. Frequency dependence of the absorption coefficient of a Mg-doped sLN crystal near the photorefractive threshold $(0.7 \mathrm{~mol} \% \mathrm{Mg}$ concentration) at $300 \mathrm{~K}$. The black solid line is obtained from FIR FT spectroscopy, ${ }^{92}$ the red line from TDTS, the dashed black line indicating values considered more reliable. 

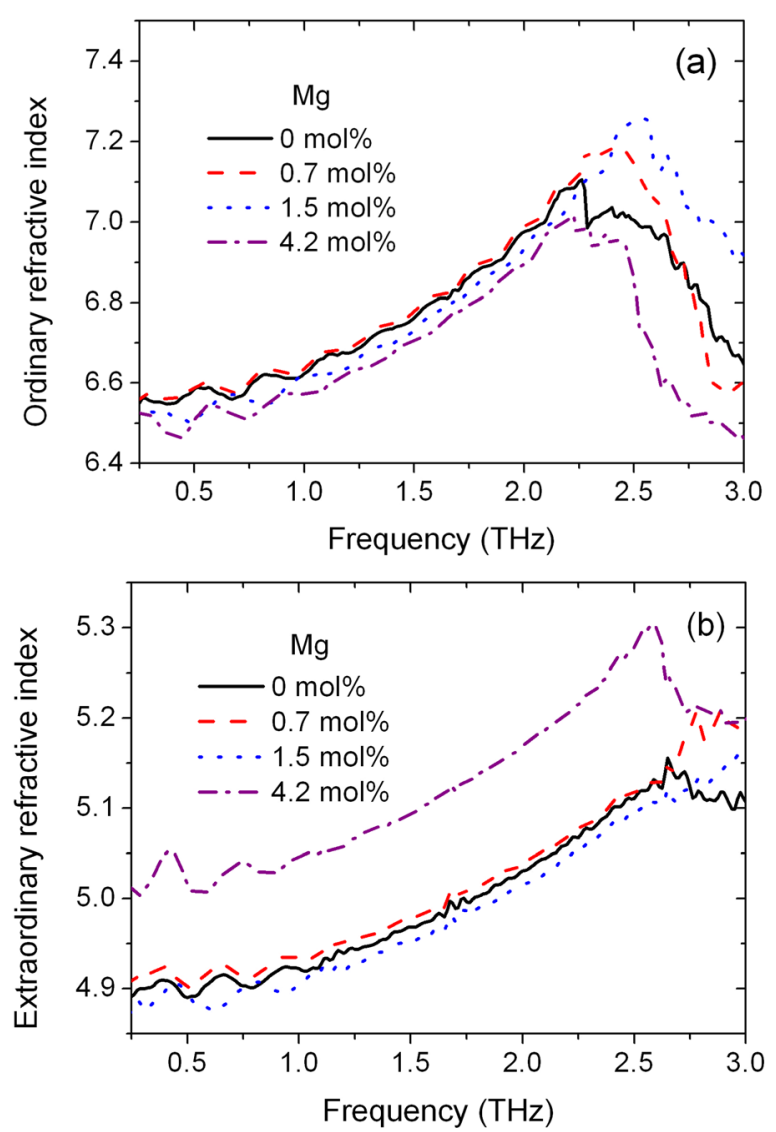

FIG. 23. Frequency dependence of ordinary (a) and extraordinary (b) refractive indices of undoped and $\mathrm{Mg}$-doped $(0.7,1.5$, and $4.2 \mathrm{~mol} . \% \mathrm{Mg}$ content) sLN crystals at $300 \mathrm{~K}$.

$4.2 \mathrm{~mol} \% \mathrm{Mg}$ content is unambiguously separated from them.

Figs. 24(a) and 24(b) show the frequency dependence of absorption coefficients at $300 \mathrm{~K}$ for ordinary and extraordinary polarization, respectively, in the case of undoped and Mg-doped sLN crystals. Apart from noises, absorption coefficients increase with frequency inside the confidential interval for both polarizations. It is obvious that the absorption coefficient values are significantly higher for ordinary than for extraordinary polarization and are practically independent of the $\mathrm{Mg}$ content especially in the ordinary case. For extraordinary polarization, as seen in Fig. 24(b) for samples with $\mathrm{Mg}$ content above the photorefractive threshold, the absorption coefficient monotonously increases with $\mathrm{Mg}$ content similarly to the $10 \mathrm{~K}$ case (see Fig. 21).

From the above results concerning $\mathrm{THz}$ absorption of Mg-doped sLN samples together with the well-known photorefraction behaviour, one can conclude that most suitable for $\mathrm{THz}$ applications is the near-threshold $(0.7 \mathrm{~mol} \% \mathrm{Mg})$ composition.

\section{Other divalent, trivalent, and tetravalent ODR dopants}

Beside $\mathrm{Mg}$, several other divalent, trivalent, or tetravalent cations (e.g., $\mathrm{Zn}^{2+}, \mathrm{In}^{3+}, \mathrm{Sc}^{3+}, \mathrm{Hf}^{4+}, \mathrm{Zr}^{4+}, \mathrm{Sn}^{4+}$ ) above a critical concentration are able to suppress the optical damage related to photorefraction in LN crystals. ${ }^{93-98}$ The


FIG. 24. Frequency dependence of the absorption coefficients for ordinary (a) and extraordinary (b) polarization in undoped and Mg-doped (0.7, 1.5, and 4.2 mol. $\% \mathrm{Mg}$ contents) sLN crystals at $300 \mathrm{~K}$.

properties of LN doped with optical damage resistant ions were first summarized in a review paper ${ }^{10}$ and later in a book by Volk et al. ${ }^{99}$ Recently, Kong et al. ${ }^{100}$ reviewed advances in the photorefraction of doped LN, focusing on tetra-, penta-, and hexavalent ions, including doubly- and even triply-doped crystals. They concluded that LN triply doped by $\mathrm{Zr}, \mathrm{Fe}$, and $\mathrm{Mn}$ shows excellent non-volatile holographic storage properties, and $\mathrm{V}$ and Mo single-doped LN have fast response and multi-wavelength storage characteristics. In this section, only recent results on ODR-ion single-doped sLN crystals are summarized.

The critical concentration, above which the photorefraction is strongly suppressed-usually called "threshold"depends on the valence of the dopant and the stoichiometry ( $\mathrm{Li}_{2} \mathrm{O}$ content or $\mathrm{Li} / \mathrm{Nb}$ ratio) of the crystal. As it was shown above for $\mathrm{Mg}$, the higher the $\mathrm{Li}_{2} \mathrm{O}$ content in the crystal, the lower the threshold concentration in crystals doped with other ODR ions. ${ }^{44,45,47}$ In addition, the increase in the valence of the dopant decreases the threshold. ${ }^{94-98}$ In general, the incorporation of ODR ions reduces the amount of antisite $\mathrm{Nb}_{\mathrm{Li}}$ in the lattice. In nearly stoichiometric $\mathrm{LN}$ crystals where the $\mathrm{Nb}_{\mathrm{Li}}$ concentration is almost zero, the threshold value of the dopant concentration can be lower than $0.2 \mathrm{~mol} \%$ as it was observed for Mg-doped sLN. ${ }^{43}$ Similarly, a remarkable decrease in the threshold 
concentration was observed for $\mathrm{Sc}^{3+}$ (Ref. 47) and $\mathrm{In}^{3+}$ doped $^{45}$ sLN crystals as compared to the congruent counterparts.

The basic advantage of choosing higher valence ODR dopants comes from their lower damage threshold concentrations; lower built-in dopant content facilitates the growth of more homogeneous crystals resulting in high quality samples for device applications. Therefore, sLN crystals with various concentrations of tetravalent $\mathrm{Zr}$ in the $0-0.45 \mathrm{~mol}$. \% range have been grown by the HTTSSG technique. ${ }^{46}$ All methods (Z-scan, UV, IR, and Raman) used to characterize the sLN:Zr crystals indicated that the photorefractive damage threshold is at about $0.1 \mathrm{~mol} . \% \mathrm{Zr}$ in the crystal. Figure 25 shows the appearance of the $\mathrm{OH}^{-}$band at $3475 \mathrm{~cm}^{-1}$ already at $0.085 \mathrm{~mol}$ \% $\mathrm{Zr}$ content, characteristic for the $\mathrm{Zr}_{\mathrm{Nb}}^{4+}-\mathrm{OH}^{-}$ complex above the threshold. The spectra were normalized to the $\mathrm{OH}^{-}$band characteristic for the pure sLN crystal at $3466 \mathrm{~cm}^{-1}$. The intensity ratio of the two bands increased with increasing $\mathrm{Zr}$ concentration.

Although the Z-scan measurement showed that the crystal containing $\approx 0.09 \mathrm{~mol} . \% \mathrm{Zr}$ is below the photorefractive threshold, the results obtained from other methods indicated that the threshold must be close to this concentration. It has been concluded that the transition between the below- and above-threshold behaviour may not be sharply defined. A similar observation was presented by Nava et al. ${ }^{101}$ for congruent $\mathrm{Zr}$-doped $\mathrm{LiNbO}_{3}$ crystals, showing that the photorefractivity is reduced at somewhat higher $\mathrm{Zr}$ concentration than the threshold determined from refractive index measurements.

The appearance of the new $\mathrm{OH}^{-}$vibrational band proved to be as one of the most sensitive methods to detect ODR ions on $\mathrm{Nb}$ site, thereby indicating the above-threshold state of the crystal. In congruent LN crystals, however, the new $\mathrm{OH}^{-}$band cannot be clearly detected for tetravalent dopants, since they overlap with the broad $\mathrm{OH}^{-}$vibrational band already present in the undoped case (see Fig. 7). In a recent systematic study on sLN crystals doped with all known ODR ions, however, the $\mathrm{OH}^{-}$bands related to the

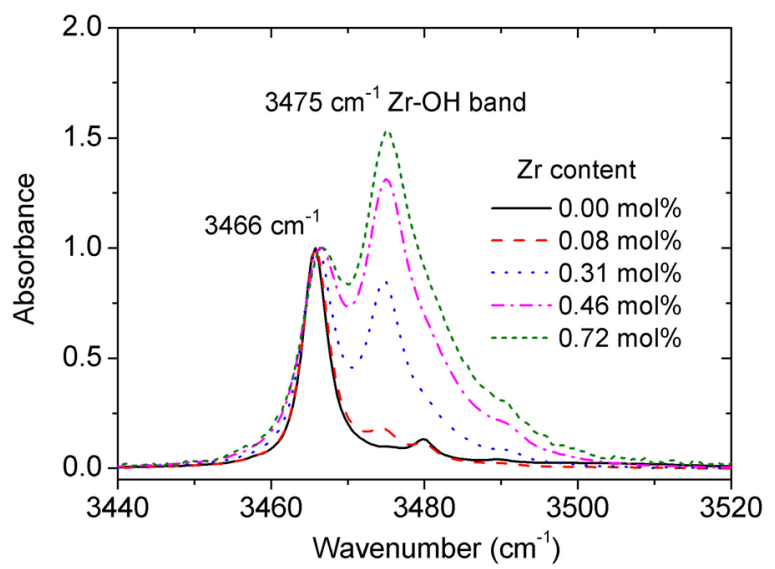

FIG. 25. Stretching vibrational bands of hydroxyl ions in Zr-doped sLN crystals. The spectra were normalized to the $\mathrm{OH}^{-}$band characteristic for the pure sLN crystal at $3466 \mathrm{~cm}^{-1}$. Reproduced with permission from L. Kovács et al., Opt. Lett. 38, 2861-2864 (2013). Copyright 2013 Optical Society of America.
$M_{N b}^{n+}-\mathrm{OH}^{-}$type complexes, where $\mathrm{M}^{\mathrm{n}+}$ is the ODR ion with valences $\mathrm{n}=2,3$, or 4 , have been clearly identified. ${ }^{102}$ Figure 26(a) shows the absorption spectra of hydroxyl ions in ODR-ion doped sLN crystals. The new absorption band appeared at higher frequency for all dopants than the $3466 \mathrm{~cm}^{-1}$ band seen in undoped sLN. In a few cases like $\mathrm{Zn}^{2+}, \mathrm{Hf}^{4+}$, and $\mathrm{Zr}^{4+}$ doped crystals, the $3466 \mathrm{~cm}^{-1}$ band is still present; presumably, the concentration of the incorporated dopants is close to the threshold value. The higher the dopant concentration in the crystal, the higher the intensity ratio between the new and the $3466 \mathrm{~cm}^{-1}$ band, as it was observed, e.g., for sLN:Zr. ${ }^{46}$

It is clearly seen that the spectra belonging to dopants of different valences form different groups in sLN crystals. The vibrational frequency for hydroxyl ions in the $M_{N b}^{2+}-\mathrm{OH}^{-}$ complex (i.e., for $\mathrm{Mg}^{2+}$ and $\mathrm{Zn}^{2+}$ dopants) is at about $3530-3535 \mathrm{~cm}^{-1}$, in agreement with that in the congruent crystal. ${ }^{65,68}$ Similarly, for $\mathrm{M}^{3+}$ dopants $\left(\mathrm{Sc}^{3+}\right.$ and $\left.\mathrm{In}^{3+}\right)$, the $\mathrm{OH}^{-}$bands appear at about $3505 \mathrm{~cm}^{-1}$, in good agreement with those observed for congruent, ${ }^{94,103}$ and nearstoichiometric $\mathrm{LN}^{45,47}$ For all $\mathrm{M}^{4+}$ tetravalent dopants (i.e., $\left.\mathrm{Hf}^{4+}, \mathrm{Zr}^{4+}, \mathrm{Sn}^{4+}\right)$, the $\mathrm{OH}^{-}$vibrational frequency is found at about $3475 \mathrm{~cm}^{-1}$ as previously shown only for $\mathrm{Zr}^{4+}$. 46,104 Consequently, the $\mathrm{OH}^{-}$vibrational frequencies of doped crystals show a monotonous decrease as a function of the valence of the dopant which can be qualitatively understood taking into account the stronger attractive force for the proton in a $M_{N b}^{2+}-\mathrm{OH}^{-}$complex compared to that in $M_{N b}^{4+}-\mathrm{OH}^{-}$. It was concluded from polarization dependence measurements that the higher the valence of the dopant, the closer the $\mathrm{O}-\mathrm{H}$ bond direction to the oxygen plane perpendicular to the crystallographic c axis of the crystal. The model of the defect complex deduced from the experiments is shown in Fig. 26(b). ${ }^{102}$

The presence of the $\mathrm{OH}^{-}$band in ODR-ion doped stoichiometric $\mathrm{LN}$ can be used to determine the threshold concentration of the dopants, even for tetravalent ions, which was not possible for congruent crystals. The low damage threshold concentration of the tetravalent ions especially in
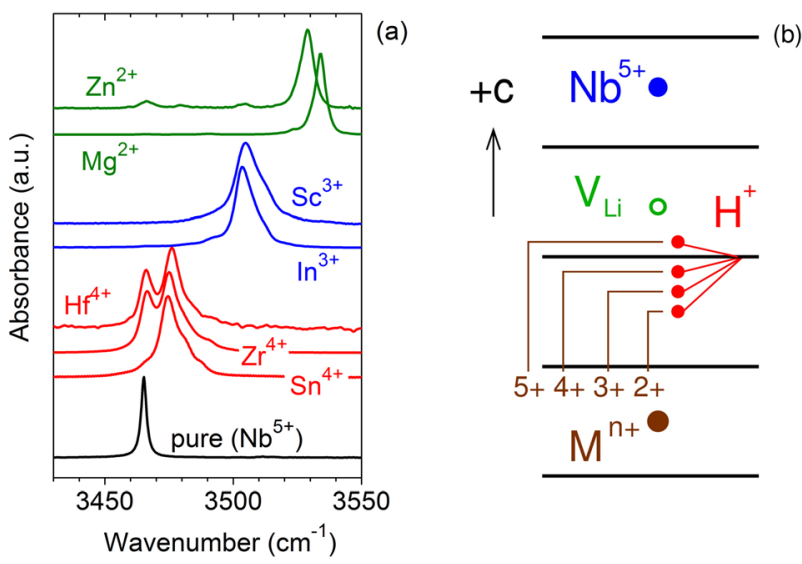

FIG. 26. Infrared absorption spectra of stoichiometric $\mathrm{LiNbO}_{3}$ crystals doped with photorefractive damage resistant ions above their threshold concentrations (a). Schematic drawing of the proton location in the $M_{N b}^{n+}$ doped sLN crystal lattice (b). Reproduced with permission from L. Kovács et al., Opt. Mater. 37, 55-58 (2014). Copyright 2014 Elsevier. 
stoichiometric $\mathrm{LiNbO}_{3}$ facilitates the growth of more homogeneous crystals, resulting in high quality samples for device applications.

\section{Transition metal and rare earth dopants}

Similarly to the case of ODR dopants, the incorporation of other cations with charges 2-4 also involves strong interaction with intrinsic defects providing charge compensation. Due to the similar octahedral surroundings of the $\mathrm{Li}$ and $\mathrm{Nb}$ sites in LN, earlier studies on cation dopants came to conflicting conclusions concerning the incorporation site. In fact, local lattice relaxation may lead to substantial changes of the potential felt by the incorporated ion, further modified by the possible presence of nearby charge compensating defects, as shown by the failure of models (e.g., superposition model calculations of crystal field constants of the spinHamiltonian) neglecting these effects. Decisive evidence about the substitution site could be obtained, however, from detailed angular dependent electron nuclear double resonance (ENDOR) studies identifying and characterizing the cation neighbours of the dopant, as performed for $\mathrm{Mn}^{2+}$ (Ref. 105) and $\mathrm{Fe}^{3+}$ (Ref. 106) in cLN, and for $\mathrm{Cr}^{3+}$ in nearthreshold LN:Mg, ${ }^{107}$ sLN (Ref. 108) and LN with various $\mathrm{Li} / \mathrm{Nb}<1$ ratios. $^{109}$ Nearest ligands were also identified for $\mathrm{Yb}^{3+}$ and $\mathrm{Nd}^{3+}$ in $\mathrm{sLN} .^{110,111}$ In addition to data on the ligand positions and/or the distribution of dopant spin density, these studies provided also information on local fields and disorder, and in the case of sLN:Cr (Ref. 108) also about the presence of a nearby proton. The ligand ENDOR results showed that in cLN, all investigated transient element dopants in their paramagnetic state were substituted at $\mathrm{Li}$ sites, while for $\mathrm{Cr}^{3+}$ in sLN or over-threshold LN:Mg substitution at the $\mathrm{Nb}$ site was found to be dominant. For the trivalent rare earth ion centers, however, up to now, no dominant transfer of the substitution site was observed by ENDOR; at least, the main axial species of $\mathrm{Yb}^{3+}$ and $\mathrm{Nd}^{3+}$ in sLN were still found to substitute at the Li site. ${ }^{110,111}$

Comparative studies of EPR of a given dopant carried out in cLN and sLN on $\mathrm{Fe}^{3+}$ (Ref. 112) or $\mathrm{Cr}^{3+}$ (Ref. 109), or in cLN and near-threshold LN:Mg on $\mathrm{Cr}^{3+}$ (Ref. 107) or $\mathrm{Ti}^{3+}$ (Refs. 113 and 114) or Er, ${ }^{115}$ showed drastic changes of the spectra; this could again be attributed to a change of the incorporation site of these trivalent dopants upon approaching the composition threshold. While for cLN and even for crystals with $\mathrm{Li}_{2} \mathrm{O}$ content equal to $49.85 \mathrm{~mol} \%$, the presence of a main axial $C r_{L i}^{3+}$ or $F e_{L i}^{3+}$ species and a large variety of axially or non-axially charge-compensated minority centers (all on Li sites) could be discerned, ${ }^{116,117}$ in SLN, only one nearly axial $C r_{N b}^{3+}$ and two axial $F e_{N b}^{3+}$ centers could be observed, which differed, however, from those reported in overthreshold cLN:Mg. This could be attributed to protons or $M g_{L i}^{2+}$ playing the role of charge compensators instead of or in addition to scarcely available cation vacancies. For an earlier summary on defects in LN and related oxides, see Ref. 118.

The observations of IR absorption bands of $M_{N b}^{n+}-\mathrm{OH}^{-}$ $-M g_{L i}^{2+}$ type complexes in overthreshold $\mathrm{LN}: \mathrm{Mg}: \mathrm{M}$ crystals with $\mathrm{M}=\mathrm{Cr}, \mathrm{Nd}$, In, Sc, etc., ${ }^{119-121}$ are also clear indications for these trivalent dopants to be at least partially incorporated at $\mathrm{Nb}$ sites. Proton induced X-ray emission (PIXE)/ channeling measurements on $\mathrm{LN}: \mathrm{Cr}$ and overthreshold $\mathrm{LN}: \mathrm{Mg}$ : $\mathrm{Cr}$ confirmed the shift from $\mathrm{Li}$ to $\mathrm{Nb}$ substitution upon $\mathrm{Mg}$-codoping, but found already in $\mathrm{LN}$ :Cr a puzzling, huge "minority" of $40 \%$ of $\mathrm{Cr}$ atoms on $\mathrm{Nb}$ sites despite the low concentration of $0.1 \mathrm{~mol} . \% \mathrm{Cr}$ used. ${ }^{122}$ Though the exact $\mathrm{Li} / \mathrm{Nb}$ ratio in these crystals remained uncharacterized, these data might be an indication for the presence of diamagnetic $\mathrm{Cr}_{\mathrm{Li}}-\mathrm{Cr}_{\mathrm{Nb}}$ pairs on adjacent $\mathrm{Li}$ and $\mathrm{Nb}$ sites. Paramagnetic exchange coupled $\mathrm{Cr}_{\mathrm{Li}}-\mathrm{Cr}_{\mathrm{Li}}$ pairs at nearby $\mathrm{Li}$ sites with slightly larger interatomic distances have been reported in Refs. 117 and 109 but only for concentrations exceeding $1 \mathrm{~mol} \%$.

Nuclear methods like Rutherford backscattering/ion beam channeling and perturbed angular correlations also contributed important information: e.g., for the nonparamagnetic $\mathrm{Hf}^{4+}$, clear indications for a change from $\mathrm{Li}$ to $\mathrm{Nb}$ substitution upon approaching stoichiometry were obtained. $^{123,124}$ EXAFS studies on a series of transition element or rare earth doped polycrystalline or powdered single crystal samples also provided information on the identity and distance of ligand shells though without selectivity for the charge and possible non-uniform surroundings of the dopant. This was sufficient in cLN to locate the dominant Li substitution site for dopant cations with charges up to $4+$, but was inconclusive or contradictory in near stoichiometric and overthreshold LN. For references see, e.g., Refs. 125-128.

For some dopant ions with lower valence, however, comparative EPR studies in cLN and sLN, carried out on $\mathrm{Mn}^{2+}$ (Ref. 129) or $\mathrm{Co}^{2+},{ }^{2}$ only showed narrowing but no change of the EPR line positions, which was a proof for unchanged incorporation at $\mathrm{Li}$ sites, as seen also for the isoelectric dopants $\mathrm{Ni}^{+}$and $\mathrm{Cu}^{2+} \cdot 131,132$

The case of the Ti dopant is of special interest since the $\mathrm{Ti}^{4+}$ state occurring in as-grown crystals has a closed-shell electron configuration similar to that of $\mathrm{Nb}^{5+}$. Both ions, occupying either $\mathrm{Li}$ or $\mathrm{Nb}$ site, can attract electron-polarons forming similar $3 \mathrm{~d}^{1}$ and $4 \mathrm{~d}^{1}$ type states, respectively, offering useful comparisons for understanding and controlling polaronic properties of $\mathrm{LN}$, a topic dealt with in a separate review of Imlau and co-workers in this volume. The EPR and optical absorption parameters of these centres also characterizing their Jahn-Teller effects have been compared in Ref. 113.

The results of simultaneous EPR and optical absorption measurements in Mg-Ti co-doped near-threshold LN (Ref. 114) are shown in Fig. 27. To obtain the paramagnetic $\mathrm{Ti}^{3+}$ charge state, high temperature reduction in vacuum had to be performed. Along with trace amounts of $T i_{L i}^{3+}$ centres well known from similarly reduced cLN:Ti crystals, $T i_{\mathrm{Nb}}^{3+}$ centres with a nearly isotropic EPR line (Ref. 113) were formed (see Fig. 27(a)) corresponding to optical absorption bands (Fig. 27(d)) slightly redshifted with respect to similar bands of $T i_{L i}^{3+}$ (Fig. 27(c)). After subsequent thermal oxidization, part of the $T i_{\mathrm{Nb}}^{3+}$ centres was returned to the $4+$ state, however, an opposite change for minority $T i_{L i}^{3+}$ centres occurred (Fig. 27(b)). A similar counter-mainstream increase in the $T i_{L i}^{3+}$ EPR signal was observed upon low temperature optical 

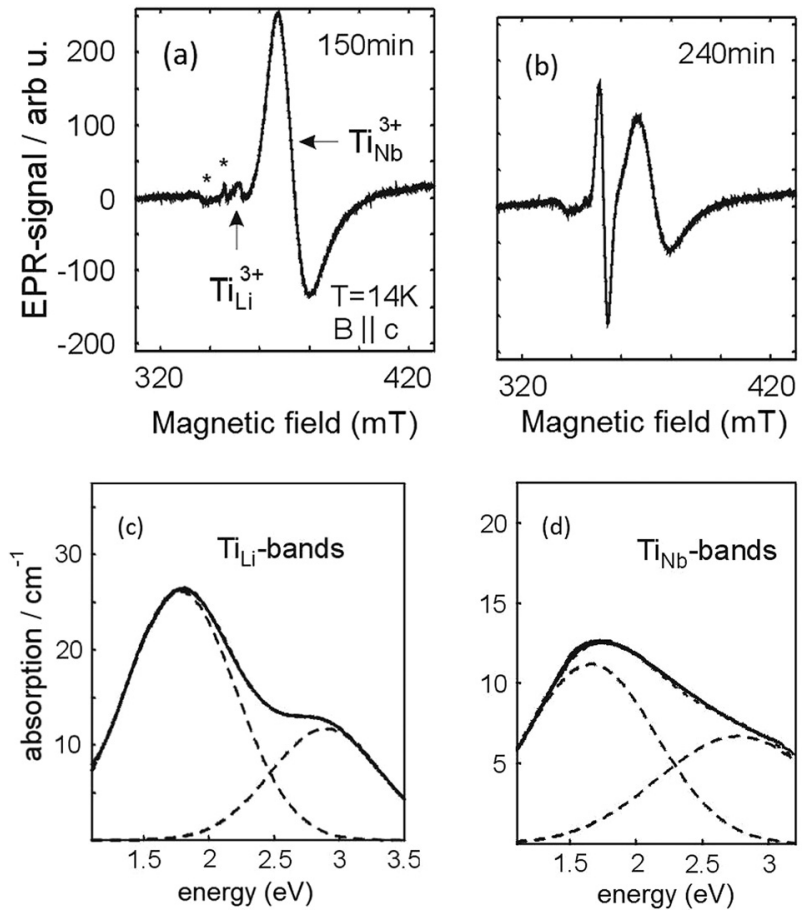

FIG. 27. Spectra of LN:Ti and LN:Mg:Ti crystals doped by $6 \mathrm{~mol} . \% \mathrm{Mg}$ and/or $0.5 \mathrm{~mol} . \% \mathrm{Ti}$ and annealed in vacuum and thin air at $850^{\circ} \mathrm{C}$. EPR spectra taken in the double-doped sample at $\mathrm{T}=14 \mathrm{~K}$ after vacuum reduction for $150 \mathrm{~min}$ (a) and after a subsequent oxidizing treatment in air for 90 min (b), asterisks denoting background signals. Optical absorption difference bands of the reduced crystals taken at RT (with respect to similarly treated crystals without $\mathrm{Ti}$ doping) assigned to the $T i_{L i}^{3+}$ (c) and $T i_{N b}^{3+}$ (d) centres, respectively, and their decomposition into Gaussians. Reproduced with permission from G. Corradi et al., Appl. Phys. B 78, 607-614 (2004). Copyright 2004 Springer Science+Business Media.

bleaching of the reduced sample as well. These effects can be explained by assuming the existence of $T i_{L i}^{3+}-N b_{\mathrm{Nb}}^{4+}$ bipolarons formed during reduction and partially ionized in the second step, leaving $\mathrm{Ti}_{L i}^{3+}$ polarons with a normal $\mathrm{Nb}_{\mathrm{Nb}}^{5+}$ neighbour. Alternatively the effects can be explained by the existence of $\mathrm{Ti}^{4+}$ pairs on neighbouring $\mathrm{Li}$ and $\mathrm{Nb}$ sites: upon reduction, the pairs are transformed into $T i_{L i}^{3+}-T i_{\mathrm{Nb}}^{3+}$ "extrinsic" bipolarons with subsequent partial oxidization to obtain $T i_{L i}^{3+}$ with a $T i_{\mathrm{Nb}}^{4+}$ neighbour. ${ }^{114,133}$

\section{THEORETICAL MODELS FOR INTRINSIC AND EXTRINSIC DEFECTS}

As discussed earlier, defects due to non-stoichiometry or doping strongly influence the properties of $\mathrm{LiNbO}_{3}$ crystals; therefore, a clear understanding of their structure is essential. Computer modelling can make an important contribution to the understanding of material properties at the atomic level. For this kind of calculations, some assumptions concerning the formation of defect structures have to be made. At the beginning of each Subsections IV A-IV C, the main assumptions and characteristics of the theoretical models used will be outlined.

The first interatomic potentials capable to reproduce basic features of the real defect structure of $\mathrm{LiNbO}_{3}$ have been elaborated by Donnerberg et al., Tomlinson et al., Catlow and co-workers. ${ }^{134-138}$ Major improvements could be achieved recently by another set of interatomic potentials $^{139}$ reproducing the properties of both the ferroelectric and paraelectric phases of $\mathrm{LiNbO}_{3}$ and yielding a generally better level of agreement with experiment. The new set of pseudopotentials was based on the GULP code ${ }^{140}$ and could be used to determine the formation energies of various intrinsic and extrinsic defects. These results are summarized in Sections IV A and IV B.

Defect structures in $\mathrm{LiNbO}_{3}$ crystals have also been investigated by first-principles methods, however, the correct treatment of boundary conditions and problems in the modelling of point defects within the density functional theory (DFT) made the calculations rather difficult. The results, similarly to the case of pseudopotential methods, supported the $\mathrm{Li}$ vacancy incorporation model by preferring clusters consisting of a niobium antisite compensated by lithium vacancies as the most stable under $\mathrm{Nb}_{2} \mathrm{O}_{5}$-rich conditions, while for $\mathrm{Li}_{2} \mathrm{O}$-rich conditions, Li-Frenkel defects turned out to have the lowest formation energy. ${ }^{141,142}$ Recently, it was shown by Li et al. ${ }^{143,144}$ mainly using hybrid functional DFT calculations that the formation energies of $\mathrm{V}_{\mathrm{Li}}$ and $\mathrm{V}_{\mathrm{Nb}}$ depended on the position of the Fermi level in the band gap and the actual occurrence of these defects was strongly determined by their tendency to form clusters among each other and with $\mathrm{Nb}_{\mathrm{Li}}$ antisite defects. A realistic charge distribution around defects was obtained by relaxing the lattice (for polarons in $\mathrm{LiNbO}_{3}$ crystals see the review of Imlau ${ }^{145}$ ).

It has been shown in Section III that hydroxyl ions are probes of the defect structure in both undoped and doped $\mathrm{LiNbO}_{3}$ crystals. Therefore, computer modelling of defects related to $\mathrm{OH}^{-}$ions is of fundamental importance. To analyse and understand the properties of $\mathrm{OH}^{-}$ions in the $\mathrm{LiNbO}_{3}$ crystal lattice, first principles theoretical calculations had to be performed. A good choice for making the required electronic structure calculations was the SIESTA computational code. ${ }^{146,147}$ The results of a calculation of proton incorporation in sLN, using density functional theory along with the supercell method implemented in SIESTA, ${ }^{148-150}$ are summarized in Subsection IV C.

\section{A. Intrinsic defects}

After decades of experimental and theoretical efforts, the controversies concerning the intrinsic defect structure of $\mathrm{LiNbO}_{3}$ are only partly resolved. ${ }^{6,9,151,152}$ Density measurements showed that neither oxygen vacancies nor oxygen interstitials are present in the lattice. ${ }^{4,153}$ It can be assumed that excess $\mathrm{Nb}$ is mainly incorporated on $\mathrm{Li}$ sites forming $\mathrm{Nb}_{\mathrm{Li}}$ antisites though $\mathrm{Nb}$ ions occupying structural interstitial sites also remain a debated option. Another important question is the mechanism of charge compensation for the surplus charges of the antisites described until recently by two competing assumptions in the literature. Initially, $\mathrm{Nb}$ vacancies $\mathrm{V}_{\mathrm{Nb}}$ (Refs. 154 and 155) were assumed to play the role of charge compensators, as indirectly suggested by early nuclear magnetic resonance (NMR) measurements ${ }^{154}$ and also by high resolution electron microscopy results. ${ }^{156}$ However, charge compensation can be realised also by $\mathrm{Li}$ vacancies, $\mathrm{V}_{\mathrm{Li}}$ as deduced from X-ray diffraction results, ${ }^{157}$ 
time of flight neutron diffraction measurements, ${ }^{158}$ and later NMR results. ${ }^{159}$ To describe recent Raman spectroscopic results, a mixed model containing both lithium and niobium vacancies was also introduced. ${ }^{160}$ Our spectroscopic results shown in Section III favour the Li vacancy model which is commonly accepted as also emphasized in Ref. 99.

Computer simulations were started to clarify the feasibility of the various defect models. The studies of Donnerberg et al. ${ }^{135}$ stressed the role of $\left(\mathrm{Nb}_{\mathrm{Li}}-\mathrm{V}_{\mathrm{Nb}}\right)$ and isolated $\mathrm{Nb}_{\mathrm{Li}}$ antisite defects. Their results had to be interpreted by assuming the existence of ilmenite-like stacking sequences in $\mathrm{LiNbO}_{3}$ as suggested by Smyth. ${ }^{161}$ To clarify the controversial situation, new potentials were simultaneously determined for the structures of $\mathrm{LiNbO}_{3}$ (ferroelectric phase), $\mathrm{Li}_{2} \mathrm{O}$, and $\mathrm{Nb}_{2} \mathrm{O}_{5}$ using the free energy minimization option of the GULP code. ${ }^{139}$ Based on the new potentials, formation energies of intrinsic defects in $\mathrm{LiNbO}_{3}$, such as vacancies, cation interstitials at structural vacancies (i.e., in empty oxygen octahedra), Frenkel and Schottky defects, were determined. ${ }^{162,163}$ Subsequently, three reactions were separately investigated, where the antisite niobium was compensated by lithium or niobium vacancies and the interstitial niobium by lithium vacancies

$$
\begin{gathered}
5 \mathrm{Li}_{\mathrm{Li}}+\frac{1}{2} \mathrm{Nb}_{2} \mathrm{O}_{5} \rightarrow 4 \mathrm{~V}_{\mathrm{Li}}^{\prime}+\mathrm{Nb}_{\mathrm{Li}}^{\cdots \cdots}+\frac{5}{2} \mathrm{Li}_{2} \mathrm{O} \\
5 \mathrm{Li}_{\mathrm{Li}}+4 \mathrm{Nb}_{\mathrm{Nb}}+\frac{1}{2} \mathrm{Nb}_{2} \mathrm{O}_{5} \rightarrow 4 \mathrm{~V}_{\mathrm{Nb}}^{\prime \prime \prime \prime \prime}+5 \mathrm{Nb}_{\mathrm{Li}}^{\cdots \cdots}+\frac{5}{2} \mathrm{Li}_{2} \mathrm{O} \\
5 \mathrm{Li}_{\mathrm{Li}}+\frac{1}{2} \mathrm{Nb}_{2} \mathrm{O}_{5} \rightarrow 5 \mathrm{~V}_{\mathrm{Li}}^{\prime}+\mathrm{Nb}_{\mathrm{int}}^{\cdots \cdots}+\frac{5}{2} \mathrm{Li}_{2} \mathrm{O}
\end{gathered}
$$

It was concluded that only the formation of an antisite niobium charge compensated by four lithium vacancies (Eq. (4.1)) was energetically feasible in accordance with the spectroscopic results presented in Section III.

\section{B. Dopant ions}

Since the most frequently used ODR ion is magnesium, most experiments and models are concerned with the incorporation of this dopant. The main assumption of these models is that $\mathrm{Mg}$ ions first substitute at $\mathrm{Li}$ sites thereby preventing the formation of $\mathrm{Nb}_{\mathrm{Li}}$ antisites. This process is completed at the threshold concentration where no antisites are left. For larger $\mathrm{Mg}$ concentrations, magnesium enters both $\mathrm{Li}$ and $\mathrm{Nb}$ sites. ${ }^{42,70,72,135}$ This scenario was refined by crystal density measurements in $\mathrm{LiNbO}_{3}$ crystals doped with $\mathrm{Mg}$ in a wide concentration range. ${ }^{164}$ Although no direct experimental evidence for the existence of additional charge compensation was found, in principle both niobium and lithium vacancies and even antisites should be admitted to describe the incorporation mechanism in detail.

Bearing this in mind, the incorporation of a number of divalent and trivalent cations into the $\mathrm{LiNbO}_{3}$ crystal lattice has been recently investigated also by potential calculations, ${ }^{162,163}$ taking into account substitution at both the $\mathrm{Li}^{+}$ and the $\mathrm{Nb}^{5+}$ sites. In all cases, considerable defect binding was found, in the sense that dopant and charge compensating defects are likely to occupy adjacent sites. In the case of divalent dopant ions, both for $0 \mathrm{~K}$ and room temperature calculations, it was found that the charge compensation mechanism with the lowest energy involves dopants entering both $\mathrm{Li}$ and $\mathrm{Nb}$ sites without intrinsic defect generation

$$
4 \mathrm{MO}+3 \mathrm{Li}_{\mathrm{Li}}+\mathrm{Nb}_{\mathrm{Nb}} \rightarrow 3 \mathrm{M}_{\mathrm{Li}}^{\cdot}+\mathrm{M}_{\mathrm{Nb}}^{\prime \prime \prime}+\mathrm{Li}_{2} \mathrm{O}+\mathrm{LiNbO}_{3},
$$

where ${ }^{\cdot}$ and ' denote positive and negative charge with respect to a normally filled lattice site. There are only two exceptions viz., the $\mathrm{Fe}^{2+}$ and $\mathrm{Cd}^{2+}$ ions, but only at room temperature, where antisite niobiums should come into existence during incorporation

$$
\begin{aligned}
\mathrm{RT} & : 4 \mathrm{MO}+3 \mathrm{Li}_{\mathrm{Li}}+2 \mathrm{Nb}_{\mathrm{Nb}} \\
& \rightarrow 3 \mathrm{M}_{\mathrm{Li}}^{\cdot}+2 \mathrm{M}_{\mathrm{Nb}}^{\prime \prime \prime}+\mathrm{Nb}_{\mathrm{Li}}^{\cdots \cdot \cdot}+\mathrm{Li}_{2} \mathrm{O}+\mathrm{LiNbO}_{3} .
\end{aligned}
$$

In the case of trivalent dopants, depending on the temperature, two different schemes were found to be energetically favourable:

$$
\begin{aligned}
& 0 \mathrm{~K}: \mathrm{M}_{2} \mathrm{O}_{3}+\mathrm{Li}_{\mathrm{Li}}+\mathrm{Nb}_{\mathrm{Nb}} \rightarrow \mathrm{M}_{\mathrm{Li}}^{\cdot \cdot}+\mathrm{M}_{\mathrm{Nb}}^{\prime \prime}+\mathrm{LiNbO}_{3}, \\
& \text { RT }: \mathrm{M}_{2} \mathrm{O}_{3}+\mathrm{Li}_{\mathrm{Li}}+2 \mathrm{Nb}_{\mathrm{Nb}} \rightarrow 2 \mathrm{M}_{\mathrm{Nb}}^{\prime \prime}+\mathrm{Nb}_{\mathrm{Li}}^{\circ \cdots}+\mathrm{LiNbO}_{3} .
\end{aligned}
$$

Again two exceptions were found: at room temperature, $\mathrm{Ce}$ and Eu dopants prefer the first scheme.

Most recently, double-doped $\mathrm{LiNbO}_{3}$ has also been studied, and the energetics of solid-state reactions leading to dopant incorporation was calculated. ${ }^{165}$ Predictions of computer modelling of this kind may be helpful for tailoring material properties without expensive and time consuming experiments.

\section{C. $\mathrm{OH}^{-}$ions}

As seen in the infrared absorption experiments, the incorporation of hydrogen into $\mathrm{LiNbO}_{3}$ during the growth process occurs in the form of an $\mathrm{OH}^{-}$ion. The experimental data have usually been analyzed by employing simplified, phenomenological models ${ }^{58,166-168}$ with only rare attempts ${ }^{169}$ to analyse and supplement them by first principles theoretical calculations. Some information on dynamics and kinetics, i.e., activation barrier height and rate constants, has been deduced from analysing the temperature dependent of ionic conductivity ${ }^{170}$ and IR spectra ${ }^{64}$ as well as holographic scattering, ${ }^{171}$ while ${ }^{1} \mathrm{H}$ NMR measurements have been employed to find the location of protons within the crystal lattice. ${ }^{172-174}$

To model a stoichiometric $\mathrm{LiNbO}_{3}$ crystal, a supercell composed of $2 \times 2 \times 2$ hexagonal unit cells (240 atoms) along with periodic boundary conditions has been employed. ${ }^{148,150}$ For starting the calculation, a Li ion was removed from the cell to compensate the charge of the proton added in a nearby position. Subsequently, the structure of the supercell has been fully optimized and relaxed by letting all nuclei move. But for the proton, all other ions essentially remained in their initial positions. The results 


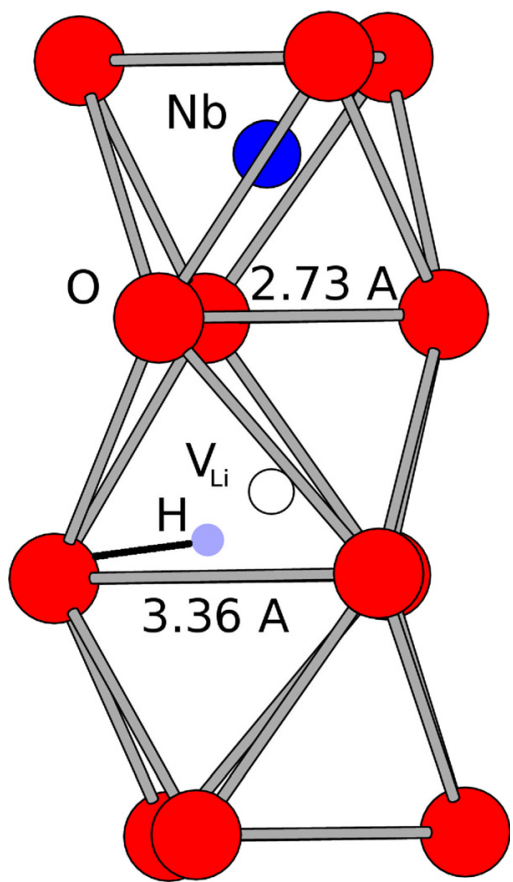

FIG. 28. The optimal proton position in the $\mathrm{LiNbO}_{3}$ crystal lattice as deduced from quantum chemical calculations. Reproduced with permission from K. Lengyel et al., IOP Conf. Ser. Mater. Sci. Eng. 15, 012015 (2010). Copyright 2010 IOP Publishing.

show that in the most stable configuration, the proton is neither on nor in the vicinity of a line connecting nearest neighbour oxygens, but is located near a bisector of an oxygen triangle, tilted by $4.3^{\circ}$ out of the oxygen plane towards a lithium vacancy. The geometry of the most stable configuration in the lattice is shown in Fig. 28. The distance of the hydrogen from the nearest oxygen, the equilibrium $\mathrm{OH}^{-}$bond length, is $r_{\text {eq }}=0.988 \AA$.

Proton dynamics was modelled using a potential energy surface (PES) derived via the Born-Oppenheimer approximation. The PES was determined on a grid of 2251 points by placing the hydrogen atom into various positions within the already relaxed supercell and calculating the total energy. Then, employing these sample points, an analytical approximation for PES has been constructed; ${ }^{150}$ the $2 \mathrm{D}$ projections of this
PES are shown in Fig. 29. Using this analytical approximation and a new method for quantum chemical calculations, the transition frequencies and dipole moments of several vibrational normal modes of the incorporated $\mathrm{OH}^{-}$and $\mathrm{OD}^{-}$ions were determined. The obtained frequencies were compared to results of IR absorption measurements. For the stretching, bending, and higher energy combination bands, the deviation between the theoretical and experimental frequencies was less than $1 \%$. This result was confirmed experimentally on a thick $\mathrm{LiNbO}_{3}$ sample where the otherwise missing lower wavenumber stretching-bending combination band could also be detected. ${ }^{149}$

\section{THz GENERATION-A PROMISING APPLICATION}

In the last decade, due to the rapid development of far infrared $(\mathrm{THz})$ sources, a $10^{7}$-fold increase was reached in $\mathrm{THz}$ pulse energy opening the way towards several applications. ${ }^{175} \mathrm{THz}$ pulses with typical energies in the fJ region with corresponding peak electric field strengths of hundreds of $\mathrm{V} / \mathrm{cm}$ are suitable for linear $\mathrm{THz}$ spectroscopy. Reaching the $\mu \mathrm{J}$ energy level with hundreds of $\mathrm{kV} / \mathrm{cm}$ electric field strength opened the way for nonlinear $\mathrm{THz}$ spectroscopy. ${ }^{175}$ For tens of $\mathrm{mJ}$ pulse energy with tens/hundreds of $\mathrm{MV} / \mathrm{cm}$ peak electric field strength, several interesting potential applications are in sight like acceleration, longitudinal compression, and undulation of relativistic electron buncheswhich can lead to attosecond pulse generation- ${ }^{176,177}$ postacceleration and monochromatization of laser-generated proton bunches with potential applications for Hadron therapy. ${ }^{178}$

Optical rectification of near infrared ultrashort laser pulses in nonlinear crystals is an effective way for generation of (near) single cycle $\mathrm{THz}$ pulses. $\mathrm{LN}$ is very suitable for that because of its extremely high second order nonlinear optical coefficient value $(168 \mathrm{pm} / \mathrm{V})$ which is 2.5 times larger than that of $\mathrm{ZnTe}$. For efficient $\mathrm{THz}$ generation, velocity matching is necessary, i.e., the group velocity of the pump has to be equal to the phase velocity of the generated $\mathrm{THz}$ wave. The extreme large refractive index difference between $\mathrm{THz}$ and optical wavelengths makes collinear phase matching in LN by conventional techniques impossible. Non-collinear
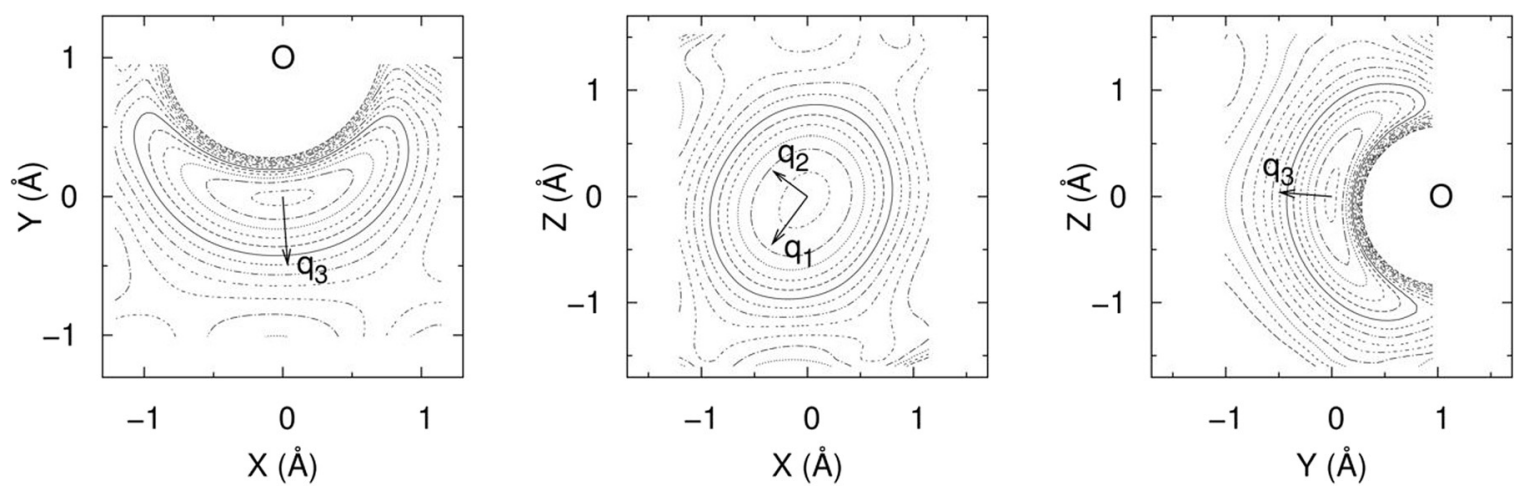

FIG. 29. The potential energy surface (PES) of the incorporated proton around the optimal location. The $\mathrm{q}_{1}, \mathrm{q}_{2}$, and $\mathrm{q}_{3}$ vectors represent the two bending and the stretching vibrational modes, respectively. Reproduced with permission from V. Szalay et al., J. Chem. Phys. 135, 1-9 (2011). Copyright 2011 American Institute of Physics. 
techniques, such as Cherenkov-type excitation ${ }^{179,180}$ and focusing to a line ${ }^{181}$ were not very effective, and the geometry of the $\mathrm{THz}$ radiation was not practical for applications. The most important innovative step in the history of high energy $\mathrm{THz}$ science was the introduction of the so called tilted pulse front (TPF) excitation technique ${ }^{182}$ as a velocity matched $\mathrm{THz}$ generation process with lots of advantages. In such a scheme, the intensity front of the pump pulse is tilted relative to its wave front by an angle of $\gamma$. Thus, instead of the pump velocity, only its projection perpendicular to the propagation direction of the generated $\mathrm{THz}$ radiation has to be equal to the $\mathrm{THz}$ velocity

$$
v_{p, g r} \cos (\gamma)=v_{T H z, p h} .
$$

Fig. 30 shows the TPF excitation scheme. The pulse front tilt is related to the angular dispersion created by the grating and is modified by an imaging system which is either a single lens (as shown in Fig. 30) or a telescopic system. The necessary in-crystal pulse front tilt is adjusted by the adequate (de)magnification.

The efficiency that can be reached by TPF excitation is lower than it would be in the case of collinear phase matching, however, even in spite of the relatively large $\left(\gamma=63.5^{\circ}\right)$ pulse front tilt angle needed in $\mathrm{LN}$, it is higher than for other nonlinear materials. The most important advantages of the TPF excitation are tunability of the $\mathrm{THz}$ frequency by varying the pulse front tilt angle, and the energy scalability.

Initially amplified Ti:sapphire sources delivering pulses with about 100 fs pulse length were used for $\mathrm{THz}$ generation. The first reported result of $\mathrm{THz}$ generation in $2 \mathrm{~mol} . \% \mathrm{Mg}$ doped sLN was $30 \mathrm{pJ}$ pulse energy at room temperature and $98 \mathrm{pJ}$ at $77 \mathrm{~K}$, with corresponding $\mathrm{THz}$ conversion efficiencies of $1.3 \times 10^{-5}$ and $4.3 \times 10^{-5}$, respectively. ${ }^{183}$ The reason of the better results at lower temperature is the significantly lower $\mathrm{THz}$ absorption, which is a key point in $\mathrm{THz}$ generation efficiency.

It was theoretically justified that taking into account all relevant material parameters (including $\mathrm{THz}$ absorption as well), $\mathrm{LN}$ is the most promising material for $\mathrm{THz}$ generation. ${ }^{184}$ The strong $\mathrm{Mg}$ dopant concentration dependence of $\mathrm{THz}$ absorption suggested the use of sLN crystals with the optimal $\approx 0.7 \mathrm{~mol} . \% \mathrm{Mg}$ content $^{181}$ instead of ones with $2 \mathrm{~mol}$. \%. This essential change in the measurement setup of Ref. 183 alone resulted in a four-fold increase in the measured $\mathrm{THz}$ pulse energy and efficiency (400 $\mathrm{pJ}$ and $\left.1.7 \times 10^{-4}\right) .{ }^{184}$

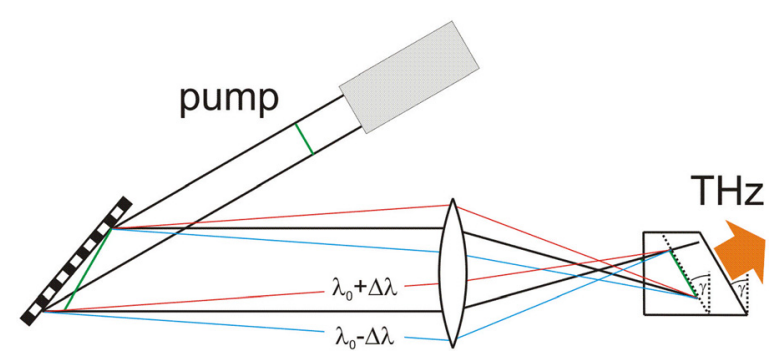

FIG. 30. The TPF excitation scheme. The propagation of the $\mathrm{THz}$ radiation is perpendicular to the TPF (green stretches).
By increasing the pump pulse energy to $500 \mu \mathrm{J}$ and 20 $\mathrm{mJ}$ in $0.7 \mathrm{~mol} . \% \mathrm{Mg}$ doped sLN, $\mathrm{THz}$ pulse energies of 240 $\mathrm{nJ}$ (Ref. 185) and $10 \mu \mathrm{J}$, (Ref. 186), were reached with corresponding conversion efficiencies of $5 \times 10^{-4}$ and $6 \times 10^{-4}$, respectively.

It was shown that imaging conditions have to be set in a way that the TPF and the image of the grating become tangential to each other inside the crystal in order to obtain the optimal transform limited pump pulse length values along the TPF. ${ }^{187}$ In order to optimize the THz output either for pulse energy ${ }^{187}$ or for peak electric field strength, ${ }^{188}$ model calculations were performed taking into account $\mathrm{THz}$ and pump absorption, multi-photon-absorption, noncollinear propagation of the pump and the $\mathrm{THz}$ beam, variation of pulse length due to material and angular dispersion. ${ }^{187,188}$ Varied parameters were temperature, crystal length, and pump pulse duration. It was found that in the case of LN with optimal thickness, the optimal pump pulse duration is between 350 and $600 \mathrm{fs}$ depending on temperature. It was theoretically predicted that instead of pump pulses with $\approx 100 \mathrm{fs}$ pulse length (used initially), longer transform limited pump pulses are needed. The reason is that for the shortest pulses, the pulse duration changes very fast during the propagation in the crystal, and for a finite crystal length, the spatially averaged pulse duration is shortest not for the shortest pulses, but for pulses having optimal Fourier transform pulse duration. ${ }^{188}$ Furthermore, the temperature has to be as low as possible. ${ }^{188}$

It was also declared that although at higher $\mathrm{THz}$ frequencies, semiconductors are competitive with sLN, this is not the case for lower frequencies, where for the generation of $\mathrm{THz}$ pulses with large bandwidth $\mathrm{sLN}$ is the most advantageous. ${ }^{187}$

As a result of experiments with quasi-optimized setups at $1030 \mathrm{~nm}$ pump wavelength at room temperature, $\mathrm{THz}$ pulse energies of $125 \mu \mathrm{J}$ (Ref. 189) and $430 \mu \mathrm{J}$ (Ref. 190) with corresponding conversion efficiencies of 0.25 (Ref. 189 ) and $0.77 \%$ (Ref. 190) were obtained in sLN:0.7 mol. \% $\mathrm{Mg}$ with nearly transform limited pump pulse durations of 1.3 ps (Ref. 189) and $785 \mathrm{fs},{ }^{190}$ respectively. Theoretical predictions of Ref. 187 were verified with the enhanced THz pulse energy and efficiency values. At cryogenic temperatures using pump pulses with closer to optimal lengths, $\mathrm{THz}$ pulse energies exceeding $1 \mathrm{~mJ}$ are in sight.

Fig. 31 demonstrates the powerful development due to the TPF technique. The rapid increase in THz pulse energy and $\mathrm{THz}$ generation efficiency achieved in SLN in the last decade is shown.

The TPF $\mathrm{THz}$ generation setups used in experiments ${ }^{183-186,189-192}$ suffer from imaging errors, leading to local broadening of pump pulses along the tilted pulse front resulting in a limitation for the pump spot size and for the $\mathrm{THz}$ pulse energy. ${ }^{187}$ In order to exclude this limiting factor, a so called contact-grating setup was proposed, which means that a relief dielectric periodic structure is etched on the crystal surface making the imaging optics superfluous. ${ }^{193}$ For this setup, THz generation efficiencies exceeding $10 \%$ with tens of mJ pulse energy are predicted. 


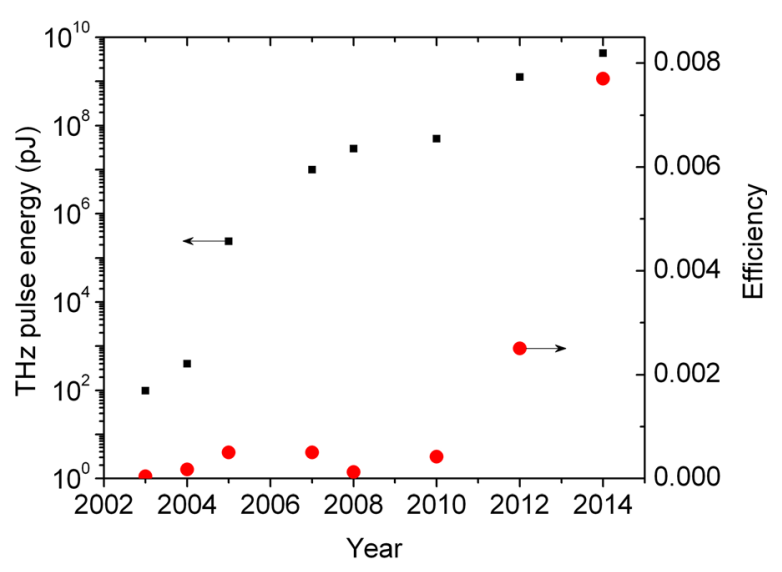

FIG. 31. Upscaling of the THz pulse energy (black squares, left axis, note the logarithmic scale) obtained with the TPF technique using Mg doped sLN. The corresponding $\mathrm{THz}$ generation efficiencies (red circles, right axis) are also shown. The data points are taken from Refs. 183-186, 189-191, and 192.

\section{SUMMARY AND OUTLOOK}

Development of over half a century in the field of $\mathrm{LiNbO}_{3}$ sets a good example on the co-operation and communication between fundamental scientists, device designers, and engineers. By now, defect formation mechanisms are essentially clarified and satisfactory, or at least better understanding of the impact of stoichiometry and doping on the physical properties is achieved. Crystals with extremely low intrinsic defect contents offer extraordinary opportunities for producing controlled defect systems as examples of crystal engineering. Established and recent applications, including real-time holography based on polaronic states, $\mathrm{THz}$ generation, waveguides, and nanostructured devices as discussed in the present and following papers of this volume, open further perspectives for the use of LN. Future research targets may be the extension of transparency and damage resistance towards the UV region by the combination of a partial $\mathrm{Ta}-\mathrm{Nb}$ exchange and the use of $\mathrm{Zr}$ as an ODR additive. ${ }^{194}$

As the demand for crystals has increased, cost reduction by scaling-up (i.e., growing crystals with $>75 \mathrm{~mm}$ diameter) has become the main driving force also for sLN growth. Enlarged crystal diameter poses additional problems for controlling heat and mass transfer and also for the homogenization of the melt composition, meaning new technological challenges for the refinement and renewal of growth equipment, including furnace design and control systems.

To overcome these problems, alternative technologies are still competing, examples are the "low melt-level Czochralski" technique ${ }^{195}$ (a variant of the double crucible method ensuring the stability of the crystal-melt system by using extremely small melt heights of $1-3 \mathrm{~mm}$ in the crucibles), or the "heat field rotation" method proposed by Kokh and co-workers ${ }^{196}$ allowing to govern the heat and mass transfer even in a very viscous liquid phase. The dynamic development of bulk growth technology promises further progress in the next decades.

\section{ACKNOWLEDGMENTS}

Support of the Hungarian Scientific Research Fund (OTKA) Grant Nos. K 83390, K 101846 and funding under the Contract No. SROP-4.2.2.A-11/1/KONV-20120065 are kindly acknowledged. A supercomputer operated by the National Information Infrastructure Development Institute (Hungary) has been used for quantum chemical calculations.

${ }^{1}$ G. E. Peterson and J. R. Carruthers, J. Solid-State Chem. 1, 98-99 (1969).

${ }^{2}$ J. R. Carruthers, G. E. Peterson, M. Grasso, and P. M. Bridenbaugh, J. Appl. Phys. 42, 1846-1851 (1971).

${ }^{3}$ R. L. Byer, J. F. Young, and R. S. Feigelson, J. Appl. Phys. 41, 2320-2325 (1970).

${ }^{4}$ P. Lerner, C. Legras, and J. P. Dumas, J. Cryst. Growth 3-4, 231-235 (1968).

${ }^{5}$ L. O. Svaasand, M. Eriksrud, G. Nakken, and A. P. Grande, J. Cryst. Growth 22, 230-232 (1974).

${ }^{6} \mathrm{~A}$. Räuber, in Current Topics in Materials Science, edited by E. Kaldis (North-Holland, Amsterdam, 1978), Vol. 1, pp. 481-601.

${ }^{7}$ R. S. Weis and T. K. Gaylord, Appl. Phys. A 37, 191-203 (1985).

${ }^{8}$ EMIS Datareviews Series No. 5, edited by S. C. Abrahams (INSPEC The Institution of Electrical Engineers, London and New York, 1989).

${ }^{9}$ A. M. Prokhorov and Y. S. Kuzminov, Series in Optics and Optoelectronics (CRC Press, 1990).

${ }^{10}$ T. Volk and M. Wöhlecke, Ferroelectrics Review 1, 195-262 (1998).

${ }^{11}$ Y. S. Luh, M. M. Fejer, R. L. Byer, and R. S. Feigelson, J. Cryst. Growth 85, 264-269 (1987).

${ }^{12}$ P. F. Bordui, R. G. Norwood, C. D. Bird, and G. D. Calvert, J. Cryst. Growth 113, 61-68 (1991).

${ }^{13}$ K. Kitamura, J. K. Yamamoto, N. Iyi, S. Kimura, and T. Hayashi, J. Cryst. Growth 116, 327-332 (1992).

${ }^{14}$ K. Polgár, Á. Péter, L. Kovács, G. Corradi, and Z. Szaller, J. Cryst. Growth 177, 211-216 (1997).

${ }^{15}$ L. E. Myers and W. R. Bosenberg, IEEE J. Quantum Elect. 33, 1663-1672 (1997).

${ }^{16}$ J. A. L'Huillier, G. Torosyan, M. Theuer, C. Rau, Y. Avetisyan, and B. Beigang, Appl. Phys. B 86, 197-208 (2007).

${ }^{17}$ V. I. Voronkova, N. F. Evlanova, and V. K. Yanovsky, Kristallografiya 23, 234-236 (1978).

${ }^{18}$ S. Kondo, S. Miyazawa, S. Fushimi, and K. Sugii, Appl. Phys. Lett. 26, 489-491 (1975).

${ }^{19}$ J. Hemmerling and R. Hergt, Krist. Tech. 15, 795-801 (1980).

${ }^{20}$ T. Hibiya, H. Suzuki, I. Yonenaga, S. Kimura, T. Kawaguchi, T. Shishido, and T. Fukuda, J. Cryst. Growth 144, 213-217 (1994).

${ }^{21}$ C. Huang, S. Wang, and N. Ye, J. Alloys Compd. 502, 211-214 (2010).

${ }^{22}$ E. S. Vartanyan, in Lecture on the All-Union Conference on Crystal Growth, Tsachkadzor-Aghveran, Armenian SSR, 1985.

${ }^{23}$ G. I. Malovichko, V. G. Grachev, L. P. Yurchenko, V. Ya. Proshko, E. P. Kokanyan, and V. T. Gabrielyan, Phys. Status Solidi A 133, K29-K32 (1992).

${ }^{24}$ G. Malovichko, V. G. Grachev, E. P. Kokanyan, O. F. Schirmer, K. Betzler, B. Gather, F. Jermann, S. Klauer, U. Schlarb, and M. Wöhlecke, Appl. Phys. A 56, 103-108 (1993).

${ }^{25}$ M. Cochez, M. Ferriol, L. Pöppl, K. Polgár, and Á. Péter, J. Alloys Compd. 386, 238-245 (2005).

${ }^{26}$ Á. Péter, K. Polgár, M. Ferriol, L. Pöppl, I. Földvári, M. Cochez, and Zs. Szaller, J. Alloys Compd. 386, 246-252 (2005).

${ }^{27}$ G. Dravecz, Á. Péter, K. Polgár, and L. Kovács, J. Cryst. Growth 286, 334-337 (2006).

${ }^{28}$ K. Polgár, Á. Péter, and I. Földvári, Opt. Mater. 19, 7-11 (2002).

${ }^{29}$ B. A. Scott, E. A. Giess, B. L. Olson, G. Burns, A. W. Smith, and F. O'Kane, Mater. Res. Bull. 5, 47-56 (1970).

${ }^{30}$ T. Ikeda and K. Kiyohashi, Jpn. J. Appl. Phys. Part 1 9, 1541-1542 (1970).

${ }^{31}$ K. Polgár, Á. Péter, and M. Ferriol, Phys. Status Solidi A 201, 284-288 (2004).

${ }^{32}$ I. Földvári, K. Polgár, R. Voszka, and R. N. Balasanyan, Cryst. Res. Technol. 19, 1659-1661 (1984).

${ }^{33}$ L. Kovács, G. Ruschhaupt, K. Polgár, G. Corradi, and M. Wöhlecke, Appl. Phys. Lett. 70, 2801-2803 (1997). 
${ }^{34}$ M. D. Serrano, V. Bermúdez, L. Arizmendi, and E. Diéguez, J. Cryst. Growth 210, 670-676 (2000).

${ }^{35} \mathrm{~K}$. Niwa, Y. Furukawa, S. Takewa, and K. Kitamura, J. Cryst. Growth 208, 493-500 (2000).

${ }^{36}$ Y. Furukawa, K. Kitamura, S. Takekawa, K. Niwa, Y. Yajima, N. Iyi, I. Mnushkina, P. Guggenheim, and J. M. Martin, J. Cryst. Growth 211, 230-236 (2000).

${ }^{37}$ C.-Y. Beh, T.-C. Chong, H. Kumagai, and M. Hirano, J. Cryst. Growth 171, 501-505 (1997).

${ }^{38}$ Á. Péter, I. Hajdara, Zs. Szaller, K. Lengyel, and L. Kovács, J. Cryst. Growth 371, 102-106 (2013).

${ }^{39}$ Zs. Szaller, Á. Péter, K. Polgár, and Gy. Szabó, J. Cryst. Growth 360, 181-184 (2012)

${ }^{40}$ A. Grisard, E. Lallier, K. Polgár, and Á. Péter, Electron. Lett. 36, 1043-1044 (2000)

${ }^{41}$ V. Gopalan, T. E. Mitchell, Y. Furukawa, and K. Kitamura, Appl. Phys. Lett. 72, 1981-1983 (1998).

${ }^{42}$ J. J. Liu, W. L. Zhang, and G. Y. Zhang, Phys. Status Solidi A 156, 285-291 (1996).

${ }^{43}$ Á. Péter, K. Polgár, L. Kovács, and K. Lengyel, J. Cryst. Growth 284 , 149-155 (2005).

${ }^{44}$ S. Fang, B. Wang, T. Zhang, F. Ling, and Y. Zhao, Mater. Chem. Phys. 89, 249-252 (2005).

${ }^{45}$ S. Q. Fang, Z. X. Han, Y. J. Qiao, Y. Y. Liu, and Q. Jia, Cryst. Res. Technol. 44, 1211-1214 (2009).

${ }^{46}$ L. Kovács, Zs. Szaller, K. Lengyel, Á. Péter, I. Hajdara, G. Mandula, L. Pálfalvi, and J. Hebling, Opt. Lett. 38, 2861-2864 (2013).

${ }^{47}$ M. Nakamura, S. Takekawa, Y. Liu, and K. Kitamura, J. Cryst. Growth 281, 549-555 (2005).

${ }^{48}$ Y. Furukawa, K. Kitamura, S. Takakawa, A. Miyamoto, M. Terao, and N. Suda, Appl. Phys. Lett. 77, 2494-2496 (2000).

${ }^{49}$ M. Wöhlecke, G. Corradi, and K. Betzler, Appl. Phys. B 63, 323-330 (1996).

${ }^{50}$ D. Redfield and W. J. Burke, J. Appl. Phys. 45, 4566-4571 (1974).

${ }^{51}$ P. F. Bordui, R. G. Norwood, D. H. Jundt, and M. M. Fejer, J. Appl. Phys. 71, 875-879 (1992).

${ }^{52}$ X. Li, Y. Kong, H. Liu, L. Sun, J. Xu, S. Chen, L. Zhang, Z. Huang, S. Liu, and G. Zhang, Opt. Mater. 23, 295-298 (2003).

${ }^{53}$ G. Malovichko, V. Grachev, and O. Schirmer, Appl. Phys. B 68, 785-793 (1999).

${ }^{54}$ Y. Chen, W. Zhang, Y. Shu, C. Lou, Y. Kong, Z. Huang, J. Xu, and G. Zhang, Opt. Mater. 23, 295-298 (2003).

${ }^{55}$ G. Ravi, K. Kitamura, S. Takekawa, M. Nakamura, Y. Liu, and H. Hatano, Mater. Sci. Eng., B 109, 232-235 (2004).

${ }^{56}$ D. H. Jundt, M. C. C. Kajiyama, D. Djukic, and M. Falk, J. Cryst. Growth 312, 1109-1113 (2009).

${ }^{57}$ M. Y. Salloum, O. S. Grunsky, A. A. Manshina, A. S. Tveryanovich, and Yu. S. Tveryanovich, Russ. Chem. Bull. 58, 2228-2232 (2009).

${ }^{58}$ L. Kovács, V. Szalay, and R. Capelletti, Solid State Commun. 52, 1029-1031 (1984).

${ }^{59}$ L. Kovács, M. Wöhlecke, A. Jovanovic, K. Polgár, and S. Kapphan, J. Phys. Chem. Solids 52, 797-803 (1991).

${ }^{60}$ L. Kovács, K. Polgár, and R. Capelletti, Cryst. Lattice Defects Amorphous Mater. 15, 115-121 (1987).

${ }^{61}$ G. Dravecz and L. Kovács, Appl. Phys. B 88, 305-307 (2007).

${ }^{62}$ G. Dravecz, L. Kovács, Á. Péter, K. Polgár, and P. Bourson, Phys. Status Solidi C 4, 1313-1316 (2007).

${ }^{63}$ D. L. Staebler and J. J. Amodei, Ferroelectrics 3, 107-114 (1972).

${ }^{64}$ K. Lengyel, L. Kovács, G. Mandula, and R. Rupp, Ferroelectrics 257, 255-262 (2001).

${ }^{65} \mathrm{G}$. G. Zhong, J. Jian, and Z. K. Wu, in 11th International Quantum Electronics Conference, 23-26 June 1980, Boston, MA, IEEE Cat. No. 80, CH 1561-0, p. 631.

${ }^{66}$ D. A. Bryan, R. R. Rice, R. Gerson, H. E. Tomaschke, K. L. Sweeney, and L. E. Halliburton, Opt. Eng. 24, 024138 (1985).

${ }^{67}$ L. J. Hu, Y. H. Chang, M. L. Hu, M. W. Chang, and W. S. Tse, J. Raman Spectrosc. 22, 333-337 (1991).

${ }^{68}$ K. Polgár, L. Kovács, I. Földvári, and I. Cravero, Solid State Commun. 59, 375-379 (1986).

${ }^{69}$ D. A. Bryan, R. Gerson, and H. E. Tomaschke, Appl. Phys. Lett. 44, 847-849 (1984).

${ }^{70}$ B. C. Grabmaier and F. Otto, J. Cryst. Growth 79, 682-688 (1986).

${ }^{71}$ H. Donnerberg, S. M. Tomlinson, C. R. A. Catlow, and O. F. Schirmer, Phys. Rev. B 44, 4877-4883 (1991).
${ }^{72}$ N. Iyi, K. Kitamura, Y. Yajima, S. Kimura, Y. Furukawa, and M. Sato, J. Solid State Chem. 118, 148-152 (1995).

${ }^{73}$ K. Lengyel, Á. Péter, K. Polgár, L. Kovács, and G. Corradi, Phys. Status Solidi C 2, 171-174 (2005).

${ }^{74}$ K. Lengyel, L. Kovács, Á. Péter, K. Polgár, and G. Corradi, Appl. Phys. B: Lasers Opt. 87, 317-322 (2007).

${ }^{75}$ E. Libowitzky, Monatsh. Chem. 130, 1047-1059 (1999).

${ }^{76}$ K. Lengyel, L. Kovács, Á. Péter, K. Polgár, G. Corradi, A. Baraldi, and R. Capelletti, Appl. Phys. Lett. 96, 191907 (2010).

${ }^{77}$ L. Arizmendi, E. J. Ambite, and J. L. Plaza, Opt. Mater. 35, 2411-2413 (2013).

${ }^{78}$ J. Koppitz, O. F. Schirmer, M. Wöhlecke, A. I. Kuznetsov, and B. C. Grabmaier, Ferroelectrics 92, 233-241 (1989).

${ }^{79}$ Y. Furukawa, K. Kitamura, S. Takekawa, K. Niwa, and H. Hatano, Opt. Lett. 23, 1892-1894 (1998).

${ }^{80}$ M. D. Fontana and P. Bourson, Appl. Phys. Rev. (this issue).

${ }^{81}$ R. F. Schaufele and M. J. Weber, Phys. Rev. 152, 705-707 (1966).

${ }^{82}$ A. Ridah, P. Bourson, M. D. Fontana, and G. Malovichko, J. Phys.: Condens. Matter 9, 9687-9694 (1997).

${ }^{83}$ R. Mouras, M. D. Fontana, P. Bourson, and A. V. Postnikov, J. Phys.: Condens. Matter 12, 5053-5060 (2000).

${ }^{84}$ K. Lengyel, L. Kovács, Á. Péter, K. Polgár, G. Corradi, and P. Bourson, Phys. Status Solidi C 4, 847-850 (2007).

${ }^{85}$ M. Sheik-Bahae, A. A. Said, T. H. Wei, D. J. Hagan, and E. W. Van Stryland, IEEE J. Quantum Electron. 26, 760-769 (1990).

${ }^{86}$ J. A. Hermann and R. G. McDuff, J. Opt. Soc. Am. B 10, 2056-2064 (1993).

${ }^{87}$ L. Pálfalvi and J. Hebling, Appl. Phys. B 78, 775-780 (2004).

${ }^{88}$ L. Pálfalvi, G. Almási, J. Hebling, Á. Péter, and K. Polgár, Appl. Phys. Lett. 80, 2245-2247 (2002).

${ }^{89}$ L. Pálfalvi, J. Hebling, G. Almási, Á. Péter, K. Polgár, K. Lengyel, and R. Szipőcs, J. Appl. Phys. 95, 902-908 (2004).

${ }^{90}$ L. Pálfalvi, J. Hebling, G. Almási, Á. Péter, and K. Polgár, J. Opt. A 5, S280-S283 (2003).

${ }^{91}$ T. Volk, N. Rubinina, and M. Wöhlecke, J. Opt. Soc. Am. B 11, 1681-1687 (1994)

${ }^{92}$ L. Pálfalvi, J. Hebling, J. Kuhl, Á. Péter, and K. Polgár, J. Appl. Phys. 97, 123505 (2005)

${ }^{93}$ T. R. Volk, N. M. Rubinina, V. I. Pryalkin, V. Krasnikov, and V. V. Volkov, Ferroelectrics 109, 345-350 (1990).

${ }^{94}$ T. Volk, M. Wöhlecke, N. Rubinina, N. V. Razumovski, F. Jermann, C. Fischer, and R. Böwer, Appl. Phys. A 60, 217-225 (1995).

${ }^{95}$ J. K. Yamamoto, K. Kitamura, N. Iyi, S. Kimura, Y. Furukawa, and M. Sato, Appl. Phys. Lett. 61, 2156-2158 (1992).

${ }^{96}$ E. P. Kokanyan, L. Razzari, I. Cristiani, V. Degiorgio, and J. B. Gruber, Appl. Phys. Lett. 84, 1880-1882 (2004).

${ }^{97}$ L. Sun, F. Guo, Q. Lv, H. Yu, H. Li, W. Cai, Y. Xu, and L. Zhao, Cryst. Res. Technol. 42, 1117-1122 (2007).

${ }^{98}$ L. Wang, S. Liu, Y. Kong, S. Chen, Z. Huang, L. Wu, R. Rupp, and J. Xu, Opt. Lett. 35, 883-885 (2010).

${ }^{99}$ T. Volk and M. Wöhlecke, Lithium Niobate, Springer Series in Materials Science Vol. 115 (Springer-Verlag, Berlin, Heidelberg, 2008).

${ }^{100}$ Y. Kong, S. Liu, and J. Xu, Materials 5, 1954-1971 (2012).

${ }^{101}$ G. Nava, P. Minzioni, W. Yan, J. Parravicini, D. Grando, E. Musso, I. Cristiani, N. Argolas, M. Bazzan, M. V. Ciampolillo, A. Zaltron, C. Sada, and V. Degiorgio, Opt. Mat. Express 1, 270-277 (2011).

${ }^{102}$ L. Kovács, Zs. Szaller, K. Lengyel, and G. Corradi, Opt. Mater. 37, 55-58 (2014)

${ }^{103}$ S. Shimamura, Y. Watanabe, T. Sota, K. Suzuki, N. Iyi, Y. Yajima, K. Kitamura, T. Yamazaki, A. Sugimoto, and K. Yamagishi, J. Phys.: Condens. Matter 8, 6825-6832 (1996).

${ }^{104}$ Y. Fan, C. Xu, S. Xia, C. Guan, L. Cao, Q. He, and G. Jin, J. Cryst. Growth 312, 1875-1878 (2010).

${ }^{105}$ G. Corradi, H. Söthe, J.-M. Spaeth, and K. Polgár, J. Phys.: Condens. Matter 2, 6603-6618 (1990).

${ }^{106}$ H. Söthe and J.-M. Spaeth, J. Phys.: Condens. Matter 4, 9901-9908 (1992).

${ }^{107}$ G. Corradi, H. Söthe, J.-M. Spaeth, and K. Polgár, J. Phys.: Condens. Matter 3, 1901-1908 (1991).

${ }^{108}$ V. Grachev and G. Malovichko, Phys. Rev. B 62, 7779-7790 (2000).

${ }^{109}$ G. Malovichko, V. Grachev, A. Hofstaetter, E. Kokanyan, A. Scharmann, and O. Schirmer, Phys. Rev. B 62, 224116 (2002).

${ }^{110} \mathrm{G}$. Malovichko, V. Bratus, M. Munro, E. Kokanyan, S. Okulov, and V. Grachev, Phys. Status Solidi C 4, 1346-1351 (2007). 
${ }^{111}$ G. Malovichko, V. Bratus, V. Grachev, and E. Kokanyan, Phys. Status Solidi B 246, 215-225 (2009).

${ }^{112}$ G. I. Malovichko, V. G. Grachev, O. F. Schirmer, and B. Faust, J. Phys.: Condens. Matter 5, 3971-3976 (1993).

${ }^{113}$ G. Corradi, I. M. Zaritskii, A. Hofstaetter, K. Polgár, and L. G. Rakitina, Phys. Rev. B 58, 8329-8337 (1998).

${ }^{114}$ G. Corradi, M. Meyer, L. Kovács, and K. Polgár, Appl. Phys. B 78, 607-614 (2004).

${ }^{115}$ D. Bravo, A. Martin, and F. J. Lopez, Solid. State Commun. 112, 541-544 (1999).

${ }^{116}$ G. Malovichko, V. Grachev, and S. N. Lukin, Sov. Phys. Solid State 28, 553-557 (1986).

${ }^{117}$ G. Malovichko, V. Grachev, E. Kokanyan, and O. Schirmer, Phys. Rev. B 59, 9113-9125 (1999).

${ }^{118}$ B. Briat, V. G. Grachev, G. I. Malovichko, O. F. Schirmer, and M. Wöhlecke, in Photorefractive Materials and Their Applications 2, edited by P. Günter and J.-P. Huignard (Springer, 2007), pp. 9-49.

${ }^{119}$ L. Kovács, I. Földvári, I. Cravero, K. Polgár, and R. Capelletti, Phys. Lett. A 133, 433-437 (1988).

${ }^{120}$ L. Kovács, Zs. Szaller, I. Cravero, I. Földvári, and C. Zaldo, J. Phys. Chem. Solids 51, 417-420 (1990).

${ }^{121}$ L. Kovács, L. Rebouta, J. C. Soares, M. F. da Silva, M. Hage-Ali, J. P. Stoquert, P. Siffert, J. A. Sanz-García, G. Corradi, Zs. Szaller, and K. Polgár, J. Phys.: Condens. Matter 5, 781-794 (1993).

${ }^{122}$ A. Kling, J. C. Soares, M. F. da Silva, J. A. Sanz-García, E. Diéguez, and F. Agulló-López, Nucl. Instrum. Methods Phys. Res., Sect. B 136-138, 426-430 (1998).

${ }^{123}$ J. G. Marques, A. Kling, J. C. Soares, L. Rebouta, M. F. da Silva, E. Diéguez, and F. Agulló-López, Nucl. Instrum. Methods Phys. Res., Sect. B 136-138, 431-435 (1998).

${ }^{124}$ J. G. Marques and K. Lorenz, Opt. Eng. 53, 060901 (2014).

${ }^{125} \mathrm{C}$. Zaldo and C. Prieto, Ferroelectrics 134, 47-51 (1992).

${ }^{126}$ G. Corradi, A. V. Chadwick, T. West, K. Cruickshank, and M. Paul, Radiat. Eff. Defects Solids 134, 219-222 (1995).

${ }^{127}$ J. García Solé, L. E. Bausá, D. Jaque, E. Montoya, H. Murrieta, and F. Jaque, Spectrochim. Acta A 54, 1571-1581 (1998).

${ }^{128}$ T. Vitova, J. Hormes, K. Peithmann, and T. Woike, Phys. Rev. B 77, 144103 (2008)

${ }^{129}$ G. Malovichko, OSA TOPS 27, 59-66 (1999).

${ }^{130}$ Y. N. Choi, I.-W. Park, S. S. Kim, S. S. Park, and S. H. Choh, J. Phys.: Condens. Matter 11, 4723-4730 (1999).

${ }^{131}$ G. Korradi, K. Polgár, A. A. Bugaii, I. M. Zaritskii, L. G. Rakitina, V. G. Grachev, and N. I. Derjugina, Sov. Phys. Solid State 28, 412-417 (1986).

${ }^{132}$ X. Q. Feng and T. B. Tang, J. Phys.: Condens. Matter 5, 2423-2430 (1993).

${ }^{133}$ G. Corradi, M. Meyer, and K. Polgár, Phys. Status Solidi C 2, 132-135 (2005).

${ }^{134}$ S. M. Tomlinson, C. M. Freeman, C. R. A. Catlow, H. Donnerberg, and M. Leslie, J. Chem. Soc. Faraday Trans. 2 85, 367-383 (1989).

${ }^{135}$ H. Donnerberg, S. M. Tomlinson, C. R. A. Catlow, and O. F. Schirmer, Phys. Rev. B 40,11909-11916 (1989).

${ }^{136}$ S. M. Tomlinson, C. R. A. Catlow, H. Donnerberg, and M. Leslie, Mol. Simul. 4, 335-339 (1990).

${ }^{137}$ H. J. Donnerberg, S. M. Tomlinson, and C. R. A. Catlow, J. Phys. Chem. Solids 52, 201-210 (1991)

${ }^{138}$ H. Donnerberg, Atomic Simulations of Electrooptic and Magnetooptic Oxide Materials, Springer Series 'Transactions in Modern Physics' (Springer, Berlin, 1999).

${ }^{139}$ R. A. Jackson and M. E. G. Valerio, J. Phys.: Condens. Matter 17, 837-844 (2005)

${ }^{140}$ J. D. Gale, J. Chem. Soc. Faraday Trans. 93, 629-637 (1997).

${ }^{141}$ H. Xu, D. Lee, J. He, S. B. Sinnott, V. Gopalan, V. Dierolf, and S. R. Phillpot, Phys. Rev. B 78, 174103 (2008).

${ }^{142}$ Q. K. Li, B. Wang, C. H. Woo, H. Wang, and R. Wang, J. Phys. Chem. Solids 68, 1336-1340 (2007).

${ }^{143}$ Y. Li, W. G. Schmidt, and S. Sanna, Phys. Rev. B 89, 094111 (2014).

${ }^{144}$ Y. Li, W. G. Schmidt, and S. Sanna, Phys. Rev. B 91, 174106 (2015).

${ }^{145}$ M. Imlau, Appl. Phys. Rev. (this issue).

${ }^{146}$ E. Artacho, E. Anglada, O. Dieguez, J. D. Gale, A. Garcia, J. Junquera, R. M. Martin, P. Ordejón, J. M. Pruneda, D. Sánchez-Portal, and J. M. Soler, J. Phys.: Condens. Matter 20, 064208 (2008).

${ }^{147}$ R. M. Martin, Electronic Structure, Basic Theory and Practical Methods (Cambridge University Press, Cambridge, England, 2004).
${ }^{148}$ K. Lengyel, V. Timon, A. Hernandez-Laguna, V. Szalay, and L. Kovács, IOP Conf. Ser. Mater. Sci. Eng. 15, 012015 (2010).

${ }^{149}$ L. Kovács, K. Lengyel, and V. Szalay, Opt. Lett. 36, 3714-3716 (2011).

${ }^{150}$ V. Szalay, K. Lengyel, L. Kovács, V. Timon, and A. Hernandez-Laguna, J. Chem. Phys. 135, 124501 (2011).

${ }^{151}$ Properties of Lithium Niobate, edited by K. K. Wong (IEE, London, 2004).

${ }^{152}$ O. F. Schirmer, O. Thiemann, and M. Wöhlecke, J. Phys. Chem. Solids 52, 185-200 (1991).

${ }^{153}$ L. Kovács and K. Polgár, Cryst. Res. Technol. 21, K101-K104 (1986).

${ }^{154}$ G. E. Peterson and A. Carnevale, J. Chem. Phys. 56, 4848-4851 (1972).

${ }^{155}$ S. C. Abrahams and P. Marsh, Acta Crystallogr. B 42, 61-68 (1986).

${ }^{156}$ C. Leroux, G. Nihoul, G. Malovichko, V. Grachev, and C. Boulesteix, J. Phys. Chem. Solids 59, 311-319 (1998).

${ }^{157}$ N. Iyi, K. Kitamura, F. Izumi, J. K. Yamamoto, T. Hayashi, H. Asano, and S. Kimura, J. Solid State Chem. 101, 340-352 (1992).

${ }^{158}$ N. Zotov, H. Boysen, F. Frey, Th. Metzger, and E. Born, J. Phys. Chem. Solids 55, 145-152 (1994).

${ }^{159}$ J. Blümel, E. Born, and Th. Metzger, J. Phys. Chem. Solids 55, 589-593 (1994).

${ }^{160}$ F. Abdi, M. D. Fontana, M. Aillerie, and P. Bourson, Appl. Phys. A 83, 427-434 (2006).

${ }^{161}$ D. M. Smyth, in Proceedings of the 6th IEEE International Symposium on Applications of Ferroelectrics (IEEE, New York, 1986), pp. 115-117.

${ }^{162}$ R. M. Araujo, K. Lengyel, R. A. Jackson, M. E. G. Valerio, and L. Kovács, Phys. Status Solidi C 4, 1201-1204 (2007).

${ }^{163}$ R. M. Araujo, K. Lengyel, R. A. Jackson, L. Kovács, and M. E. G. Valerio, J. Phys.: Condens. Matter 19, 046211 (2007).

${ }^{164}$ Q. Zhang and X. Feng, Phys. Status Solidi A 121, 429-435 (1990).

${ }^{165}$ R. M. Araujo, M. E. G. Valerio, and R. A. Jackson, Proc. R. Soc. A 470, 20140406 (2014).

${ }^{166}$ M. Wöhlecke and L. Kovács, Crit. Rev. Solid State Mater. Sci. 26, 1-86 (2001).

${ }^{167}$ J. M. Cabrera, J. Olivares, M. Carrascosa, J. Rams, R. Mülller, and E. Diéguez, Adv. Phys. 45, 349-392 (1996).

${ }^{168}$ S. V. Yevdokimov and A. V. Yatsenko, Crystallogr. Rep. 48, 542-546 (2003).

${ }^{169}$ H. H. Nahm and C. H. Park, Appl. Phys. Lett. 78, 3812-3814 (2001).

${ }^{170}$ S. Klauer, M. Wöhlecke, and S. Kapphan, Phys. Rev. B 45, 2786-2799 (1992).

${ }^{171}$ A. Ellabban, G. Mandula, M. Fally, R. A. Rupp, and L. Kovács, Appl. Phys. Lett. 78, 844-846 (2001).

${ }^{172}$ M. Engelsberg, R. E. de Souza, L. H. Pacobahyba, and G. C. do Nascimento, Appl. Phys. Lett. 67, 359-361 (1995).

${ }^{173}$ Y. Kong, J. Xu, W. Zhang, and G. Zhang, Phys. Lett. A 250, 211-213 (1998).

${ }^{174}$ Y. Kong, J. Xu, W. Zhang, and G. Zhang, J. Phys. Chem. Solids 61, 1331-1335 (2000).

${ }^{175}$ Terahertz Spectroscopy and Imaging, Springer Series in Optical Sciences, edited by K.-E. Peiponen, A. Zeitler, and M. KuwataGonokami (Springer, Berlin Heidelberg, 2013), Vol. 171.

${ }^{176}$ J. Hebling, J. A. Fülöp, M. I. Mechler, L. Pálfalvi, C. Tőke, and G. Almási, e-print arXiv:1109.6852.

${ }^{177}$ L. J. Wong, A. Fallahi, and F. X. Kärtner, Opt. Express 21, 9792-9806 (2013).

${ }^{178}$ L. Pálfalvi, J. A. Fülöp, Gy. Tóth, and J. Hebling, Phys. Rev. ST Accel. Beams 17, 031301 (2014).

${ }^{179}$ D. H. Auston, K. P. Cheung, J. A. Valdmanis, and D. A. Kleinman, Phys. Rev. Lett. 53, 1555-1558 (1984).

${ }^{180}$ D. A. Kleinman and D. H. Auston, IEEE J. Quantum Electron. 20, 964-970 (1984).

${ }^{181}$ A. G. Stepanov, J. Hebling, and J. Kuhl, Appl. Phys. B 81, 23-26 (2005).

${ }^{182}$ J. Hebling, G. Almasi, I. Z. Kozma, and J. Kuhl, Opt. Express 10, 1161-1166 (2002).

${ }^{183}$ A. G. Stepanov, J. Hebling, and J. Kuhl, Appl. Phys. Lett. 83, 3000-3002 (2003).

${ }^{184}$ J. Hebling, A. G. Stepanov, G. Almási, B. Bartal, and J. Kuhl, Appl. Phys. B 78, 593-599 (2004).

${ }^{185}$ A. G. Stepanov, J. Kuhl, I. Z. Kozma, E. Riedle, G. Almási, and J. Hebling, Opt. Express 13, 5762-5768 (2005). 
${ }^{186}$ K. L. Yeh, M. C. Hofmann, J. Hebling, and K. A. Nelson, Appl. Phys. Lett. 90, 171121 (2007).

${ }^{187}$ J. A. Fülöp, L. Pálfalvi, G. Almási, and J. Hebling, Opt. Express 18, 12311-12327 (2010).

${ }^{188}$ J. A. Fülöp, L. Pálfalvi, M. C. Hoffmann, and J. Hebling, Opt. Express 19, 15090-15097 (2011).

${ }^{189}$ J. A. Fülöp, L. Pálfalvi, S. Klingebiel, G. Almási, F. Krausz, S. Karsch, and J. Hebling, Opt. Lett. 37, 557-559 (2012).

${ }^{190}$ J. A. Fülöp, Z. Ollmann, Cs. Lombosi, C. Skrobol, S. Klingebiel, L. Pálfalvi, F. Krausz, S. Karsch, and J. Hebling, Opt. Express 22, 20155-20163 (2014).
${ }^{191}$ A. G. Stepanov, L. Bonacina, S. V. Chekalin, and J.-P. Wolf, Opt. Lett. 33, 2497-2499 (2008).

${ }^{192}$ A. G. Stepanov, S. Henin, Y. Petit, L. Bonacina, J. Kasparian, and J.-P. Wolf, Appl. Phys. B 101, 11-14 (2010).

${ }^{193}$ L. Pálfalvi, J. A. Fülöp, G. Almási, and J. Hebling, Appl. Phys. Lett. 92, 171107 (2008).

${ }^{194}$ F. Liu, Y. Kong, W. Li, H. Liu, S. Liu, S. Chen, X. Zhang, R. Rupp, and J. Xu, Opt. Lett. 35, 10-12 (2010).

${ }^{195}$ P. V. Smirnov and A. A. Rusanov, Tech. Phys. 55, 1669-1679 (2010).

${ }^{196}$ A. Kokh, V. Vlezko, K. Kokh, N. Kononova, P. Villeval, and D. Lupinski, J. Cryst. Growth 360, 158-161 (2012). 